University of Wollongong

Research Online

Australian Institute for Innovative Materials -

Papers

Australian Institute for Innovative Materials

$1-1-2018$

\title{
Magnetic and Structural Transitions Tuned through Valence Electron Concentration in Magnetocaloric Mn(Co1-xNix)Ge
}

Qing Yon Ren

University of New South Wales

Wayne D. Hutchison

University of New South Wales

Jian Li Wang

University of Wollongong, jianli@uow.edu.au

Andrew J. Studer

Australian Centre for Neutron Scattering

Stewart J. Campbell

University of New South Wales, stewart.campbell@adfa.edu.au

Follow this and additional works at: https://ro.uow.edu.au/aiimpapers

Part of the Engineering Commons, and the Physical Sciences and Mathematics Commons

Research Online is the open access institutional repository for the University of Wollongong. For further information contact the UOW Library: research-pubs@uow.edu.au 


\title{
Magnetic and Structural Transitions Tuned through Valence Electron Concentration in Magnetocaloric Mn(Co1-xNix)Ge
}

\author{
Abstract \\ The structural and magnetic properties of magnetocaloric $\mathrm{Mn}$ (Co 1-x Ni x ) Ge compounds have been \\ studied. Two responses to the increase of valence electron concentration on substitution of $\mathrm{Ni}$ (3d $84 \mathrm{~s} 2$ \\ ) for Co (3d $74 s 2$ ) in the orthorhombic phase (Pnma) are proposed: expansion of unit-cell volume and \\ redistribution of valence electrons. We present experimental evidence for electronic redistribution \\ associated with the competition between magnetism and bonding. This competition in turn leads to \\ complex dependences of the reverse martensitic transformation temperature $\mathrm{T} M$ (orthorhombic to \\ hexagonal (P6 $3 / \mathrm{mmc})$ ) and the magnetic structures on the Ni concentration. Magnetic transitions from \\ ferromagnetic structures below $x=0.50$ to noncollinear spiral antiferromagnetic structures above $x=0.55$ \\ at low temperature (e.g., $5 \mathrm{~K}$ ) are induced by modification of the density of states at the Fermi surface due \\ to the redistribution of valence electrons. $\mathrm{T} \mathrm{M}$ is found to decrease initially with increasing $\mathrm{Ni}$ content and \\ then increase. Both direct and inverse magnetocaloric effects are observed.

\section{Disciplines} \\ Engineering | Physical Sciences and Mathematics

\section{Publication Details} \\ Ren, Q., Hutchison, W. D., Wang, J., Studer, A. J. \& Campbell, S. (2018). Magnetic and Structural \\ Transitions Tuned through Valence Electron Concentration in Magnetocaloric Mn(Co1-xNix)Ge. Chemistry \\ of Materials, 30 (4), 1324-1334.
}




\title{
Magnetic and structural transitions tuned through valence electron concentration in magnetocaloric $\mathrm{Mn}\left(\mathrm{Co}_{1-\mathrm{x}} \mathrm{Ni}_{\mathrm{x}}\right) \mathrm{Ge}$
}

\author{
Qingyong Ren, ${ }^{*}+\S \# \|$ Wayne D. Hutchison, ${ }^{* \dagger}$ Jianli Wang, ${ }^{*, \mp}$ Andrew J. Studer, ${ }^{\perp}$ and Stewart J. \\ Campbell ${ }^{\dagger}$
}

${ }^{\dagger}$ School of Physical, Environmental and Mathematical Sciences, UNSW Canberra at the Australian Defence Force Academy, Canberra, ACT 2600, Australia

${ }^{\ddagger}$ Institute for Superconductivity and Electronic Materials, University of Wollongong, Wollongong, NSW 250o, Australia

${ }^{\perp}$ Australian Centre for Neutron Scattering, Locked Bag 2001, Kirrawee DC NSW 2232, Australia

${ }^{\S}$ School of Physics and Astronomy, Shanghai Jiao Tong University, Shanghai 200240, China

${ }^{\#}$ Key Laboratory of Artificial Structures and Quantum Control, School of Physics and Astronomy, Shanghai Jiao Tong University, Shanghai, 200240, China

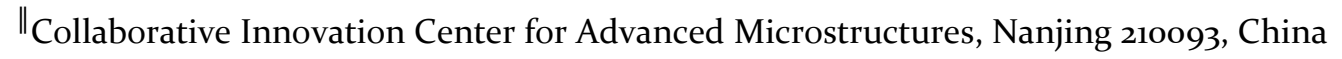

'College of Physics, Jilin University, Changchun 130012, China

\begin{abstract}
The structural and magnetic properties of magnetocaloric $\mathrm{Mn}\left(\mathrm{Co}_{1-\mathrm{x}} \mathrm{Ni}_{\mathrm{x}}\right) \mathrm{Ge}$ compounds have been studied. Two responses to the increase of valence electron concentration on substitution of $\mathrm{Ni}\left(3 \mathrm{~d}^{8} 4 \mathrm{~s}^{2}\right)$ for Co $\left(3 \mathrm{~d}^{7} 4 \mathrm{~s}^{2}\right)$ in the orthorhombic phase (Pnma) are proposed - expansion of unit cell volume and redistribution of valence electrons. We present experimental evidence for electronic redistribution associated with the competition between magnetism and bonding. This competition in turn leads to complex dependences of the reverse martensitic transformation temperature $T_{\mathrm{M}}$ (orthorhombic to hexagonal $\left(\mathrm{Pb}_{3} / \mathrm{mmc}\right)$ ) and the magnetic structures on the $\mathrm{Ni}$ concentration.
\end{abstract}

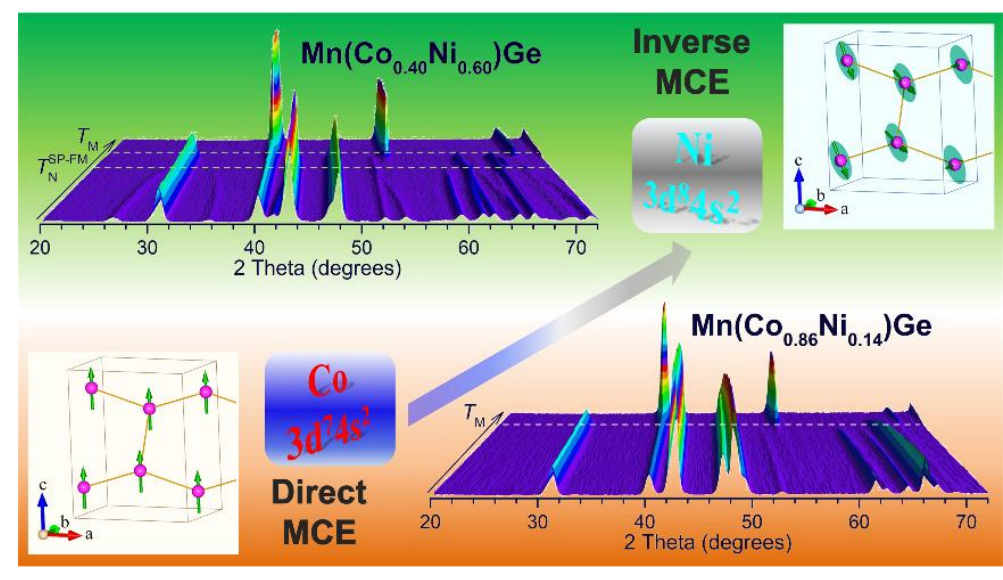
Magnetic transitions from ferromagnetic structures below $\mathrm{x}=0.50$ to non-collinear spiral antiferromagnetic structures above $\mathrm{x}=0.55$ at low temperature (e.g. $5 \mathrm{~K}$ ) are induced by modification of the density of states at the Fermi surface due to the redistribution of valence electrons. $T_{M}$ is found to decrease initially with increasing Ni content and then increase. Both direct and inverse magnetocaloric effects are observed.

\section{INTRODUCTION}

The structural and magnetic properties of MnCoGebased alloys have been studied extensively in recent years (e.g.1-5); this stems mainly from their potential application as magnetic cooling materials based on the magnetocaloric effect (MCE). There are two stable crystallographic structures, corresponding to the nominal hightemperature hexagonal (Hex) phase with $\mathrm{Ni}_{2}$ In-structure $\left(\mathrm{Pb}_{3} / \mathrm{mmc}\right)$ and the nominal low-temperature orthorhombic (Orth) phase with TiNiSi-type structure (Pnma) (see Figure 1 and Figure $S_{1}$ in the Supporting Information). ${ }^{6}$ It was reported that both collinear ferromagnetic (FM) and non-collinear spiral antiferromagnetic (spiral-AFM) structures may exist in the orthorhombic phase at low temperature. $^{7-10}$ The presence of ferromagnetic or spiral antiferromagnetic structures in the orthorhombic phase would allow scope for a direct (positive) $\mathrm{MCE}^{11-13}$ or inverse (negative) MCE. ${ }^{14-16}$ It is therefore important to study the mechanism for the magnetic transfer between FM and spiral-AFM in the orthorhombic phase.

One mechanism for a non-collinear magnetic structure is the competition between symmetric superexchange and the antisymmetric Dzyaloshinsky-Moriya (DM) interaction, ${ }^{17,18}$ such as in $\mathrm{CuB}_{2} \mathrm{O}_{7},{ }^{19} \mathrm{LiFeAs}_{2} \mathrm{O}_{7}{ }^{20}$ and $\mathrm{FeBO}_{3}{ }^{21}$ The 
Hexagonal

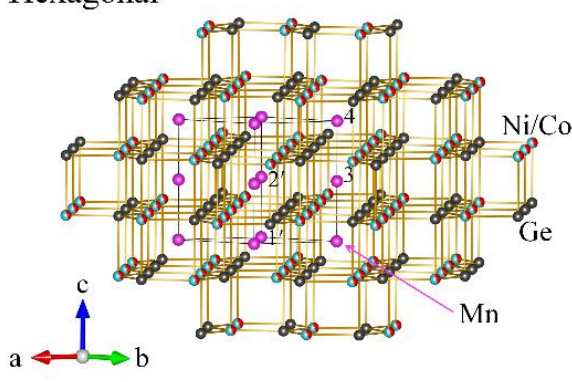

(a)

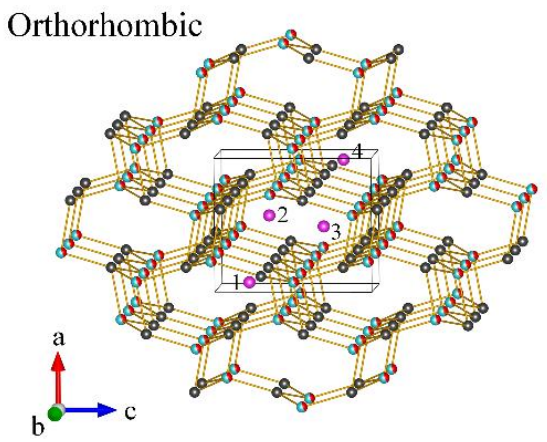

(d)

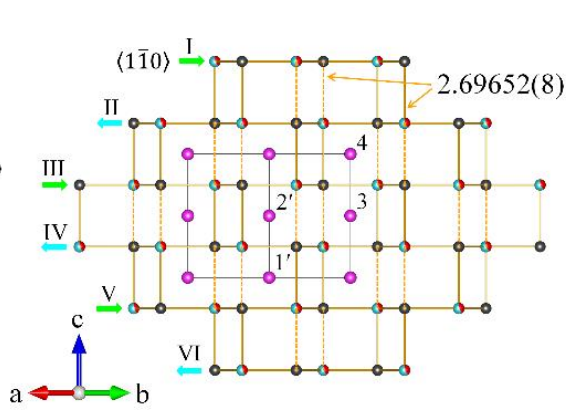

(b)

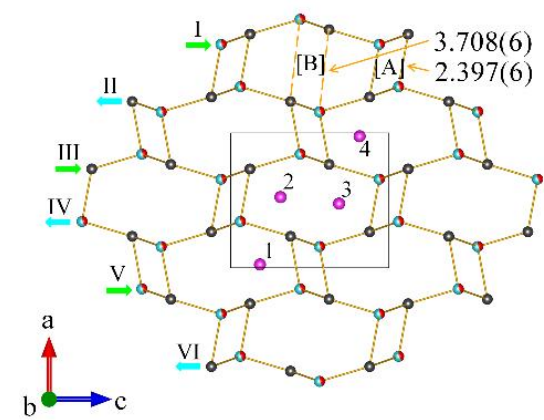

(e)

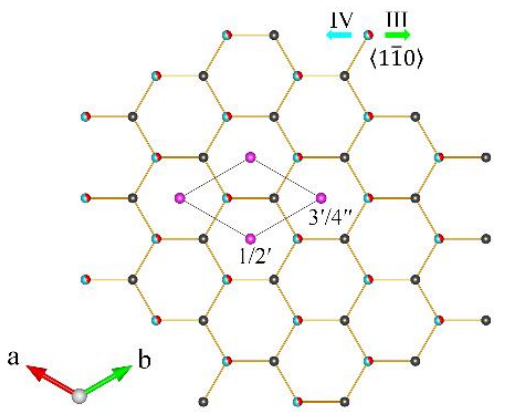

(c)

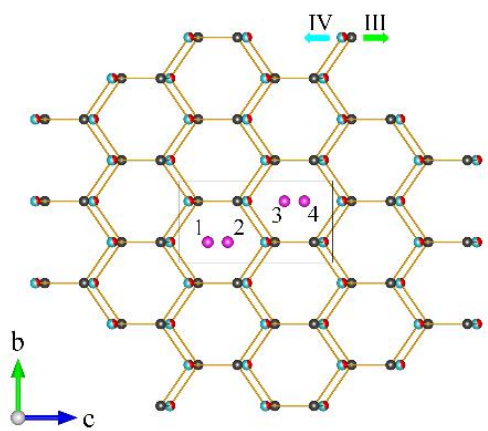

(f)

Figure ${ }_{1}$ Crystal structures and $\mathrm{Co} / \mathrm{Ni}-\mathrm{Ge}$ networks in the $\mathrm{Mn}\left(\mathrm{Co}_{0.40} \mathrm{Ni}_{\text {o.6o }}\right) \mathrm{Ge}$ sample with (a), (b), (c) a Ni $\mathrm{Ni}_{2}$ In-type hexagonal structure $\left(\mathrm{Pb}_{3} / \mathrm{mmc}\right.$ ) and (d), (e), (f) a TiNiSi-type orthorhombic structure (Pnma). Only the Mn atoms in the first unit cell are shown. Both structures are built from two-dimensional layers (indicated by I, II, ...) of edge-sharing six-membered $\mathrm{Co} / \mathrm{Ni}-\mathrm{Ge}$ rings. (a) and (d) are three-dimensional views, (b) and (e) are two-dimensional views projected on the (no) plane and ac-plane, and (c) and (f) are the III and IV layers projected on the $a b$ - and $b c$-planes for the hexagonal and orthorhombic structures, respectively. The numbered Mn atoms are used as guides for the rotation of the networks. The annotations " and '"' in (a), (b) and (c) are used as indicators of the atoms on the inner plane and the next-inner plane, respectively. The $\mathrm{Co} / \mathrm{Ni}-\mathrm{Ge}$ bonds between the two-dimensional layers are separated into two groups, marked as $[\mathrm{A}]$ and $[\mathrm{B}]$, respectively. Bonds $[\mathrm{B}]$ were broken during the martensitic transformation from the hexagonal structure to the orthorhombic structure. The figures are created based on the Rietveld refinement results of the x-ray diffraction pattern for $\mathrm{Mn}\left(\mathrm{Co}_{0.40} \mathrm{Ni}_{0.60}\right) \mathrm{Ge}$ at room temperature $(\sim 295 \mathrm{~K}$, see Figure 2).

DM interaction is a relativistic correction to the usual superexchange due to spin-orbit coupling. ${ }^{18,22}$ One fundamental macroscopic feature of this antisymmetric coupling takes place in non-centrosymmetric magnetic crystals. ${ }^{23,}{ }^{24}$ Another possible reason derives from competition between interactions such as Ruderman-KitelKasuya-Yosida (RKKY) in itinerant systems ${ }^{25}$, 26 or Heisenberg exchanges in localised moment systems. ${ }^{27,28}$ Different from the DM interaction that depends on lattice symmetry, these interactions depend strongly on the distances between the magnetic moments. The RKKY interaction is long range interaction, ${ }^{29}$ with oscillation of the magnetic interactions being responsible for a spiral structure. $^{30}$ In the Heisenberg model, frustration between nearest-neighbour (NN) and next-nearest-neighbour (NNN) exchange interactions can likewise cause a spiral structure. $^{31,32}$

An alternative explanation for a non-collinear spiralAFM builds on the stability of the band structure. Earlier reports in Mn-based orthorhombic systems indicated that a high density of states at the Fermi surface $\left(N\left(E_{\mathrm{F}}\right)\right)$ makes FM unstable while a non-collinear AFM can reduce $N\left(E_{\mathrm{F}}\right){ }^{33,34}$ Such lower $N\left(E_{\mathrm{F}}\right)$ in a non-collinear AFM com- pared with a FM state is linked to the modification of Fermi surface topology which has been discussed by Lizárraga et al. ${ }^{35}$ This discussion is based on the possibility of hybridisation of the spin-up and spin-down channels for a non-collinear spin configuration. The opening of a band gap at the Fermi level due to the hybridisation would lower the total energy over a ferromagnetic configuration. It is considered that a non-collinear structure can be obtained by modifying the Fermi surface in any element or compound, especially in a ferromagnet with nesting features between the spin-up and spin-down Fermi surface, ${ }^{35-37}$ e.g. through application of high pressure ${ }^{38}$ or modification of the constituent elements. ${ }^{39}$ Such noncollinear structures generally correspond to the systems exhibiting small unit cell volumes and small magnetic moments, e.g. in $\mathrm{Fe}-\mathrm{Ni}$ Invar alloys ${ }^{40}$ and zinc-blende MnAs. ${ }^{36}$

In the case of MnCoGe-based compounds, it was reported that the valence electron concentration $e / a$ (VEC, defined as the average number of valence electrons per atom) has a strong influence on the magnetic properties. ${ }^{41,42}$ In the present work, the magnetic transfer between ferromagnetism and spiral antiferromagnetism 
in the orthorhombic structure of MnCoGe will be tuned by modifying VEC through partial substitution of $\mathrm{Ni}$ $\left(3 \mathrm{~d}^{8} 4 \mathrm{~s}^{2}\right)$ for Co $\left(3 \mathrm{~d}^{7} 4 \mathrm{~s}^{2}\right)$. A comprehensive set of fifteen $\mathrm{Mn}\left(\mathrm{Co}_{1-\mathrm{X}} \mathrm{Ni}_{\mathrm{x}}\right) \mathrm{Ge}$ compounds with a broad $\mathrm{Co} / \mathrm{Ni}$ ratio (o.12 $\leq \mathrm{x} \leq 1 . \mathrm{oo}$ ) have been prepared and investigated over the temperature range $5-450 \mathrm{~K}$ using magnetisation, $\mathrm{x}$-ray and neutron diffraction measurements. In addition, the relationship of the VEC with magnetic structures and structural transitions will be discussed from the aspects of electronic redistribution and unit cell volume, which is associated with the modification of the density of states at the Fermi surface $\left(N\left(E_{\mathrm{F}}\right)\right)$.

\section{EXPERIMENTAL SECTION}

Synthesis Fifteen polycrystalline $\mathrm{Mn}\left(\mathrm{Co}_{1-\mathrm{x}} \mathrm{Ni}_{\mathrm{x}}\right) \mathrm{Ge}$ samples with $\mathrm{x}=0.12,0.14,0.16,0.18,0.20,0.30,0.40,0.50$, $0.55,0.58,0.60,0.70,0.80,0.90$ and 1.00 ( $\sim 2$ grams each sample) were prepared by arc melting stoichiometric amounts of $\mathrm{Ni}, \mathrm{Co}, \mathrm{Ge}$ and $\mathrm{Mn}$ (, purities > 99.95 wt\%) under an argon atmosphere on a water cooled $\mathrm{Cu}$ hearth. The oxidised surface of the Mn flakes was first removed using diluted nitric acid. The ingots were melted four times to ensure homogeneity with 3\% excess Mn added to compensate for mass loss during the melting process. The ingots were wrapped with Ta foil and sealed in quartz glass tubes under vacuum. The samples were then annealed in a horizontal tube furnace at $850{ }^{\circ} \mathrm{C}$ for 7 days. Finally, the samples were quenched into iced-water and ground into powder using an agate mortar/pestle for the measurements.

$\mathrm{X}$-ray diffraction The quality and phases of all samples were checked by $\mathrm{x}$-ray diffraction measurements at room temperature $(\sim 295 \mathrm{~K})$ using a PANalytical diffractometer with $\mathrm{CuK} \alpha$ radiation. In addition to the neutron diffraction measurements outlined below, the structures and related martensitic reverse transformation temperatures were investigated by variable temperature $\mathrm{x}$-ray diffraction measurements over the temperature range from $20 \mathrm{~K}$ to $310 \mathrm{~K}$ in $10 \mathrm{~K}$ steps. A holding time of $10 \mathrm{~min}$ was used at every temperature step to ensure thermal equilibrium.

Magnetic measurements Magnetic measurements were performed on the polycrystalline samples using a Quantum Design physical property measurement system (PPMS). The magnetisation versus temperature at constant-field sweeps were performed in an applied magnetic field of $0.01 \mathrm{~T}$ with $5 \mathrm{~K}$ steps over a temperature range of 5 - $300 \mathrm{~K}$ or 5 - $320 \mathrm{~K}$. Two measurement sequences were used: heating after zero-field cooling (ZFC) and field cooling $(\mathrm{FC})$ at a rate of $0.7 \mathrm{~K} / \mathrm{min}$. The field-dependent isothermal magnetisations were recorded in fields up to $5 \mathrm{~T}$ in steps of $0.2 \mathrm{~T}$ or $0.25 \mathrm{~T}$ around the magnetic phase transitions temperatures in $5 \mathrm{~K}$ steps, using the standard isothermal process. ${ }^{43}$

Neutron powder diffraction Neutron powder diffraction experiments were performed on $\mathrm{Mn}\left(\mathrm{Co}_{1-\mathrm{x}} \mathrm{Ni}_{\mathrm{x}}\right) \mathrm{Ge}$ samples with $\mathrm{x}=0.14,0.40,0.55,0.58,0.60,0.90$ and 1.00 using the high-intensity powder diffractometer WOMBAT at the OPAL Reactor (Lucas Heights, Australia) with a neutron wavelength of $2.4143 \AA \AA^{44} \mathrm{~A}$ continuous

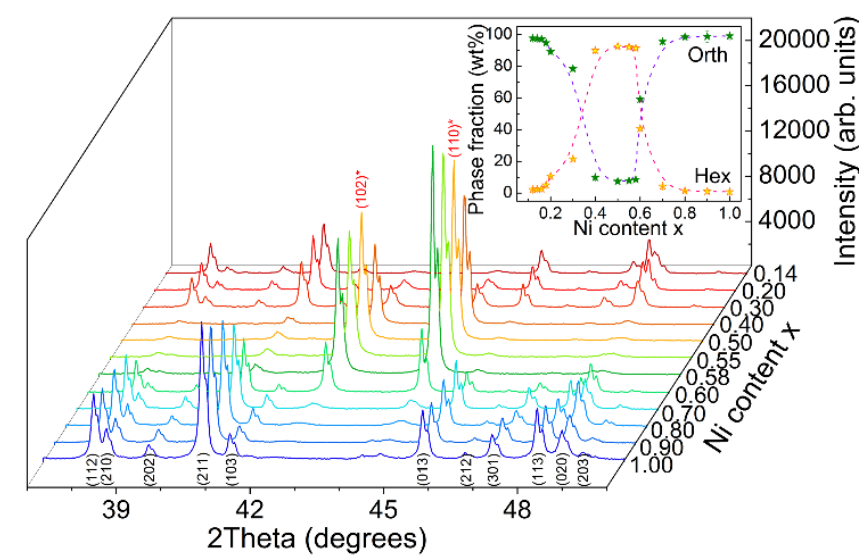

Figure $2 \mathrm{X}$-ray diffraction patterns of $\mathrm{Mn}\left(\mathrm{CO}_{1-\mathrm{x}} \mathrm{Ni}_{\mathrm{x}}\right) \mathrm{Ge}$ samples $(\mathrm{x}=0.14$ to 1.00$)$ at room temperature $(\sim 295 \mathrm{~K})$. The Miller indices of reflections from the hexagonal and orthorhombic structures are indexed with and without asterisks, respectively. Inset are the fractions of the hexagonal and orthorhombic phases as a function of $\mathrm{Ni}$ content $\mathrm{x}(\mathrm{x}=0.12$ to 1.00). Interestingly, it is noted that the orthorhombic phase fraction decreases from $98(3) \mathrm{wt} \%(\mathrm{x}=0.12)$ to $13.5(5) \mathrm{wt} \%(\mathrm{x}=0.40)$ and then increases from $12.3(6) \mathrm{wt} \%(\mathrm{x}=0.58)$ to $99(4) \mathrm{wt} \%$ $(\mathrm{x}=1.00)$.
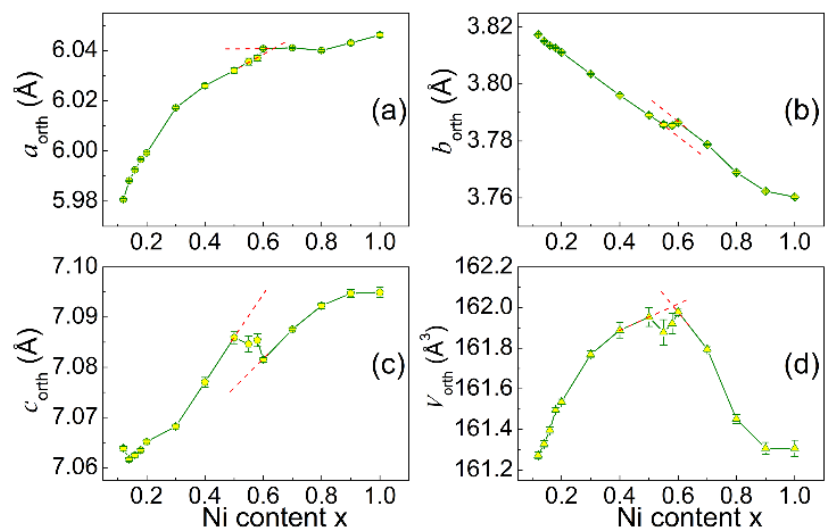

Figure 3 (a), (b) and (c) Lattice parameters and (d) unit cell volumes for the orthorhombic phase in the $\mathrm{Mn}\left(\mathrm{Co}_{1-\mathrm{x}} \mathrm{Ni}_{\mathrm{x}}\right) \mathrm{Ge}$ $(\mathrm{x}=0.12$ to 1.00$)$ from the room temperature $\mathrm{x}$-ray diffraction patterns of Figure 2. The full lines are guides to the eye with the dashed lines indicating the slight discontinuities in $a_{\text {orth }}$, $b_{\text {orth }}$ and $c_{\text {orth }}$ around $\mathrm{x}=0.55$ as discussed in the text. The errors bars are as shown (in some cases the uncertainty is smaller than the symbol).

detector bank of $160^{\circ} \times 120 \mathrm{~mm}$ high was used. Variable temperature measurements were carried out in zero magnetic field using a top loading cryofurnace over the temperature range $5 \mathrm{~K}$ to $450 \mathrm{~K}$. Refinements of both the $\mathrm{x}$-ray diffraction and neutron patterns were performed using the Rietveld method and irreducible representation theory using the program FullProf. ${ }^{45}, 46$

\section{RESULTS AND DISCUSSIONS}

Structural description X-ray diffraction patterns of $\mathrm{Mn}\left(\mathrm{Co}_{1-\mathrm{x}} \mathrm{Ni}_{\mathrm{x}}\right) \mathrm{Ge}(\mathrm{x}=0.14$ to 1.00$)$ at room temperature are presented in Figure 2. All of the samples were found to 
exhibit the TiNiSi-type orthorhombic structure (Pnma) and/or the $\mathrm{Ni}_{2}$ In-type hexagonal structure $\left(\mathrm{PG}_{3} / \mathrm{mmc}\right)$. Examples of the refinements of the x-ray diffraction patterns are given in Figure S2. There are no discernible impurities (neutron diffraction measurement with higher resolution demonstrates a small fraction of the impurity phase $\mathrm{MnNi}_{1.25} \mathrm{Ge}_{0.75}(\leq 2(1) \mathrm{wt} \%)$ in the samples with $\mathrm{x}=$ 0.90 and 1.00). The fraction of the orthorhombic phase at room temperature initially decreases with $\mathrm{Ni}$ content and then increases as shown in the inset of Figure 2. As noted the hexagonal and orthorhombic structures of the $\mathrm{Mn}\left(\mathrm{Co}_{0.40} \mathrm{Ni}_{\text {o.60 }}\right) \mathrm{Ge}$ at room temperature are shown in Figure 1. It is considered that the $\mathrm{Co} / \mathrm{Ni}$ ( $2 d$ site) and the $\mathrm{Ge}(2 \mathrm{C}$ site) atoms form a three-dimensional fiveconnected $\left({ }_{3} \mathrm{D}_{5} \mathrm{C}\right)$ network in the hexagonal structure. ${ }^{47}$ This network can be viewed as being built from twodimensional flat layers of edge-sharing six-membered $\mathrm{Co} / \mathrm{Ni}-\mathrm{Ge}$ rings. The $\mathrm{Co} / \mathrm{Ni}-\mathrm{Ge}$ honeycomb is stitched together by $\mathrm{Mn}$ atoms. X-ray diffraction of the MnCoGe single crystal indicated that Co atoms have much larger thermal vibrations in the hexagonal structure (along the $a_{\text {hex }}$-axis) than in the orthorhombic structure. ${ }^{6}$ This large vibration amplitude of Co brings about higher entropy in the high-temperature hexagonal structure and hence leads to a diffusionless and displacive structural transition into the low-temperature orthorhombic structure. During this transition, the adjacent two-dimensional $\mathrm{Co} / \mathrm{Ni}-\mathrm{Ge}$ layers in the hexagonal structure glide towards opposite directions along $\langle 1 \overline{1} 0\rangle$ as indicated by the bold arrows in Figure 1. As a result of the release of the Co thermal vibration, bonds between the $\mathrm{Co} / \mathrm{Ni}-\mathrm{Ge}$ layers are varied dramatically and half of them (short dashes in Figure $1(\mathrm{e})$, labelled as [B]) are broken. The flat $\mathrm{Co} / \mathrm{Ni}-\mathrm{Ge}$ layers are wrinkled and become pseudo-zigzag layers in the orthorhombic structure. Finally the ${ }_{3} \mathrm{D}_{5} \mathrm{C} \mathrm{Co} / \mathrm{Ni}-\mathrm{Ge}$ network in the hexagonal structure changes as a $3 \mathrm{D}_{4} \mathrm{C}$ Co/Ni-Ge network in the orthorhombic structure, in agreement with the description by Landrum et al..$^{48}$

As described previously, ${ }^{49}$ the relationships between the lattice parameters of the two structures depicted in Figure 1 can be derived as: $a_{\text {orth }} \sim c_{\text {hex }}, b_{\text {orth }} \sim a_{\text {hex }}, c_{\text {orth }} / \sqrt{3}_{3} \sim a_{\text {hex }}$ and $V_{\text {orth }} / 2 \sim V_{\text {hex }}$. The lattice parameters as functions of $\mathrm{Ni}$ content $\mathrm{x}$ for the orthorhombic phase in $\mathrm{Mn}\left(\mathrm{Co}_{1-}\right.$ $\left.{ }_{x} \mathrm{Ni}_{\mathrm{x}}\right) \mathrm{Ge}(\mathrm{x}=0.12$ to 1.00) as determined from Rietveld refinements of the x-ray diffraction patterns (Figure 2) are shown in Figure 3. While the value of $b_{\text {orth }}$ is found to decrease from 3.817(1) $\AA$ for $\mathrm{x}=0.12$ to $3.760(1) \AA$ for $\mathrm{x}=1.0$ (Figure $3(\mathrm{~b})$ ) on substitution of Ni of atomic radius $1.21 \AA$ for Co of atomic radius $1.26 \AA$, $a_{\text {orth }}$ and $c_{\text {orth }}$ increase from

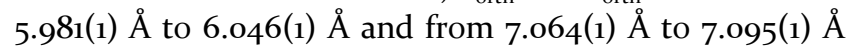
(Figures $3(\mathrm{a})$ and $3(\mathrm{c})$ respectively). Such pronounced anisotropy leads to the interesting variation in unit cell volume $V_{\text {orth }}$ shown in Figure $3(\mathrm{~d})$. $V_{\text {orth }}$ does not follow Vegard's law but rather exhibits a $\Lambda$-like dependence on the Ni content $\mathrm{x}$ : increases firstly with $\mathrm{Ni}$ content to $\mathrm{x} \sim$ 0.55 and then decreases. In addition, it is noted that slight discontinuities are also observed in $a_{\text {orth }}, b_{\text {orth }}$ and $c_{\text {orth }}$ around $\mathrm{x}=0.55$, as indicated by the dashed lines in Figure 3(a), 3(b), 3(c).
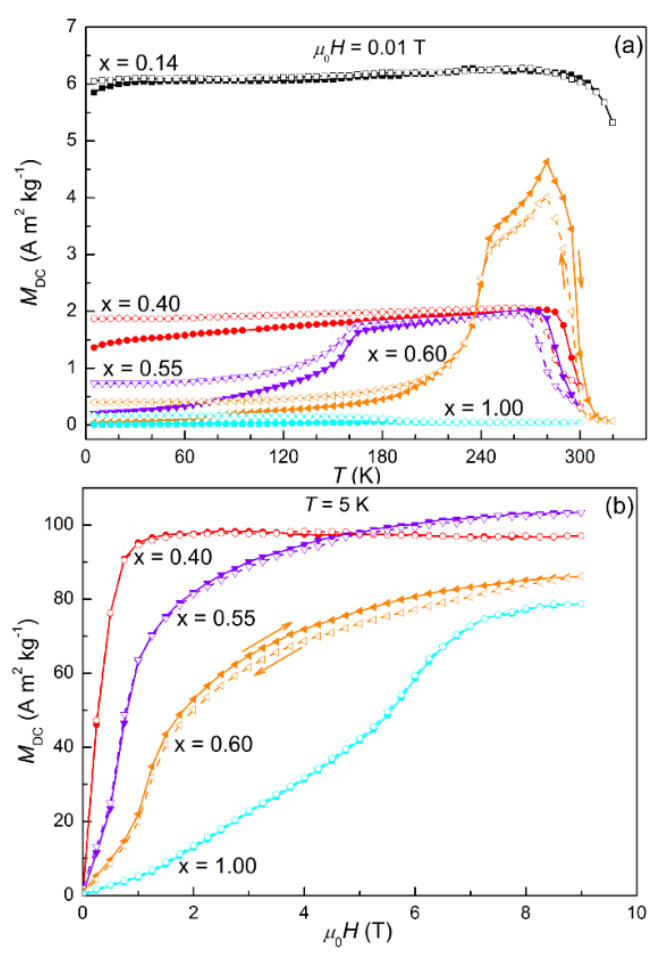

Figure 4 (a) Temperature dependences of the magnetisation for the $\mathrm{Mn}\left(\mathrm{Co}_{1-\mathrm{x}} \mathrm{Ni}_{\mathrm{x}}\right) \mathrm{Ge}$ samples, $\mathrm{x}=0.14,0.40,0.55,0.60$ and 1.0o, in an applied field of $\mu_{\mathrm{o}} H=0.01 \mathrm{~T}$ on warming after zero-field cooling (ZFC, solid symbols) and field cooling (FC, open symbols). (b) Field dependence of the magnetisation for samples at $5 \mathrm{~K}$ with $\mathrm{x}=0.40,0.55$, o.6o and 1.00.

Magnetisation Magnetisation curves in an applied magnetic field of $0.01 \mathrm{~T}$ for $\mathrm{Mn}\left(\mathrm{Co}_{1-\mathrm{x}} \mathrm{Ni}_{\mathrm{x}}\right) \mathrm{Ge}$ with $\mathrm{x}=0.14,0.4 \mathrm{O}$, 0.55, o.6o and 1.00 are shown in Figure 4(a) (for more information, see Figure $S_{3}$ ). The samples with $\mathrm{x}=0.14,0.40$ and 0.50 exhibit ferromagnetic-like behaviour below the magnetisation transition temperatures. In contrast, the magnetisation curves for the samples with $\mathrm{x}=0.55,0.58$ and 0.60 have antiferromagnetic-like features at low temperature followed by a transition to ferromagnetism at 155(4) K, 210 (4) K and 245(4) K, respectively. As evident in Figure $\mathrm{S}_{3}$ the magnetisations for Ni-rich samples with $\mathrm{x}$ $\geq 0.70$ are significantly reduced compared with the magnetisations of the other samples. As outlined below, analysis of the neutron diffraction patterns demonstrate that for the $\mathrm{Mn}\left(\mathrm{Co}_{1-\mathrm{x}} \mathrm{Ni}_{\mathrm{x}}\right) \mathrm{Ge}$ with $\mathrm{x} \geq 0.7$, the antiferromagnetic phase transforms directly to paramagnetic phase at the corresponding Néel temperature $T_{\mathrm{N}}$ (the transition temperatures are listed in Table $\mathrm{S} 1$ ).

The magnetic transitions from ferromagnetic structure to antiferromagnetic structure with increasing $\mathrm{Ni}$ content $\mathrm{x}$ at $5 \mathrm{~K}$ are illustrated by the isothermal magnetisations curves in Figure 4(b). As evident in Figure 4(b), while the magnetic isotherm for the $\mathrm{Mn}\left(\mathrm{Co}_{1-\mathrm{x}} \mathrm{Ni}_{\mathrm{x}}\right) \mathrm{Ge}$ with $\mathrm{x}=0.4 \mathrm{O}$ increases rapidly with magnetic field, metamagnetic behaviours are observed for the samples with $\mathrm{x}=0.55$, 0.60 and 1.oo. Such metamagnetic behaviours indicate the rotation of the antiferromagnetic moment towards a ferromagnetic alignment under applied magnetic field. In addition, a higher magnetic field is needed to align the anti- 
ferromagnetic moments with increasing Ni content, e.g. the ferromagnetic alignment occurs at $\mu_{\mathrm{o}} H \sim 6$.o $\mathrm{T}$ for $\mathrm{x}=$ 1.0o compared with $\mu_{\mathrm{o}} H \sim 1.2 \mathrm{~T}$ for $\mathrm{x}=0.6 \mathrm{o}$. This indicates that the antiferromagnetic phase becomes increasingly stable with the increased $\mathrm{Ni}$ content.

The magnetic transitions in the $\mathrm{Mn}\left(\mathrm{Co}_{1-\mathrm{x}} \mathrm{Ni}_{\mathrm{x}}\right) \mathrm{Ge}$ samples with $\mathrm{x}=0.40$ to 0.60 occur between $\sim 28 \mathrm{o} \mathrm{K}$ and $\sim 310 \mathrm{~K}$. Trung et al. have demonstrated that magnetic transitions occurring in the temperature range $275 \mathrm{~K}$ to $345 \mathrm{~K}$ in MnCoGe-based compounds generally coincide with a structural transition, and that such coincidence provides scope for the formation of magneto-structural transitions from ferromagnetic orthorhombic structure (FM-Orth) to paramagnetic hexagonal structure (PM-Hex) and hence an associated large MCE." Therefore it is also expected that a magneto-structural transition and large MCE will be observed in the $\mathrm{Mn}\left(\mathrm{Co}_{1-\mathrm{x}} \mathrm{Ni}_{\mathrm{x}}\right) \mathrm{Ge}$ samples with $\mathrm{x}=0.40$ to o.6o. More details about the magnetic transition temperatures obtained for the present $\mathrm{Mn}\left(\mathrm{Co}_{1-\mathrm{x}} \mathrm{Ni}_{\mathrm{x}}\right) \mathrm{Ge}$ samples are summarised in Table $S_{1}$. It is also noted that the thermal hysteresis, $\Delta T_{\text {hys }}$, i.e. the difference in magnetic transition temperature on warming and cooling, decreases from $15(2) \mathrm{K}$ for $\mathrm{x}=0.40$ to $5(2) \mathrm{K}$ for $\mathrm{x}=0.60$. Such decrease of thermal hysteresis is advantageous for improving the energy efficiency in magnetocaloric materials. $^{50}$

Magnetic structures As demonstrated from the magnetisation measurements, $\mathrm{Mn}\left(\mathrm{Co}_{1-\mathrm{x}} \mathrm{Ni}_{\mathrm{x}}\right) \mathrm{Ge}$ with $\mathrm{Ni}$ concentrations in the range $\mathrm{x}=0.14$ to $\mathrm{x}=1.00$ exhibit ferromagnetic and antiferromagnetic behaviours. The magnetic structures of these compounds have been investigated in three different regions delineated by the magnetic phase transitions: samples with $\mathrm{x} \leq 0.50$ show a single FM/PM transition; samples with $0.55 \leq \mathrm{x}<\sim 0.70$ have an AFM/FM transition and a FM/PM transition; samples with $\mathrm{x}>\sim 0.70$ exhibit a single AFM/PM transition. It is reported that the $\mathrm{Ni}$ atoms do not carry a magnetic moment in $\mathrm{MnCoGe} / \mathrm{MnNiGe}$-based alloys. ${ }^{8}$ In addition, following our previous study of $\left(\mathrm{Mn}_{0.98} \mathrm{Fe}_{0.02}\right) \mathrm{CoGe}$ and $\mathrm{Mn}\left(\mathrm{Co}_{0.96} \mathrm{Fe}_{\mathrm{o.04}}\right) \mathrm{Ge}$, the magnetic moment on Co atoms was shown to be too small to be resolved by neutron powder diffraction measurements. ${ }^{4} 5$ Therefore in the present work only the magnetic moments on the Mn sublattice of the $\mathrm{Mn}\left(\mathrm{Co}_{1-\mathrm{x}} \mathrm{Ni}_{\mathrm{x}}\right) \mathrm{Ge}$ compounds are considered in the analysis of the neutron diffraction patterns. In addition, the Ni/Co occupancies obtained through the Rietveld refinements of the neutron diffraction patterns match well with the nominal compositions of the samples (see Table S2).

1) Magnetic structures for $\mathrm{Mn}\left(\mathrm{Co}_{1-x} \mathrm{Ni} \mathrm{i}_{x}\right) \mathrm{Ge}(\mathrm{x}=0.14$ and o.40) The neutron powder diffraction patterns for $\mathrm{Mn}\left(\mathrm{Co}_{0.86} \mathrm{Ni}_{\text {o.14 }}\right) \mathrm{Ge}$ and $\mathrm{Mn}\left(\mathrm{Co}_{\text {o.6o }} \mathrm{Ni}_{\text {o.40 }}\right) \mathrm{Ge}$ are shown in Figures $\mathrm{S}_{4}(\mathrm{a})$ and $\mathrm{S}_{4}(\mathrm{~b})$. Both samples have the orthorhombic structure at low temperatures, followed by a structural transition to the high-temperature hexagonal structure at 370(2) K and 299(1) K, respectively. No satellite peaks are observed in the diffraction patterns, precluding an incommensurate structure in these two samples. Analysis of the magnetic structure was carried out

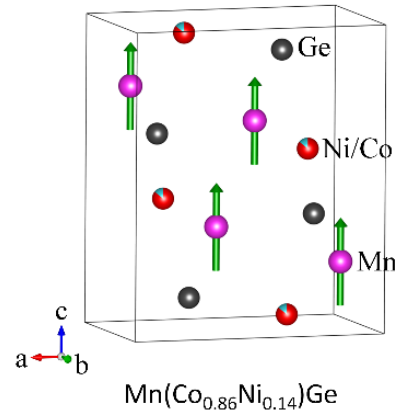

(a)

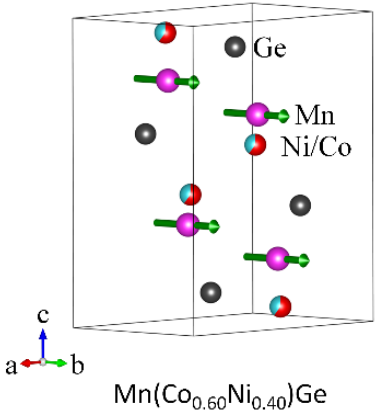

(b)
Figure 5 The magnetic structures in the orthorhombic phase of (a) $\mathrm{Mn}\left(\mathrm{Co}_{\mathrm{o} .86} \mathrm{Ni}_{\text {o.14 }}\right) \mathrm{Ge}$ and (b) $\mathrm{Mn}\left(\mathrm{Co}_{\text {o.6o }} \mathrm{Ni}_{\text {o.40 }}\right) \mathrm{Ge}$ at $5 \mathrm{~K}$. Each sample has a ferromagnetic structure: the magnetic moments in $\mathrm{Mn}\left(\mathrm{Co}_{0.86} \mathrm{Ni}_{\mathrm{o} .14}\right) \mathrm{Ge}$ point to $c_{\text {orth }}$, corresponding to the irreducible representation model $\mathrm{F}_{\mathrm{z}}$ of $\Gamma_{3}$; and the magnetic moments in $\mathrm{Mn}\left(\mathrm{Co}_{0.60} \mathrm{Ni}_{\text {o.40 }}\right)$ Ge point to $b_{\text {orth }}$, corresponding to the irreducible representation model $\mathrm{F}_{\mathrm{y}}$ of $\Gamma_{5}$.

using irreducible representation theory as described in our previous report..$^{5}$ (More details about the analysis of the neutron diffraction patterns are given in the Section 4.2 in the Supporting Information).

Both $\mathrm{Mn}\left(\mathrm{Co}_{0.86} \mathrm{Ni}_{\text {o.14 }}\right) \mathrm{Ge}$ and $\mathrm{Mn}\left(\mathrm{Co}_{0.60} \mathrm{Ni}_{\text {o.40 }}\right)$ Ge have ferromagnetic structures below the Curie temperatures, 345(5) K and 280(4) K, respectively (see Figures $\mathrm{S}_{3}$ and $\left.\mathrm{S}_{4}\right)$. The magnetic moments on the $\mathrm{Mn}$ sublattice align along the $c_{\text {orth }}$-axis $\left(\mathrm{FM}_{c}\right)$ in $\mathrm{Mn}\left(\mathrm{Co}_{0.86} \mathrm{Ni}_{0.14}\right) \mathrm{Ge}$ as shown in Figure $5(\mathrm{a})$; the magnetic moments on the $\mathrm{Mn}$ atoms are 3.4(1) $\mu_{\mathrm{B}}$ at $5 \mathrm{~K}$. Interestingly, it is found that further doping of Ni causes a reorientation of the magnetic moments on the Mn atoms in the orthorhombic structure. For example, the 3.5(1) $\mu_{\mathrm{B}}$ magnetic moments in $\mathrm{Mn}\left(\mathrm{Co}_{\text {o.60 }} \mathrm{Ni}_{\text {o.40 }}\right)$ Ge lie along the $b_{\text {orth }}$-axis $\left(\mathrm{FM}_{b}\right)$ at $5 \mathrm{~K}$ as shown in Figure $5(\mathrm{~b})$. Moreover there are other differences apparent: $\mathrm{Mn}\left(\mathrm{Co}_{0.86} \mathrm{Ni}_{\text {o.14 }}\right) \mathrm{Ge}$ has separated magnetic and structural transitions at 345(5) $\mathrm{K}$ and 370(2) K, while $\mathrm{Mn}\left(\mathrm{Co}_{\text {o.6o }} \mathrm{Ni}_{\text {o.4o }}\right) \mathrm{Ge}$ has only one FM-Orth/PM-Hex first order magneto-structural transition (FOMST) at 299(1) K with a full width at half maximum of 13(1) K.

2) Magnetic structures for $\mathrm{Mn}\left(\mathrm{Co}_{1-x} \mathrm{Ni}{ }_{x}\right) \mathrm{Ge}(x=0.55,0.58$ and 0.60$)$ The $\mathrm{Mn}\left(\mathrm{Co}_{1-\mathrm{x}} \mathrm{Ni}_{\mathrm{x}}\right) \mathrm{Ge}$ samples with $\mathrm{x}=0.55,0.58$ and 0.60 are found to exhibit similar magnetic structures and phase transitions. The neutron powder diffraction patterns for $\mathrm{Mn}\left(\mathrm{Co}_{1-\mathrm{x}} \mathrm{Ni}_{\mathrm{x}}\right) \mathrm{Ge}$ with $\mathrm{x}=0.60$ are shown in Figure 6(a) with the diffraction patterns for $\mathrm{Mn}\left(\mathrm{Co}_{1-}\right.$ ${ }_{x} \mathrm{Ni}_{\mathrm{x}}$ ) Ge with $\mathrm{x}=0.55$ and 0.58 shown in Figures $\mathrm{S}_{4}(\mathrm{c})$ and $\mathrm{S}_{4}(\mathrm{~d})$. The $\mathrm{Mn}\left(\mathrm{Co}_{0.40} \mathrm{Ni}_{\text {o.6o }}\right) \mathrm{Ge}$ sample is taken as an example for discussion of these magnetic structures.

From the neutron data of Figure 6(a) it is concluded that the orthorhombic structure dominates in $\mathrm{Mn}\left(\mathrm{Co}_{\text {o.40 }} \mathrm{Ni}_{\text {o.6o }}\right)$ Ge below 312(1) K. In addition, a group of satellite peaks is observed below 245(5) $\mathrm{K}$, indicating a possible incommensurate AFM structure. Enhancement of several nuclear scattering peaks (e.g. (103) peak around 2 theta $\sim 66.5^{\circ}$ in Figure 6(a); also see Figure S6 for variation of the $(101)_{\text {orth }}$ peak intensity with temperature) as 

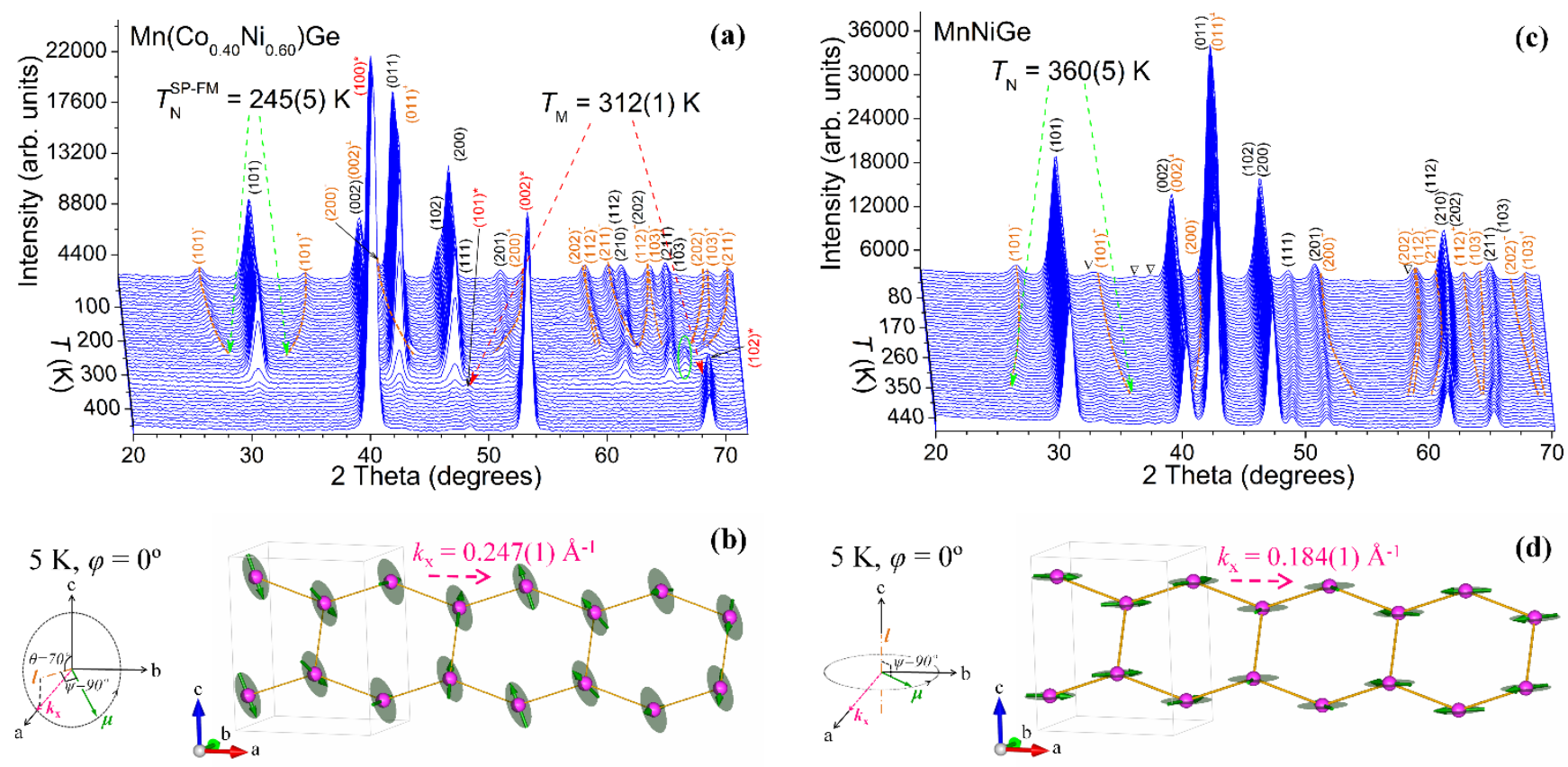

Figure 6 Neutron diffraction patterns $\left(\lambda=2.4142 \AA\right.$ ) for (a) $\mathrm{Mn}\left(\mathrm{Co}_{0.40} \mathrm{Ni}_{\mathrm{o} .60}\right) \mathrm{Ge}$ and (c) MnNiGe over the temperature range $10 \mathrm{~K}$ to $450 \mathrm{~K}$. Most of the peaks are identified as the orthorhombic structure (Miller indices without asterisk) and the hexagonal structure (Miller indices with asterisks). A small fraction of the impurity phase $\mathrm{MnNi}_{2} \mathrm{Ge}(\leq \mathbf{2}(\mathbf{1})$ wt $\%)$ is observed in $\mathrm{MnNiGe}$, as indicated by triangles in (c). The orange curves indicate the evolution of the magnetic satellite peaks. Some satellite peaks which are too small to be discerned are not marked. The green circle around 2 theta $\sim 66.5^{\circ}$ in (a) indicates the enhancement of the diffraction intensity on the (103) peak of the orthorhombic structure in $\mathrm{Mn}\left(\mathrm{Co}_{0.40} \mathrm{Ni}_{\text {o.6o }}\right)$ Ge above 245(5) K. (b) and (d) are the magnetic structures in the orthorhombic phase at $5 \mathrm{~K}$ for $\mathrm{Mn}\left(\mathrm{Co}_{0.40} \mathrm{Ni}_{\text {o.6o }}\right) \mathrm{Ge}$ and $\mathrm{MnNiGe}$, respectively. The propagation vectors are $0.247(1) \AA^{-1}$ and o.184(1) $\AA^{-1}$ along $a_{\text {orth }}$ for both samples. $\theta$ angles are $70^{\circ}$ and $0^{\circ}$, corresponding to cycloidal-spiral (CS) structure and a simple cycloidal (SC) structure, for $\mathrm{Mn}\left(\mathrm{Co}_{0.40} \mathrm{Ni}_{0.60}\right) \mathrm{Ge}$ and $\mathrm{MnNiGe}$, respectively.

well as disappearance of the satellite peaks are observed above $245(5) \mathrm{K}$ in $\mathrm{Mn}\left(\mathrm{Co}_{0.40} \mathrm{Ni}_{\mathrm{o} .60}\right) \mathrm{Ge}$. According to the magnetisation data in Figure $4(\mathrm{a})$, this increase of the peak intensity may be the result of a magnetic transition to a ferromagnetic structure. On further warming the $\mathrm{Mn}\left(\mathrm{Co}_{\text {o.40 }} \mathrm{Ni}_{\text {o.6o }}\right) \mathrm{Ge}$ sample transforms to the hexagonal structure at 312(1) K.

The propagation vectors for $\mathrm{Mn}\left(\mathrm{Co}_{0.40} \mathrm{Ni}_{\text {o.6o }}\right) \mathrm{Ge}$ below 245(5) $\mathrm{K}$ were determined using the K-search software embedded in FullProf. The results indicate that the magnetic moments propagate along the $a_{\text {orth-axis with the }}$ magnetic peaks found to be well matched using a conical structure. A schematic coordinate system for the arrangement of a magnetic moment in this conical model in which the magnetic moment $\boldsymbol{\mu}$ lies on a cone with a half angle of $\psi$ is given in Figure $S_{7}$. The spherical angles of the spiral (cone) axis $\boldsymbol{l}$ of the first atom are $\theta$ and $\varphi$ with respect to spherical coordinates, with determination of the parameters $\psi, \theta$ and $\varphi$ given in Section 4.4.1 of the supplementary information.

The Rietveld refinement results for the neutron diffraction pattern of $\mathrm{Mn}\left(\mathrm{Co}_{0.40} \mathrm{Ni}_{\text {o.6o }}\right) \mathrm{Ge}$ at $5 \mathrm{~K}$ are shown in Figure S1o(a). The optimal parameters for the conical structure are $\psi=90^{\circ}, \theta=70^{\circ}$ and $\varphi=0^{\circ}$, corresponding to a flat cycloidal-spiral (CS) structure. The propagation vector is determined as $\boldsymbol{k}_{\mathrm{x}}=0.247(1) \AA^{-1}$ along the $a_{\text {orth-axis. The }}$ configuration of this magnetic structure is shown in Figure $6(\mathrm{~b})$, and the refinement results are summarised in
Table 1. Rietveld refinements of the diffraction patterns above 245(5) $\mathrm{K}$ demonstrate a ferromagnetic structure with the magnetic moment pointing along $b_{\text {orth }}\left(\mathrm{FM}_{b}\right)$, similar to the magnetic structure in $\mathrm{Mn}\left(\mathrm{Co}_{\text {o.6o }} \mathrm{Ni}_{\text {o.40 }}\right) \mathrm{Ge}$. As an example, the refinement results for the neutron diffraction pattern of $\mathrm{Mn}\left(\mathrm{Co}_{0.60} \mathrm{Ni}_{\text {o.4o }}\right) \mathrm{Ge}$ at $280 \mathrm{~K}$ are summarised in Table 1.

3) Magnetic structures for $\mathrm{Mn}\left(\mathrm{Co}_{1-x} \mathrm{Ni} \mathrm{i}_{x}\right) \mathrm{Ge}(x=0.90$ and 1.0o) Satellite peaks are also observed in the neutron powder diffraction patterns for $\mathrm{Mn}\left(\mathrm{Co}_{\text {o.10 }} \mathrm{Ni}_{\text {o.9o }}\right) \mathrm{Ge}$ below 350(5) K (Figure $\mathrm{S}_{4}(\mathrm{e})$ ) and MnNiGe below 360(5) K (Figure 6(c)). In this case, there is no AFM/FM transition. The Orth/Hex structural transition temperatures $T_{\mathrm{M}}$ are also much higher: $442(5) \mathrm{K}$ for $\mathrm{Mn}\left(\mathrm{Co}_{\text {o.10 }} \mathrm{Ni}_{\text {o.9o }}\right) \mathrm{Ge}$ and $>450 \mathrm{~K}$ for $\mathrm{MnNiGe}$ compared with $\mathrm{Mn}\left(\mathrm{Co}_{1-\mathrm{x}} \mathrm{Ni}_{\mathrm{x}}\right) \mathrm{Ge}$ compounds $(\mathrm{x}=0.12 \leq \mathrm{x} \leq 0.8 \mathrm{o})$.

The Rietveld refinement for $\mathrm{MnNiGe}$ at $5 \mathrm{~K}$ is shown in Figure S1o(b) resulting in the values $\psi=90^{\circ}, \theta=0^{\circ}, \varphi=0^{\circ}$ and $\boldsymbol{k}_{\mathrm{x}}=0.184(2) \AA^{-1}$. This is a simple cycloidal (SC) magnetic structure with magnetic moments in the $a b$-plane as shown in Figure 6(d). Clearly there are differences in the magnetic structures of $\mathrm{Mn}\left(\mathrm{Co}_{0.40} \mathrm{Ni}_{\text {o.6o }}\right) \mathrm{Ge}$ and $\mathrm{MnNiGe}$ at $5 \mathrm{~K}$. In fact, in the $\mathrm{Mn}\left(\mathrm{Co}_{1-\mathrm{x}} \mathrm{Ni}_{\mathrm{x}}\right) \mathrm{Ge}$ samples the angle $\theta$ of the spiral axis $\boldsymbol{l}$ ranges between $0^{\circ}$ and $90^{\circ}$ with $\mathrm{Ni}$ content $\mathrm{x}$ and with temperature in a slightly irregular manner (see Figure S9; as does the propagation vector discussed below). For $\mathrm{x}=0.55$ to $0.60, \theta$ generally decreases with increasing temperature while remarkably for $\mathrm{x}=0.90$ and 


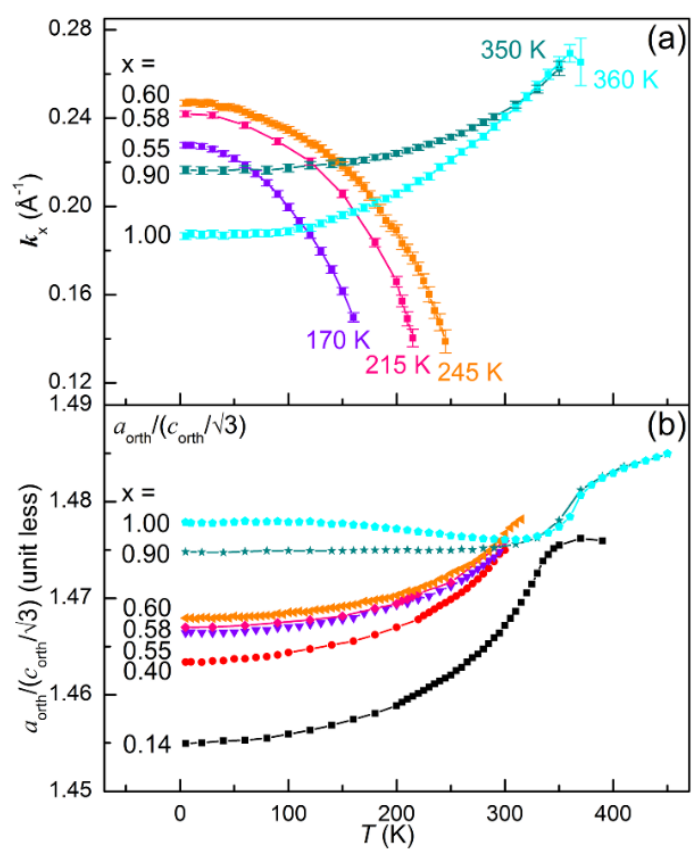

Figure 7 (a) Variation of the propagation vector versus temperature for the incommensurate spiral structures in the $\mathrm{Mn}\left(\mathrm{Co}_{1-\mathrm{x}} \mathrm{Ni}_{\mathrm{x}}\right) \mathrm{Ge}$ samples. The temperature at the end point of each curve is the Néel temperature of the corresponding sample. (b) Thermal evolution of the lattice parameter ratio $a_{\text {orth }} /\left(c_{\text {orth }} / \sqrt{3}\right)$ for the set of $\mathrm{Mn}\left(\mathrm{Co}_{1-\mathrm{x}} \mathrm{Ni}_{\mathrm{x}}\right) \mathrm{Ge}$ samples indicated.

1.0o, $\theta$ starts at zero at low temperature and flips to $90^{\circ}$ $\left(70^{\circ}\right)$ near $18 \mathrm{~K}(220 \mathrm{~K})$, respectively.

4) Variation of propagation vector $\boldsymbol{k}_{x}$ Close comparison of the neutron diffraction patterns of $\mathrm{Mn}\left(\mathrm{Co}_{\text {o.40 }} \mathrm{Ni}_{\text {o.6o }}\right) \mathrm{Ge}$ in Figure 6(a) and those of MnNiGe in Figure 6(c), reveals that the satellite peaks move towards the nuclear peaks in
$\mathrm{Mn}\left(\mathrm{Co}_{\text {o.40 }} \mathrm{Ni}_{\text {o.6o }}\right) \mathrm{Ge}$ with increasing temperature whereas the satellite peaks shift away from the nuclear peaks in $\mathrm{MnNiGe}$. A detailed comparison of the propagation vector $\boldsymbol{k}_{\mathrm{x}}$ for different Ni content $\mathrm{x}$ as functions of temperature iss hown in Figure $7(\mathrm{a})$. The propagation vector $\boldsymbol{k}_{\mathrm{x}}$ decreases with increasing temperature in the samples with $\mathrm{x}$ $=0.55,0.58$ and 0.60 while in contrast, $\boldsymbol{k}_{\mathrm{x}}$ increases with temperature for samples with $\mathrm{x}=0.90$ and 1.00. Given the strong dependence of the rotation angle (propagation vector) in a spiral structure on the lattice parameters, ${ }^{51-53}$ the different temperature dependences of the magnetic propagation vectors $\left(\boldsymbol{k}_{\mathrm{x}}, \mathrm{o}, \mathrm{o}\right)$ in $\mathrm{Mn}\left(\mathrm{Co}_{1-\mathrm{x}} \mathrm{Ni}_{\mathrm{x}}\right) \mathrm{Ge}$ with $\mathrm{x} \geq$ 0.55 are considered as the results of different anisotropic thermal evolutions of the lattice parameters. As shown in Figure $7(\mathrm{~b})$, the $\mathrm{Mn}\left(\mathrm{Co}_{1-\mathrm{x}} \mathrm{Ni}_{\mathrm{x}}\right) \mathrm{Ge}$ samples with $\mathrm{x}=0.55$, 0.58 and 0.60 have different temperature dependences of the $a_{\text {orth }} /\left(c_{\text {orth }} / \sqrt{3}\right)$ ratios from those with $\mathrm{x}=0.90$ and 1.oo. More information about the analysis of the neutron patterns is given in the supporting information, e.g. temperature dependences of the magnetic moments are shown in Figure S11.

Magnetic phase diagram Based on the findings from the present magnetisation, variable temperature $x$-ray and neutron diffraction studies, we have constructed a magnetic phase diagram for annealed $\mathrm{Mn}\left(\mathrm{Co}_{1-\mathrm{x}} \mathrm{Ni}_{\mathrm{x}}\right) \mathrm{Ge}$ as shown in Figure 8. Although the incommensurate magnetic structures have different $\theta$ in the samples with $\mathrm{x}=$ $0.55,0.58,0.60,0.90$ and 1.00 these can be considered as a uniform phase with a spiral structure (spiral-Orth). $T_{\mathrm{M}}$ is dependent on the Ni content $\mathrm{x}$ : $T_{\mathrm{M}}$ initially decreases with $\mathrm{x}$ up to $\sim 0.50$, and then increases with $\mathrm{x}$ from 0.55 onwards. In contrast to the magnetic phase diagram of Nizioł et al., ${ }^{10}$ (for which martensitic structural transition temperatures $T_{\mathrm{M}}>\sim 430 \mathrm{~K}$ are reported) our results show that the structural transition temperature $T_{\mathrm{M}}$ for a broad

Table 1 The crystallographic and magnetic data of $\mathrm{Mn}\left(\mathrm{Co}_{1-\mathrm{x}} \mathrm{Ni}_{\mathrm{x}}\right) \mathrm{Ge}$ with $\mathrm{x}=0.14,0.40,0.60$ and 1.00 as determined from Rietveld refinements of the neutron diffraction patterns at $5 \mathrm{~K}$ (also at $280 \mathrm{~K}$ for $\mathrm{x}=0.60$ ). FM $\mathrm{FM}_{b}$, CS, SP represent paramagnetic, ferromagnetic along $c_{\text {orth }}$-axis, ferromagnetic along $b_{\text {orth }}$-axis and cycloidal-spiral and spiral structures, respectively.

\begin{tabular}{|c|c|c|c|c|c|c|c|c|c|c|}
\hline \multirow{2}{*}{$\begin{array}{l}\text { Sample } \\
\mathrm{T}(\mathrm{K})\end{array}$} & \multicolumn{2}{|c|}{$\mathrm{Mn}(\mathrm{Coo} .86 \mathrm{Nio.14}) \mathrm{Ge}$} & \multicolumn{2}{|c|}{$\mathrm{Mn}($ Coo.6oNio.40)Ge } & \multicolumn{4}{|c|}{$\mathrm{Mn}(\mathrm{Coo} .4 \mathrm{oNio} .60) \mathrm{Ge}$} & \multicolumn{2}{|l|}{$\mathrm{MnNiGe}$} \\
\hline & $5 \mathrm{~K}$ & & $5 \mathrm{~K}$ & & $5 \mathrm{~K}$ & & $280 \mathrm{~K}$ & & $5 \mathrm{~K}$ & \\
\hline Phase & Orth. & Hex. & Orth. & Hex. & Orth. & Hex. & Orth. & Hex. & Orth. & Hex. \\
\hline Space group & Pnma & $\mathrm{Pb}_{3} / \mathrm{mmc}$ & Pnma & $\mathrm{Pb}_{3} / \mathrm{mmc}$ & Pnma & $\mathrm{Pb}_{3} / \mathrm{mmc}$ & Pnma & $\mathrm{PG}_{3} / \mathrm{mmc}$ & Pnma & $\mathrm{P}_{3} / \mathrm{mmc}$ \\
\hline a $(\AA)$ & $5.921(1)$ & $4.073(22)$ & $5 \cdot 956(1)$ & $4.072(12)$ & $5 \cdot 982(1)$ & $4.070(16)$ & $6.010(1)$ & $4.076(5)$ & $6.025(1)$ & $4.066(20)$ \\
\hline $\mathrm{b}(\AA)$ & $3.793(1)$ & & $3 \cdot 757(1)$ & & $3.738(1)$ & & $3.763(1)$ & & $3 \cdot 708(1)$ & \\
\hline c $(\AA)$ & $7.049(1)$ & $5 \cdot 304(45)$ & $7.049(1)$ & $5.282(26)$ & $7.058(1)$ & $5 \cdot 304(36)$ & $7.060(1)$ & $5 \cdot 367(12)$ & $7.061(1)$ & $5 \cdot 324(30)$ \\
\hline $\mathrm{V}\left(\AA_{3}\right)$ & $158.29(4)$ & $76.19(9)$ & $157 \cdot 70(87)$ & $75.84(48)$ & $157.81(6)$ & $76.10(66)$ & $159.65(4)$ & $77.23(21)$ & $157 \cdot 76(4)$ & $78.88(4)$ \\
\hline $\begin{array}{l}\text { Phase fraction } \\
(w \mathrm{t} \%)\end{array}$ & $99(3)$ & $1(1)$ & $99(3)$ & $1(1)$ & $99(2)$ & $1(1)$ & $98(2)$ & $2(1)$ & $98(1)$ & $1(1)^{*}$ \\
\hline $\begin{array}{l}\text { Magnetic } \\
\text { state }\end{array}$ & $\mathrm{FM}_{c}$ & $\mathrm{FM}$ & $\mathrm{FM}_{b}$ & - & CS & - & $\mathrm{FM}_{b}$ & - & SP & - \\
\hline Moment $(\mu \mathrm{B})$ & $3 \cdot 4(1)$ & - & $3 \cdot 5(1)$ & - & $3.2(1)$ & - & $2.0(1)$ & - & $3 \cdot 32$ & - \\
\hline Rp, Rwp & $3.41,4.45$ & & $3.60,4.65$ & & $2.63,3.43$ & & $2.34,3.06$ & & $2.70,3.63$ & \\
\hline Rexp, $\chi^{2}$ & $1.99,5.00$ & & $1.69,7.58$ & & $1.62,4.46$ & & $1.59,3.72$ & & $1.45,6.23$ & \\
\hline
\end{tabular}




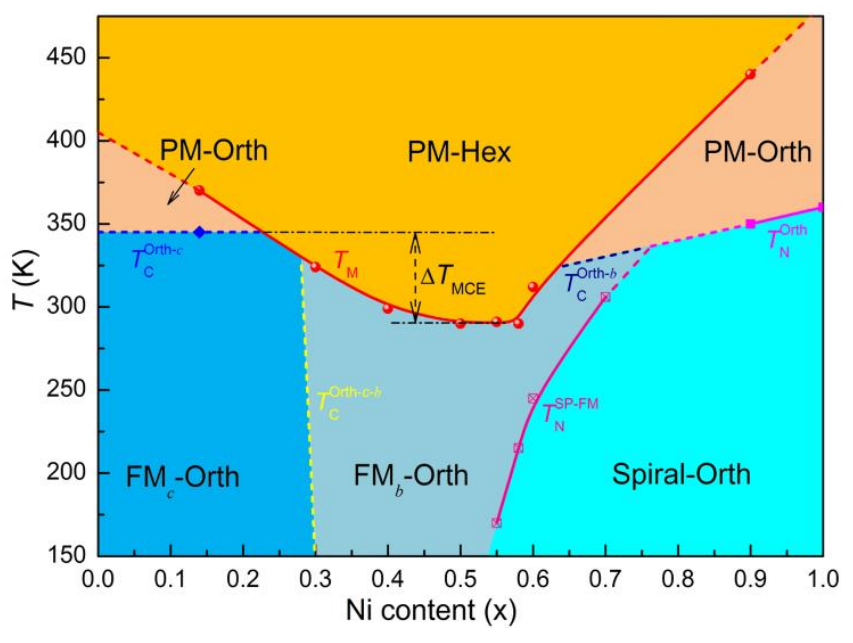

Figure 8 Partial phase diagram for the annealed $\mathrm{Mn}\left(\mathrm{Co}_{1-}\right.$ $\left.{ }_{\mathrm{x}} \mathrm{Ni}_{\mathrm{x}}\right)$ Ge $(0.14 \leq \mathrm{x} \leq 1.00)$ samples. $T_{\mathrm{C}}^{\text {Orth }-c}, T_{\mathrm{C}}^{\mathrm{Orth}-b}$ and $T_{\mathrm{N}}^{\text {Orth }}$ are the Curie temperatures for the ferromagnetic orthorhombic phase with magnetic moment along $c_{\text {orth }}$-axis, $b_{\text {orth }}{ }^{-}$ axis and the Néel temperature of the spiral orthorhombic phase, respectively. $T_{\mathrm{M}}$ is the martensitic structural transition temperature from the orthorhombic to the hexagonal structures. $T_{\mathrm{C}}^{\mathrm{Orth}-c-b}$ and $T_{\mathrm{N}}^{\mathrm{SP}-\mathrm{FM}}$ is the magnetic transition temperatures from $c_{\text {orth }}$-axis ferromagnetic structure to $b_{\text {orth-axis }}$ ferromagnetic structure and from the spiral structure to ferromagnetic structure (magnetic moment aligning along $b_{\text {orth }}{ }^{-}$ axis), respectively. $\mathrm{PM}, \mathrm{FM}_{c}, \mathrm{FM}_{b}$, SP represent paramagnetic,

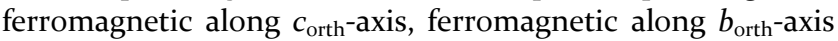
and spiral structures, respectively. $\Delta T_{\mathrm{MCE}}$ is the temperature window for magneto-structural transition and large magnetocaloric effect in annealed $\mathrm{Mn}\left(\mathrm{Co}_{1-\mathrm{x}} \mathrm{Ni}_{\mathrm{x}}\right) \mathrm{Ge}$ samples. The dashed lines represent extrapolations of transitions boundaries.

$\mathrm{Ni}$ concentration range, $\sim 0.20<\mathrm{x}<\sim 0.65$, is lower than $\sim 350 \mathrm{~K}$. This is likely to be attributed to the different sample preparations and heat treatment procedures. Through comparing $T_{\mathrm{M}}$ in Figure 8 with the thermal evolution of the magnetic moments in Figure S11, it can be concluded that a first order magneto-structural transition, FM-Orth/PM-Hex, exists within the Ni range $\sim 0.20<$ $\mathrm{x}<\sim 0.65$. As indicated in Figure 8, this range of Ni concentrations has a broad temperature window of $\Delta T_{\mathrm{MCE}}=$ 290(1) K to 345(4) K for observation of a magnetostructural transition. Large direct MCE values are expected in this temperature window. The occurrence of the spiral-AFM/FM transitions around $T_{\mathrm{N}}^{\mathrm{SP}-\mathrm{FM}}$ in $\mathrm{Mn}\left(\mathrm{CO}_{1-}\right.$ ${ }_{\mathrm{x}} \mathrm{Ni}_{\mathrm{x}}$ )Ge with $\sim 0.55<\mathrm{x}<\sim 0.75$ is also noted with an inverse magnetocaloric effect expected in this region. ${ }^{54}$

Stabilities of magnetic phases In the orthorhombic structure (Pnma) of MnCoGe/MnNiGe-based compounds, each $\mathrm{Mn}$ atom has four Mn nearest-neighbours with two characteristic Mn-Mn separations, $d_{1}$ and $d_{2}$, as depicted in Figure S1. Given the centrosymmetric TiNiSi-type structure, the Dzyaloshinsky-Moriya interaction cannot be the origin of the spiral structure in the orthorhombic phase of $\mathrm{Mn}\left(\mathrm{Co}_{1-\mathrm{x}} \mathrm{Ni}_{\mathrm{x}}\right) \mathrm{Ge}$. As an alternative explanation, it was considered that the occurrence of a spiral structure in this system is a result of the variation of the Mn-Mn dis-
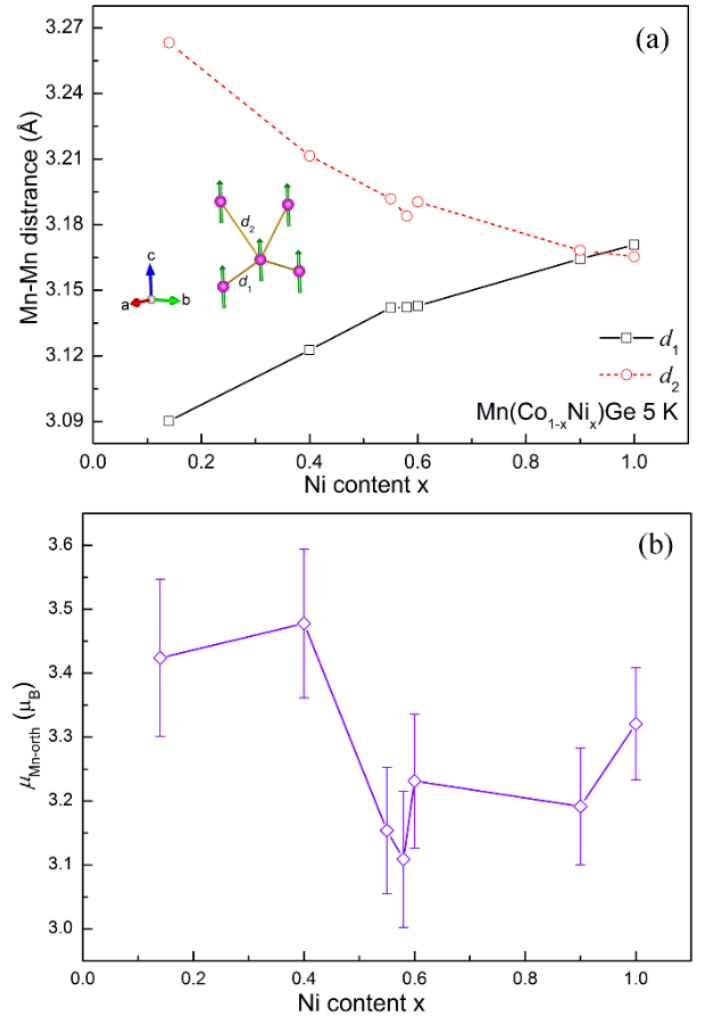

Figure 9 (a) Variation of the Mn-Mn nearest neighbours distances, $d_{1}$ and $d_{2}$, with $\mathrm{Ni}$ content $\mathrm{x}$ in the orthorhombic phase of $\mathrm{Mn}\left(\mathrm{Co}_{0.86} \mathrm{Ni}_{\text {o.14 }}\right) \mathrm{Ge}$ at $5 \mathrm{~K}$. (b) Variation of the magnetic moment on the $\mathrm{Mn}$ atoms of $\mathrm{Mn}\left(\mathrm{Co}_{1-\mathrm{x}} \mathrm{Ni}_{\mathrm{x}}\right) \mathrm{Ge}$ alloys in the orthorhombic phase with $\mathrm{Ni}$ content $\mathrm{x}$ at $5 \mathrm{~K}$.

tance, especially $d_{1}{ }^{2,3}, 55$ e.g. spiral-AFM occurs when $d_{1}>$ $\sim 2.95 \AA$ in $\operatorname{MnNi}\left(\mathrm{Ge}_{1-\mathrm{x}} \mathrm{Si}_{\mathrm{x}}\right)^{2}$ and $d_{1}>-3.37 \AA$ in $\operatorname{MnCo}\left(\mathrm{Ge}_{1-}\right.$ $\left.{ }_{x} \mathrm{P}_{\mathrm{x}}\right){ }^{3}$ The evolution of the $d_{1}$ and $d_{2} \mathrm{Mn}-\mathrm{Mn}$ distances in $\mathrm{Mn}\left(\mathrm{Co}_{1-\mathrm{x}} \mathrm{Ni}_{\mathrm{x}}\right) \mathrm{Ge}$ with $\mathrm{x}$ at $5 \mathrm{~K}$ are shown in Figure 9(a) with their temperature dependences shown in Figure $\mathrm{S}_{13}$. According to this criterion, the spiral-AFM should become more stable at high temperature due to the thermal expansion of $d_{1}$. However, the spiral-AFM was transferred to the $\mathrm{FM}_{b}$ structure at high temperature due to the thermal expansion of $d_{1}$.

However, the spiral-AFM was transferred to the $\mathrm{FM}_{b}$ structure with increasing temperature in the samples with $\mathrm{x}=0.55,0.58$ and 0.60 . Therefore, this simple interatomic criterion cannot properly explain for the occurrence of the spiral-AFM in $\mathrm{Mn}\left(\mathrm{Co}_{1-\mathrm{x}} \mathrm{Ni}_{\mathrm{x}}\right) \mathrm{Ge}$.

Here, we give a brief discussion on the origin of noncollinear spiral structure based on the experimental results. We attribute the occurrence of the spiral-AFM to the 'self- adjustment' of the system to accommodate increasing valence electron concentration (VEC, the average number of valence electrons per atom) due to the replacement of $\mathrm{Co}\left(3 \mathrm{~d}^{7} 4 \mathrm{~s}^{2}\right)$ by Ni $\left(3 \mathrm{~d}^{8} 4 \mathrm{~s}^{2}\right)$. The unit cell volume $V_{\text {orth }}$ plotted in Figure $3(\mathrm{~d})$ has a maximum for midrange Ni content: $V_{\text {orth }}$ increases initially with increasing $\mathrm{x}$ and then decreases for $\mathrm{x} \geq 0.60$. This deviation from the prediction of Vegard's law indicates that expansion of the unit cell volume is one mechanism for MnCoGe-based 


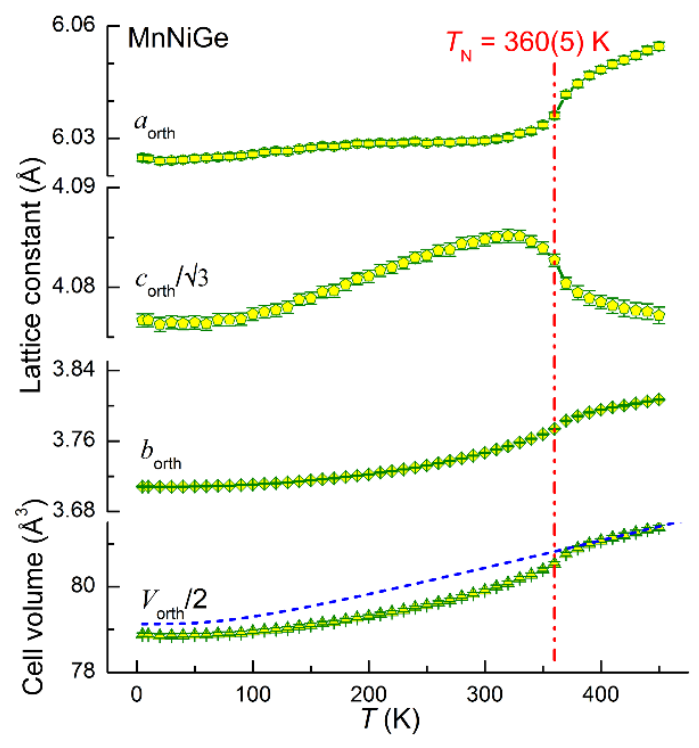

Figure 10 The lattice parameters and unit cell volume for MnNiGe sample $\left(T_{\mathrm{N}}=360(5) \mathrm{K}\right)$ determined from refinement of the neutron powder diffraction patterns. The dashed line on the unit cell volume curve represents the phonon contribution to the thermal expansion $\left(\theta_{\mathrm{D}}=320 \mathrm{~K}\right) .^{56}$

compounds to re-adjust to the increased number of valence electrons. In addition, crystal orbital overlap population (COOP) calculations for the TiNiSi family of compounds demonstrated that extra valence electrons introduced by doping would enter into the bonds between $\mathrm{Ti}$ (corresponding to $\mathrm{Mn}$ in $\mathrm{MnCoGe}$ ) and $\mathrm{Ni}-\mathrm{Si}$ networks (corresponding to $\mathrm{Co}-\mathrm{Ge}$ networks in $\mathrm{MnCoGe}$ ) and hence reduce the impact on the Ni-Si network and stabilise the crystal structure to a TiNiSi-type structure. ${ }^{48}$ By analogy, doping MnCoGe would stabilise a TiNiSi-type structure This redistribution of valence electrons would influence the density of states at the Fermi surface, $N\left(E_{\mathrm{F}}\right)$, and lead to a non-collinear structure whose occurrence can reduce the number of bands crossing the Fermi energy $E_{\mathrm{F}}{ }^{33}$

All of the anomalous behaviours in the structural and magnetic properties of $\mathrm{Mn}\left(\mathrm{Co}_{1-\mathrm{x}} \mathrm{Ni}_{\mathrm{x}}\right) \mathrm{Ge}$ can be explained by the competition between the two mechanisms for MnCoGe- based compounds to accommodate extra valence electrons as introduced above: the variation of the unit cell volume and the redistribution of valence electrons. It should be noted that this anomalous variation in unit cell volume with increasing $\mathrm{Ni}$ content, occurs despite the increased fraction of the smaller $\mathrm{Ni}$ atoms (radius $\sim 1.21 \AA$ ) compared with the Co atoms (radius 1.26 $\AA$ ). Addition of further valence electrons to $\mathrm{MnCoGe}$ settle in $\mathrm{Mn}\left(\mathrm{Co}_{1-\mathrm{x}} \mathrm{Ni}_{\mathrm{x}}\right) \mathrm{Ge}$ by, firstly, expanding the $V_{\text {orth }}$ within low Ni content samples as demonstrated by the expansion of $V_{\text {orth }}$ in Figure 3(d). The accumulation of the valence electron in the $\mathrm{Co} / \mathrm{Ni}-\mathrm{Ge}$ networks undermines the stability of the orthorhombic structure and $T_{\mathrm{M}}$ decreases with $\mathrm{x}$ in the approximate region $\mathrm{x} \sim 0.15-0.55$, as illustrated in Figure 8. However, the redistribution of the valence electrons in the cases of $\mathrm{x} \geq 0.55$ leads to the occurrence of the spiral-AFM and the modification of $N\left(E_{\mathrm{F}}\right)$. This abrupt change in $N\left(E_{\mathrm{F}}\right)$ is evidenced by the drop of the magnetic moment on Mn atoms, $\mu_{\mathrm{Mn}}$, as shown in Figure 9 (b). As a result of the electronic redistribution, the expansion pressure from the increased valence electrons on $V_{\text {orth }}$ and the impact of valence electrons on the stability of the orthorhombic structure are both reduced. Therefore, $V_{\text {orth }}$ decreases but $T_{\mathrm{M}}$ increases above $\mathrm{x}=0.55$ as observed in Figures $3(\mathrm{~d})$ and 8 . Such decreases in the values of $\mu_{\mathrm{Mn}}$ and $V_{\text {orth }}$ in $\mathrm{Mn}\left(\mathrm{Co}_{1-\mathrm{x}} \mathrm{Ni}_{\mathrm{x}}\right) \mathrm{Ge}$ are similar in behaviour to the occurrence of a non-collinear structure in other systems ${ }^{36,40}$ In particular, for zinc-blende $\mathrm{MnAs}^{36}$ and Fe$\mathrm{Ni}$ Invar alloys ${ }^{40}$, a non-collinear structure has been accompanied by smaller unit cell volumes and smaller magnetic moments compared with the unit cell volumes and magnetic moments for a collinear structure.

The electronic redistribution and the occurrence of the non-collinear spiral-AFM around $\mathrm{x}=0.55$ are also accompanied by the change in the bond strength which causes the abrupt jump of the lattice parameters of the orthorhombic structure as shown in Figures 3(a), 3(b) and 3(c). Similar competitions between magnetism and bonding due to redistribution of electronic density were also observed in $\mathrm{MnFe}(\mathrm{P}, \mathrm{Si}, \mathrm{B}) .{ }^{57}$ In addition, strong magnetovolume effects are observed via changes in the lattice around the magnetic transition for the sample with $\mathrm{x}=$ 1.00 as shown in Figure 10. To estimate the spontaneous magnetostriction which causes the changes, the phonon contribution to the lattice thermal expansion was calculated using the Grüneisen-Debye model,,$^{58,59}$ with a Debye temperature of $320 \mathrm{~K}^{56}$ and extrapolated from the temperature region above $T_{\mathrm{N}}$. The fit to the Grüneisen-Debye model is shown as the dashed line in Figure 10. The magnetic contributions are evident and the change in the unit cell volume around the Néel temperature $T_{\mathrm{N}}=360(5) \mathrm{K}$ amounts to $0.66 \%$.

The competition between the two mechanisms is also important with regard to temperature dependence of the magnetic structures. In the samples with $\mathrm{x}=0.55,0.58$ and 0.60 , the expansion of the unit cell volume $V_{\text {orth }}$ reduces the potential to change the band structure, and therefore the low-temperature spiral-AFM transfers to the $\mathrm{FM}_{b}$ at high temperatures, as shown in Figures 6(a), $\mathrm{S}_{4}(\mathrm{c}$ ), $\mathrm{S}_{4}(\mathrm{~d})$ and 8 . However, in the case of $\mathrm{x}=0.90$ and 1.0o, the further increases of the valence electron concentration cannot be accommodated merely by adjusting the unit cell volume through thermal expansion. To maintain the lowest total energy, the spiral-AFM configuration remains stable up to the transition to a paramagnetic phase.

Magnetocaloric effect According to our findings as summarised in the phase diagram (Figure 8), direct and inverse magnetocaloric effects are expected in $\mathrm{Mn}\left(\mathrm{Co}_{1-}\right.$ $\left.{ }_{x} \mathrm{Ni}_{\mathrm{x}}\right) \mathrm{Ge}$ compounds, at the martensitic transition temperatures $T_{\mathrm{M}}$ (around room temperature), and around the spiral-AFM/FM transition $T_{\mathrm{N}}^{\mathrm{SP}-\mathrm{FM}}$ (below $\sim 250 \mathrm{~K}$ ), respectively. The direct MCE values around room temperature are of greater interest with practical application in mind and are shown in Figure 11. (For inverse MCE, please see Section 6 in the supporting information). The peak values of the entropy changes for the series of $\mathrm{Mn}\left(\mathrm{Co}_{1-\mathrm{x}} \mathrm{Ni}_{\mathrm{x}}\right) \mathrm{Ge}$ 


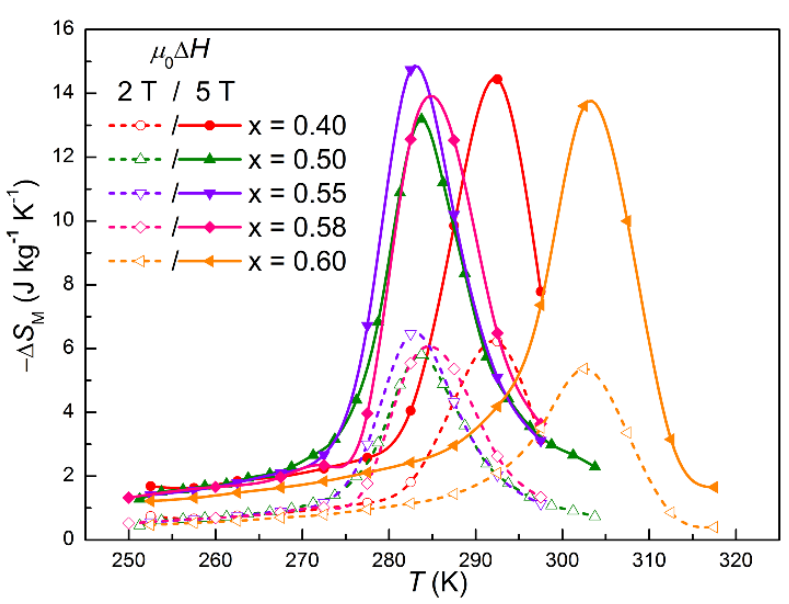

Figure 11 Isothermal magnetic entropy changes for $\mathrm{Mn}\left(\mathrm{Co}_{1-}\right.$ ${ }_{\mathrm{x}} \mathrm{Ni}_{\mathrm{x}}$ ) Ge with $\mathrm{x}=0.40$, $0.50,0.55,0.58$ and 0.60 for magnetic changes of $\mu_{\mathrm{o}} \Delta H=2 \mathrm{~T}$ (dashed lines with open symbols) and $\mu_{\mathrm{o}} \Delta H=5 \mathrm{~T}$ (solid lines with solid symbols).

compounds are: $-\Delta S_{\mathrm{M}}^{\text {peak }}\left(\mu_{\mathrm{o}} \Delta H=5 \mathrm{~T}\right)=14(2) \mathrm{J} \mathrm{kg}^{-1} \mathrm{~K}^{-1}$, $13(2) \mathrm{J} \mathrm{kg}^{-1} \mathrm{~K}^{-1}, 15(2) \mathrm{J} \mathrm{kg}^{-1} \mathrm{~K}^{-1}, 14(2) \mathrm{J} \mathrm{kg}^{-1} \mathrm{~K}^{-1}$, and $14(2) \mathrm{J} \mathrm{kg}^{-1}$ $\mathrm{K}^{-1}$ at 292(2) K, 284(2) K, 283(2) K, 285(2) K and 302(2) K for $\mathrm{x}=0.40,0.50,0.55,0.58$ and 0.60 , respectively. Note that, these values are larger than $10(2) \mathrm{J} \mathrm{kg}^{-1} \mathrm{~K}^{-1}$ at $297(1) \mathrm{K}$ in as-prepared $\left(\mathrm{Mn}_{0.98} \mathrm{Fe}_{0.02}\right) \mathrm{CoGe}^{4} ; 11(2) \mathrm{J} \mathrm{kg}^{-1} \mathrm{~K}^{-1}$ at $299(1)$ $\mathrm{K}$ in as-prepared $\mathrm{Mn}\left(\mathrm{Co}_{0.96} \mathrm{Fe}_{0.04}\right) \mathrm{Ge}^{5}$; and ${ }_{13}(2) \mathrm{J} \mathrm{kg}^{-1} \mathrm{~K}^{-1}$ at $314(1) \mathrm{K}$ in annealed $\left(\mathrm{Mn}_{\mathrm{o} .96} \mathrm{Ni}_{\text {o.04 }}\right) \mathrm{CoGe}{ }^{60}$ However, the refrigeration capacities $(R C \mathrm{~s}$, the calculation method is given in the supporting information) with $\mu_{\mathrm{o}} \Delta H=5 \mathrm{~T}$ in $\mathrm{Mn}\left(\mathrm{Co}_{1-\mathrm{x}} \mathrm{Ni}_{\mathrm{x}}\right) \mathrm{Ge}(0.40 \leq \mathrm{x} \leq \mathrm{0.60})$ are found to be significantly small compared with the values in as-prepared $\left(\mathrm{Mn}_{1-\mathrm{x}} \mathrm{Fe}_{\mathrm{x}}\right) \mathrm{CoGe}^{4}{ }^{4}$ as-prepared $\mathrm{Mn}\left(\mathrm{Co}_{1-\mathrm{x}} \mathrm{Fe}_{\mathrm{x}}\right) \mathrm{Ge}^{5}$ and annealed $\left(\mathrm{Mn}_{1-\mathrm{x}} \mathrm{Ni}_{\mathrm{x}}\right) \mathrm{CoGe} .^{60}$ These diminished $\mathrm{RC}$ values are due to the relatively smaller magnetic moment in $\mathrm{Mn}\left(\mathrm{Co}_{1-}\right.$ ${ }_{x} \mathrm{Ni}_{\mathrm{x}}$ )Ge compared with these other MnCoGe-based systems (see Table $\mathrm{S}_{4}$ and Figure $\mathrm{S}_{15}$ ). In addition, the results reported here provide experimental evidence for the redistribution of valence electrons and modification of the density of states at the Fermi surface. Following the discussion of Boeije et al. ${ }^{57}$, the electronic contribution may also play an important role in the magnetocaloric effect in MnCoGe-based compounds, similar to the $\mathrm{Fe}_{2} \mathrm{P}$-based compounds ${ }^{57}$ and ReRh.

\section{CONCLUSIONS}

Our detailed investigations of an extensive series of $\mathrm{Mn}\left(\mathrm{Co}_{1-\mathrm{x}} \mathrm{Ni}_{\mathrm{x}}\right) \mathrm{Ge}(0.12 \leq \mathrm{x} \leq 1.00)$ compounds provide insight into their crystal and magnetic structures. Our findings have led to a new explanation for the occurrence of spiral ground state in Mn-based orthorhombic alloys (Pnma).

It is concluded that the crystal and magnetic structures can be tuned by changing valence electron concentration through the substitution of $\mathrm{Ni}\left(3 \mathrm{~d}^{8} 4 \mathrm{~s}^{2}\right)$ for Co $\left(3 \mathrm{~d}^{7} 4 \mathrm{~s}^{2}\right)$. With increasing $\mathrm{Ni}$ concentration, the ferromagnetic moments along $c_{\text {orth }}$ on the Mn sublattice in the orthorhombic phase turn firstly to the $b_{\text {orth }}$ axis due to anisotropy at $5 \mathrm{~K}$. Further doping of $\mathrm{Ni}$ content leads to a non- collinear spiral antiferromagnetic structure where the magnetic moments propagate along $a_{\text {orth }}$. The occurrence of the spiral antiferromagnetic structure is accompanied by abrupt changes in lattice parameters, reduction of the unit cell volume $V_{\text {orth }}$, reduction of the magnitude of the magnetic moments on $\mathrm{Mn}$ atoms and discontinuities in the lattice parameters. These phenomena are associated with the competition between magnetism and bonding, and occur as a result of the competition between the expansion of unit cell volume and the redistribution of the valence electrons, which is associated with modification of the density of states at the Fermi surface.

The competition between the expansion of unit cell volume and the redistribution of the valence electrons also causes a decrease of the martensitic transformation temperature $T_{\mathrm{M}}$ as the $\mathrm{Ni}$ concentration in $\mathrm{Mn}\left(\mathrm{Co}_{1-}\right.$ ${ }_{x} \mathrm{Ni}_{\mathrm{x}}$ ) Ge increases up to $\mathrm{x} \sim 0.50$ and then an increase of $T_{\mathrm{M}}$ for $\mathrm{Ni}$ concentrations above $\mathrm{x} \sim 0.55$. In particular $\mathrm{a}$ first-order magneto-structural transition and large direct magnetocaloric effect in $\mathrm{Mn}\left(\mathrm{Co}_{1-\mathrm{x}} \mathrm{Ni}_{\mathrm{x}}\right) \mathrm{Ge}$ is formed with $\sim 0.20<\mathrm{x}<\sim 0.65$ while the magnetic transition from the spiral antiferromagnetic structure to the ferromagnetic structure provides scope for a region of inverse magnetocaloric effect within $\sim 0.55<\mathrm{x}<\sim 0.75$.

\section{ASSOCIATED CONTENT}

\section{Supporting information}

The Supporting information is available free of charge on ... (double click the right icon):

Relationship between $\mathrm{Mn}-\mathrm{Mn}$ and $\mathrm{Co} / \mathrm{Ni}-\mathrm{Ge}$ networks, analysis of x-ray diffraction patterns, magnetisations, additional neutron diffraction patterns, models used for magnetic structure analysis, Rietveld refinements for neutron diffraction patterns, atomic occupancies, temperature dependences of the magnetic moments, the Mn-Mn atomic distances and the lattice parameters, and analysis of MCE.

\section{AUTHOR INFORMATION}

\section{Corresponding Author}

*(Q.Y.R) E-mail: qingyong.ren@sjtu.edu.cn

*(W.D.H) E-mail: w.hutchison@adfa.edu.au

*(J.L.W) E-mail: jianli@uow.edu.au

Notes

The authors declare no competing financial interest.

\section{ACKNOWLEDGEMENTS}

This work was supported in part by grants from the Australian Research Council: Discovery project DP110102386 and LIEF grant LE10o10oo177. QYR is grateful to the UNSW Canberra for a Research Training Scholarship and the support from the National Natural Science Foundation of China (Grant No. 11774223). The authors thank Professor J. M. Cadogan, UNSW Canberra, for helpful discussions, particularly his assistance with aspects of the Rietveld refinements.

\section{REFERENCES}


(1) Barcza, A.; Gercsi, Z.; Knight, K. S.; Sandeman, K. G., Giant magnetoelastic coupling in a metallic helical metamagnet. Phys. Rev. Lett. 2010, 104, 247202.

(2) Gercsi, Z.; Sandeman, K., Structurally driven metamagnetism in $\mathrm{MnP}$ and related Pnma compounds. Phys. Rev. B 2010, 81, 224426.

(3) Gercsi, Z.; Hono, K.; Sandeman, K. G., Designed metamagnetism in CoMnGe $e_{1-\mathrm{x}} \mathrm{P}_{\mathrm{x}}$. Phys. Rev. B 2o11, 83, 174403.

(4) Ren, Q. Y.; Hutchison, W. D.; Wang, J. L.; Studer, A. J.; Din, M. F. M.; Pérez, S. M.; Cadogan, J. M.; Campbell, S. J., The magneto-structural transition in $\mathrm{Mn}_{1-\mathrm{x}} \mathrm{Fe}_{\mathrm{x}} \mathrm{CoGe}$. J. Phys. D: Appl. Phys. 2016, 49, 175003.

(5) Ren, Q. Y.; Hutchison, W. D.; Wang, J. L.; Studer, A. J.; Campbell, S. J., First-order magneto-structural transition and magnetocaloric effect in $\mathrm{Mn}\left(\mathrm{Co}_{0.96} \mathrm{Fe}_{0.04}\right) \mathrm{Ge}$. J. Alloys Compd. 2017, 693, 32-39.

(6) Jeitschko, W., A high-temperature X-ray study of the displacive phase transition in MnCoGe. Acta Crystallographica Section B 1975, 31, 1187-1190.

(7) Johnson, V.; Frederick, C. G., Magnetic and crystallographic properties of ternary manganese silicides with ordered $\mathrm{CO}_{2} \mathrm{P}$ structure. Phys. Status Solidi A 1973, 20, 331-335.

(8) Bazela, W.; Szytuła, A.; Todorović, J.; Tomkowicz, Z.; Zięba, A., Crystal and magnetic structure of NiMnGe. Phys. Status Solidi A 1976, 38, 721-729.

(9) Nizioł, S.; Bińczycka, H.; Szytula, A.; Todorović, J.; Fruchart, R.; Senateur, J. P.; Fruchart, D., Structure magnétique des MnCoSi. Phys. Status Solidi A 1978, 45, 591-597.

(10) Nizioł, S.; Bombik, A.; Bazela, W.; Szytuła, A.; Fruchart, D., Crystal and magnetic structure of $\mathrm{Co}_{\mathrm{x}} \mathrm{Ni}_{1-\mathrm{x}} \mathrm{MnGe}$ system. J. Magn. Magn. Mater. 1982, 27, 281-292.

(11) Trung, N. T.; Zhang, L.; Caron, L.; Buschow, K. H. J.; Brück, E., Giant magnetocaloric effects by tailoring the phase transitions. Appl. Phys. Lett. 2010, 96, 172504.

(12) Liu, E.; Wang, W.; Feng, L.; Zhu, W.; Li, G.; Chen, J.; Zhang, H.; Wu, G.; Jiang, C.; Xu, H.; de Boer, F., Stable magnetostructural coupling with tunable magnetoresponsive effects in hexagonal ferromagnets. Nat. commun. 2012, 3, 873.

(13) Samanta, T.; Dubenko, I.; Quetz, A.; Stadler, S.; Ali, N., Giant magnetocaloric effects near room temperature in $\mathrm{Mn}_{1-}$ ${ }_{x} \mathrm{Cu}_{\mathrm{x}}$ CoGe. Appl. Phys. Lett. 2012, 101, 242405.

(14) Sandeman, K. G.; Daou, R.; Özcan, S.; Durrell, J. H.; Mathur, N. D.; Fray, D. J., Negative magnetocaloric effect from highly sensitive metamagnetism in $\mathrm{CoMnSi}_{\mathrm{1}_{\mathrm{x}}} \mathrm{Ge}_{\mathrm{x}}$. Phys. Rev. B 2006, 74, 224436.

(15) Zhang, C. L.; Wang, D. H.; Cao, Q. Q.; Han, Z. D.; Xuan, H. C.; Du, Y. W., Magnetostructural phase transition and magnetocaloric effect in off-stoichiometric $\mathrm{Mn}_{1.9-\mathrm{x}} \mathrm{Ni}_{\mathrm{x}} \mathrm{Ge}$ alloys. Appl. Phys. Lett. 2008, 93, 122505.

(16) Samanta, T.; Dubenko, I.; Quetz, A.; Temple, S.; Stadler, S.; Ali, N., Magnetostructural phase transitions and magnetocaloric effects in $\mathrm{MnNiGe}_{1-\mathrm{x}} \mathrm{Al}_{\mathrm{x}}$. Appl. Phys. Lett. 2012, $100,052404$.

(17) Dzyaloshinsky, I., A thermodynamic theory of "weak" ferromagnetism of antiferromagnetics. J. Phys. Chem. Solids 1958, 4, 241-255.

(18) Moriya, T., Anisotropic Superexchange Interaction and Weak Ferromagnetism. Phys. Rev. 1960, 120, 91-98.

(19) Roessli, B.; Schefer, J.; Petrakovskii, G. A.; Ouladdiaf, B.; Boehm, M.; Staub, U.; Vorotinov, A.; Bezmaternikh, L., Formation of a magnetic soliton lattice in copper metaborate. Phys. Rev. Lett. 2001, 86, 1885-8.

(20) Rousse, G.; Rodríguez-Carvajal, J.; Wurm, C.; Masquelier, C., Spiral magnetic structure in the iron diarsenate $\mathrm{LiFeAs}_{2} \mathrm{O}_{7}: \mathrm{A}$ neutron diffraction study. Phys. Rev. B 2013, 88, 214433.

(21) Dmitrienko, V. E.; Ovchinnikova, E. N.; Collins, S. P.; Nisbet, G.; Beutier, G.; Kvashnin, Y. O.; Mazurenko, V. V.;
Lichtenstein, A. I.; Katsnelson, M. I., Measuring the Dzyaloshinskii-Moriya interaction in a weak ferromagnet. Nat. Phys. 2014, 10, 202-206.

(22) Cheong, S.-W.; Mostovoy, M., Multiferroics: a magnetic twist for ferroelectricity. Nat. Mater. 2007, 6, 13-20.

(23) Roszler, U. K.; Bogdanov, A. N.; Pfleiderer, C., Spontaneous skyrmion ground states in magnetic metals. Nature 2006, 442, 797-801.

(24) Leonov, A., Chiral skyrmion states in noncentrosymmetric magnets. arXiv:1406.2177 2014.

(25) Lee, S.; Paramekanti, A.; Kim, Y. B., RKKY Interactions and the Anomalous Hall Effect in Metallic Rare-Earth Pyrochlores. Phys. Rev. Lett. 2013, 111, 196601.

(26) Braunecker, B.; Simon, P., Interplay between Classical Magnetic Moments and Superconductivity in Quantum OneDimensional Conductors: Toward a Self-Sustained Topological Majorana Phase. Phys. Rev. Lett. 2013, 111, 147202.

(27) Lawes, G.; Kenzelmann, M.; Rogado, N.; Kim, K. H.; Jorge, G. A.; Cava, R. J.; Aharony, A.; Entin-Wohlman, O.; Harris, A. B.; Yildirim, T.; Huang, Q. Z.; Park, S.; Broholm, C.; Ramirez, A. P., Competing magnetic phases on a kagome staircase. Phys. Rev. Lett. 2004, 93, 247201.

(28) Abakumov, A. M.; Tsirlin, A. A.; Perez-Mato, J. M.; Petřiček, V.; Rosner, H.; Yang, T.; Greenblatt, M., Spiral ground state against ferroelectricity in the frustrated magnet BiMnFe $_{2} \mathrm{O}_{6}$. Phys. Rev. B 2011, 83, 214402.

(29) Blundell, S., Magnetism in condensed matter. Oxford University Press: Oxford, 2001.

(30) Flint, R.; Senthil, T., Chiral RKKY interaction in $\operatorname{Pr}_{2} \mathrm{Ir}_{2} \mathrm{O}_{7}$. Phys. Rev. B 2013, 87, 125147.

(31) Hase, M.; Pomjakushin, V. Y.; Keller, L.; Dönni, A.; Sakai, O.; Yang, T.; Cong, R.; Lin, J.; Ozawa, K.; Kitazawa, H., Spiral magnetic structure in spin-5/2 frustrated trimerized chains in $\mathrm{SrMn}_{3} \mathrm{P}_{4} \mathrm{O}_{14}$. Phys. Rev. B 2011, 84, 184435.

(32) Qureshi, N.; Ressouche, E.; Mukhin, A. A.; Ivanov, V. Y.; Barilo, S. N.; Shiryaev, S. V.; Skumryev, V., Stabilization of multiferroic spin cycloid in $\mathrm{Ni}_{3} \mathrm{~V}_{2} \mathrm{O}_{8}$ by light Co doping. Phys. Rev. B 2013, 88, 174412.

(33) Eriksson, T.; Bergqvist, L.; Burkert, T.; Felton, S.; Tellgren, R.; Nordblad, P.; Eriksson, O.; Andersson, Y., Cycloidal magnetic order in the compound IrMnSi. Phys. Rev. B 2005, 71, 174420.

(34) Zach, R.; Tobola, J.; Średniawa, B.; Kaprzyk, S.; Guillot, M.; Fruchart, D.; Wolfers, P., Magnetic interactions in the $\mathrm{MnFe}_{1-\mathrm{x}} \mathrm{Co}_{\mathrm{x}} \mathrm{P}$ series of solid solutions. J. Phys.: Condens. Matter 2007, 19, 376201.

(35) Lizárraga, R.; Nordstrom, L.; Bergqvist, L.; Bergman, A.; Sjostedt, E.; Mohn, P.; Eriksson, O., Conditions for noncollinear instabilities of ferromagnetic materials. Phys. Rev. Lett. 2004, 93, 107205.

(36) Sanyal, B.; Eriksson, O.; Aron, C., Volume-dependent exchange interactions and noncollinear magnetism in zincblende MnAs. Phys. Rev. B 20o6, 74, 184401.

(37) Lizárraga, R.; Nordström, L.; Eriksson, O., Noncollinear spin states in $\mathrm{TlCO}_{2} \mathrm{Se}_{2-\mathrm{x}} \mathrm{S}_{\mathrm{x}}$ alloys from first principles. Phys. Rev. B 2007, 75, 024425.

(38) Delczeg-Czirjak, E. K.; Pereiro, M.; Bergqvist, L.; Kvashnin, Y. O.; Di Marco, I.; Li, G.; Vitos, L.; Eriksson, O., Origin of the magnetostructural coupling in $\mathrm{FeMnP}_{0.75} \mathrm{Si}_{0.25}$. Phys. Rev. B 2014, 90, 214436.

(39) Lizárraga, R.; Bergman, A.; Björkman, T.; Liu, H. P.; Andersson, Y.; Gustafsson, T.; Kuchin, A. G.; Ermolenko, A. S.; Nordström, L.; Eriksson, O., Crystal and magnetic structure investigation of $\mathrm{TbNi}_{5-\mathrm{x}} \mathrm{Cu}_{\mathrm{x}}(\mathrm{x}=0,0.5,1.0,1.5,2.0)$ : Experiment and theory. Phys. Rev. B 2006, 74, 094419.

(40) van Schilfgaarde, M.; Abrikosov, I. A.; Johansson, B., Origin of the Invar effect in iron-nickel alloys. Nature 1999, 400, 46-49. 
(41) Fang, Y. K.; Yeh, J. C.; Chang, W. C.; Li, X. M.; Li, W., Structures, magnetic properties, and magnetocaloric effect in $\mathrm{MnCo}_{1-\mathrm{x}} \mathrm{Ge}(0.02 \leqslant \mathrm{x} \leqslant 0.2)$ compounds. J. Magn. Magn. Mater. 2009, 321, 3053-3056.

(42) Liu, E. K.; Zhu, W.; Feng, L.; Chen, J. L.; Wang, W. H.; Wu, G. H.; Liu, H. Y.; Meng, F. B.; Luo, H. Z.; Li, Y. X., Vacancytuned paramagnetic/ferromagnetic martensitic transformation in Mn-poor $\mathrm{Mn}_{1-\mathrm{x}} \mathrm{CoGe}$ alloys. Europhys. Lett. 2010, 91, 17003.

(43) Caron, L.; Ou, Z. Q.; Nguyen, T. T.; Cam Thanh, D. T.; Tegus, O.; Brück, E., On the determination of the magnetic entropy change in materials with first-order transitions. J. Magn. Magn. Mater. 2009, 321, 3559-3566.

(44) Studer, A. J.; Hagen, M. E.; Noakes, T. J., Wombat: The high-intensity powder diffractometer at the OPAL reactor. Physica B: Condensed Matter 2006, 385, 1013-1015.

(45) Rietveld, H., A profile refinement method for nuclear and magnetic structures. J. Appl. Crystallogr. 1969, 2, 65-71.

(46) Rodríguez-Carvajal, J., Recent advances in magnetic structure determination by neutron powder diffraction. Physica B: Condensed Matter 1993, 192, 55-69.

(47) Anzai, S.; Ozawa, K., Coupled nature of magnetic and structural transition in MnNiGe under pressure. Phys. Rev. B 1978, 18, 2173-2178.

(48) Landrum, G. A.; Hoffmann, R.; Evers, J.; Boysen, H., The TiNiSi Family of Compounds: Structure and Bonding. Inorg. Chem. 1998, 37, 5754-5763.

(49) Johnson, V., Diffusionless orthorhombic to hexagonal transitions in ternary silicides and germanides. lnorg. Chem. 1975, 14, 1117-1120.

(50) Provenzano, V.; Shapiro, A. J.; Shull, R. D., Reduction of hysteresis losses in the magnetic refrigerant $\mathrm{Gd}_{5} \mathrm{Si}_{2} \mathrm{Ge}_{2}$ by the addition of iron. Nature 2004, 429, 853-857.

(51) Udvardi, L.; Khmelevskyi, S.; Szunyogh, L.; Mohn, P.; Weinberger, P., Helimagnetism and competition of exchange interactions in bulk giant magnetoresistance alloys based on $\mathrm{MnAu}_{2}$. Phys. Rev. B 2006, 73, 104446.

(52) Hortamani, M.; Sandratskii, L.; Zahn, P.; Mertig, I., Physical origin of the incommensurate spin spiral structure in $\mathrm{Mn}_{3} \mathrm{Si}$. J. Appl. Phys. 2009, 105, o7E506.

(53) Tung, J. C.; Guo, G. Y., Ab initiostudies of spin-spiral waves and exchange interactions in $3 d$ transition metal atomic chains. Phys. Rev. B 2011, 83, 144403.

(54) Krenke, T.; Duman, E.; Acet, M.; Wassermann, E. F.; Moya, X.; Manosa, L.; Planes, A., Inverse magnetocaloric effect in ferromagnetic Ni-Mn-Sn alloys. Nat. Mater. 2005, 4, 450.

(55) Bażela, W.; Szytula, A.; Todorović, J.; Zięba, A., Crystal and magnetic structure of the $\mathrm{NiMnGe}_{1-\mathrm{n}} \mathrm{Si}_{\mathrm{n}}$ System. Phys. Status Solidi A 1981, 64, 367-378.

(56) Wang, J. L.; Shamba, P.; Hutchison, W. D.; Gu, Q. F.; Md Din, M. F.; Ren, Q. Y.; Cheng, Z. X.; Kennedy, S. J.; Campbell, S. J.; Dou, S. X., Magnetocaloric Effect and Magnetostructural Coupling in $\mathrm{Mn}_{0.92} \mathrm{Fe}_{0.08}$ CoGe Compound. J. Appl. Phys. 2015, 117, 17 Dio3.

(57) Boeije, M. F. J.; Roy, P.; Guillou, F.; Yibole, H.; Miao, X. F.; Caron, L.; Banerjee, D.; van Dijk, N. H.; de Groot, R. A.; Brück, E., Efficient Room-Temperature Cooling with Magnets. Chem. Mater. 2016, 28, 4901-4905.

(58) Wang, J. L.; Campbell, S. J.; Cadogan, J. M.; Studer, A. J.; Zeng, R.; Dou, S. X., Magnetocaloric effect in layered $\mathrm{NdMn}_{2} \mathrm{Ge}_{\text {o.4 }} \mathrm{Si}_{1.6}$. Appl. Phys. Lett. 2011, 98, 232509.

(59) Li, G.; Wang, J.; Cheng, Z.; Ren, Q.; Fang, C.; Dou, S., Large entropy change accompanying two successive magnetic phase transitions in $\mathrm{TbMn}_{2} \mathrm{Si}_{2}$ for magnetic refrigeration. Appl. Phys. Lett. 2015, 106, 182405.

(6o) Ren, Q. New materials for magnetic refrigeration: the magnetocaloric effect in MnCoGe-based intermetallics. Doctoral thesis, The University of New South Wales, Canberra, Australia, 2016. 


\title{
Supporting Information
}

\section{Magnetic and structural transitions tuned through valence electron concentration in the magnetocaloric $\operatorname{Mn}\left(\mathrm{Co}_{1-\mathrm{x}} \mathrm{Ni}_{\mathrm{x}}\right) \mathrm{Ge}$}

\author{
Qingyong Ren, ${ }^{\dagger}, \S \# \|$ Wayne D. Hutchison, ${ }^{* \dagger}$ Jianli Wang, ${ }^{*} \pitchfork$ Andrew J. Studer, ${ }^{\perp}$ \\ and Stewart J. Campbell ${ }^{\dagger}$
}

${ }^{\dagger}$ School of Physical, Environmental and Mathematical Sciences, The University of New South Wales, Canberra, ACT 2600, Australia

${ }^{\ddagger}$ Institute for Superconductivity and Electronic Materials, University of Wollongong, Wollongong, NSW 2522, Australia

${ }^{\perp}$ Australian Centre for Neutron Sc attering, Locked Bag 2001, Kirrawee DC NSW 2232, Australia

${ }^{\S}$ School of Physics and Astronomy, Shanghai Jiao Tong University, Shanghai 200240, China

${ }^{\#}$ Key Laboratory of Artificial Structures and Quantum Control, School of Physics and Astronomy, Shanghai Jiao Tong University, Shanghai, 200240, China

$\|_{\text {Collaborative Innovation Center for Advanced Microstructures, Nanjing 210093, China }}$

"College of Physics, Jilin University, Changchun 130012, China

\section{Table of Contents}

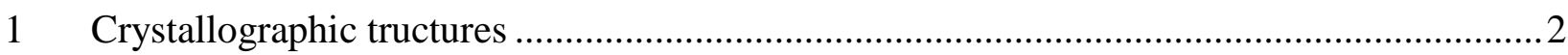

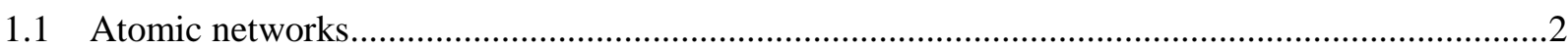

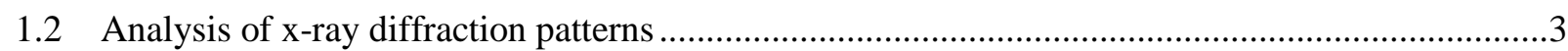

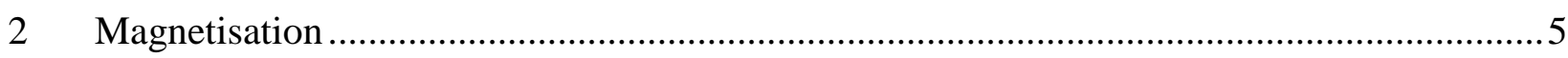

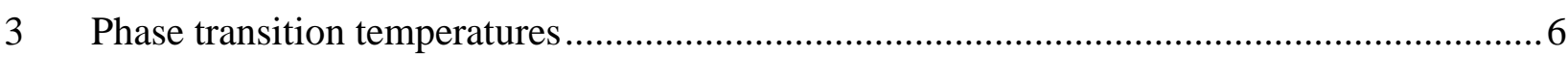

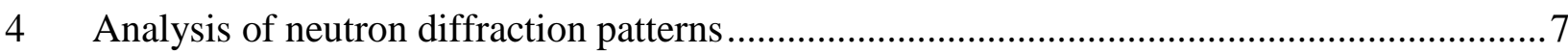

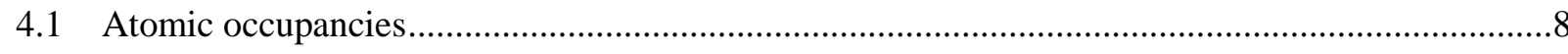

4.2 Irreducible representation analysis of ferromagnetic structures ..................................................

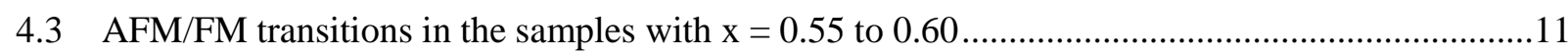

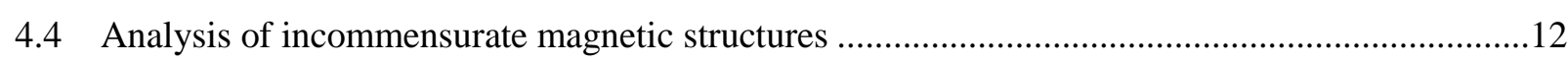

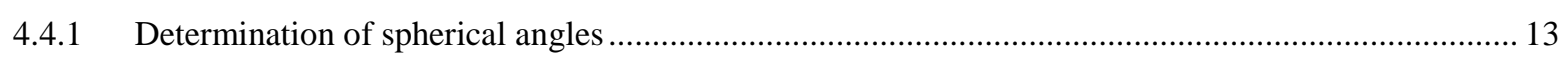

4.4.2 Rietveld refinements of different spiral structures .......................................................................... 15

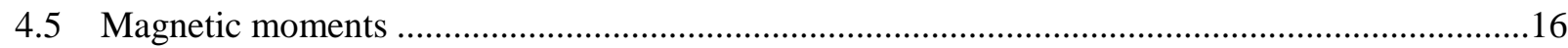

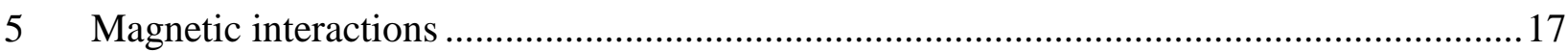

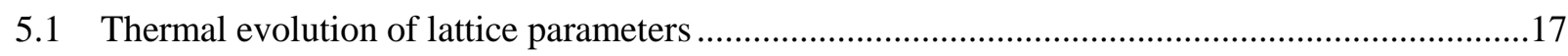

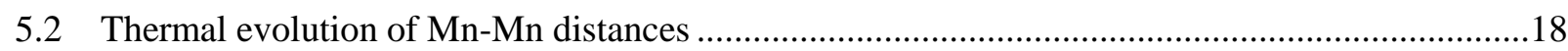

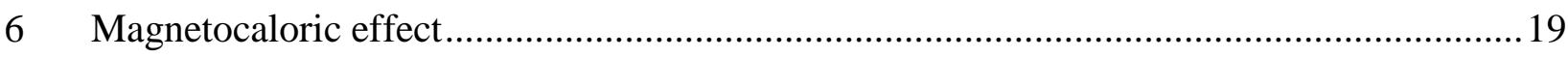

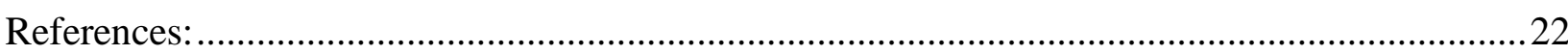




\section{Crystallographic tructures}

\subsection{Atomic networks}

In the orthorhombic structure (Pnma) of MnCoGe/MnNiGe-based compounds, each $\mathrm{Mn}$ atom has four Mn nearest-neighbours with two characteristic Mn-Mn separations, $d_{1}$ and $d_{2}$, as shown in Figure S1. The Mn atoms form 3 dimensional (3D) Mn-Mn interaction networks. This 3D Mn-Mn network comprises of two zigzag chains which penetrate through two groups of $\mathrm{Co} / \mathrm{Ni}-\mathrm{Ge}$ rings

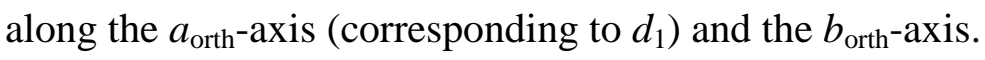

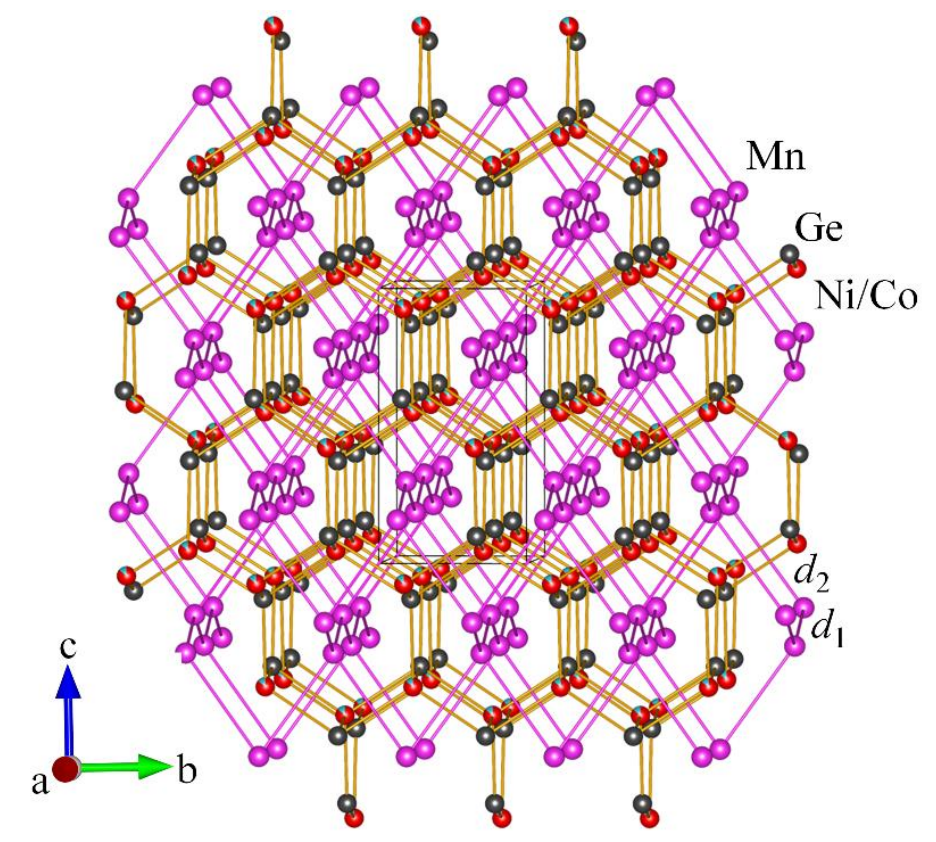

(a)

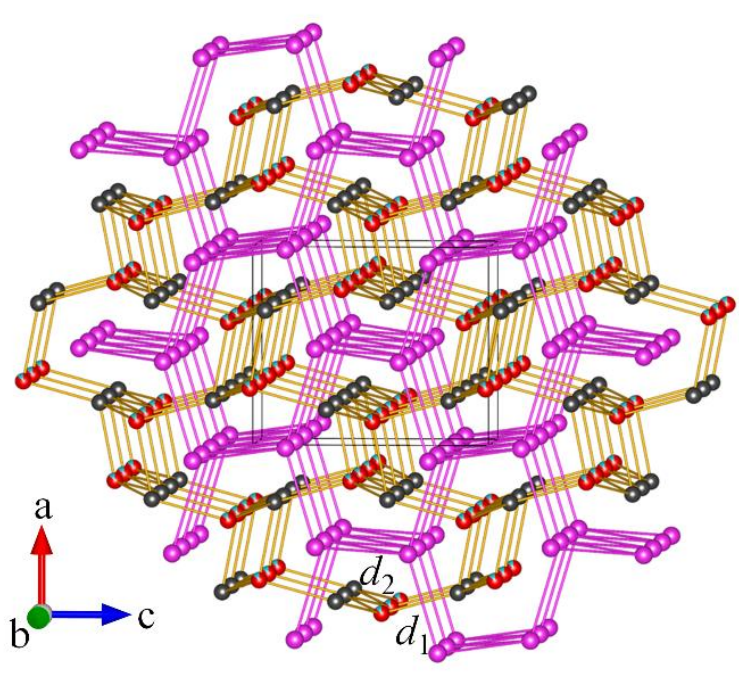

(b)

Figure $\mathrm{S} 1 \mathrm{Mn}-\mathrm{Mn}$ networks in the $\mathrm{Co} / \mathrm{Ni}-\mathrm{Ge}$ networks in the orthorhombic phase of the $\mathrm{Mn}\left(\mathrm{Co}_{0.86} \mathrm{Ni}_{0.14}\right) \mathrm{Ge}$ sample. (Lattice parameters and atomic positions are from the Rietveld refinement of the neutron pattern at $5 \mathrm{~K}$, see Figure $\mathrm{S} 4(\mathrm{a})$ ). In the $\mathrm{Co} / \mathrm{Ni}-\mathrm{Ge}$ networks, there are two

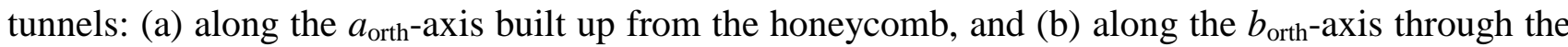
eight-rings which form from the partial break of $\mathrm{Ni} / \mathrm{Co}-\mathrm{Ge}$ bonds between the $\mathrm{Co} / \mathrm{Ni}-\mathrm{Ge}$ layers during the martensitic transition. There are two kinds of Mn-Mn nearest neighbours, $d_{1}$ and $d_{2}$, penetrating these two kinds of tunnels. 


\subsection{Analysis of x-ray diffraction patterns}
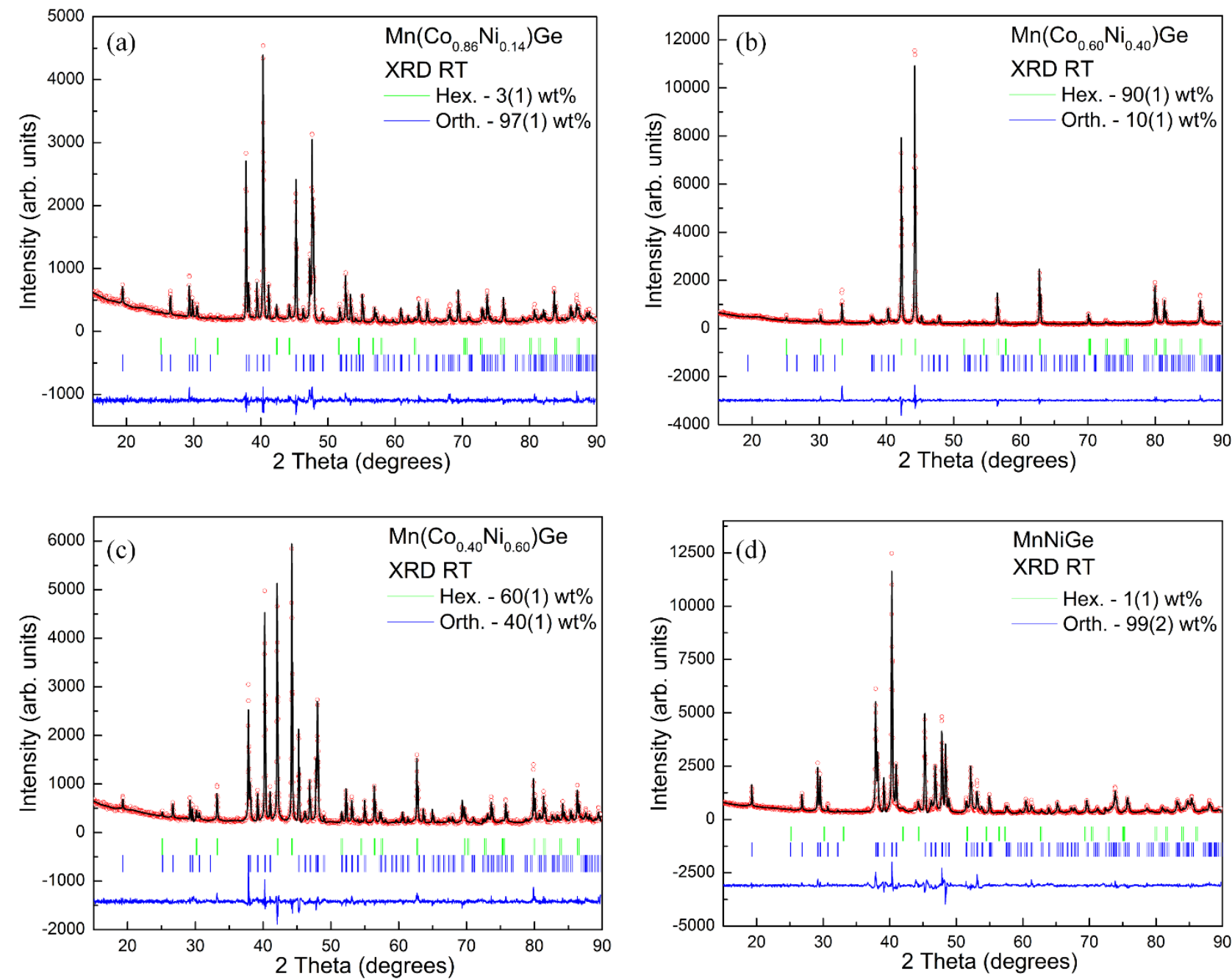

Figure S2 Rietveld refinements of the x-ray diffraction patterns for (a) $\mathrm{Mn}\left(\mathrm{Co}_{0.86} \mathrm{Ni}_{0.14}\right) \mathrm{Ge}$, (b) $\mathrm{Mn}\left(\mathrm{Co}_{0.60} \mathrm{Ni}_{0.40}\right)$, (c) $\mathrm{Mn}\left(\mathrm{Co}_{0.40} \mathrm{Ni}_{0.60}\right) \mathrm{Ge}$ and (d) $\mathrm{MnNiGe}$ at room temperature. The circles and solid lines on the circles are observed and calculated data, respectively. The horizontal rows of Bragg markers (from top to bottom) represent structures of the hexagonal and the orthorhombic phases, respectively. The trace lines represent the difference between observed and calculated data. Fractions of the hexagonal and the orthorhombic phases are given. No impurity phase was observed in these diffraction patterns. It is noted that the neutron diffraction experiments demonstrate a tiny impurity phase in the $\mathrm{Mn}\left(\mathrm{Co}_{1-\mathrm{x}} \mathrm{Ni}_{\mathrm{x}}\right) \mathrm{Ge}$ samples with $\mathrm{x}=0.90$ and 1.00. It is $\mathrm{MnCo}_{1.25} \mathrm{Ge}_{0.75}$ with a space group of $P 6_{3} / m m c$. The phase fraction of this impurity is so small $(\leq 2(1) \mathrm{wt} \%)$ that the $\mathrm{x}$-ray diffraction experiment cannot identify.

As shown in Figure 3 in the main context, the variation of lattice parameters of the orthorhombic phase agrees well with the Vegard's law in $\mathrm{Mn}(\mathrm{Co} 1-\mathrm{xNix}) \mathrm{Ge}$ in the region of $\mathrm{x}=0.12,0.14, \ldots, 0.20$, 
far below the critical concentration for the occurrence of spiral magnetic structures $(x=\sim 0.55)$. This observation confirms the slight increase in the Ni concentration, confirming the correctness of our careful sample preparation procedures. 


\section{Magnetisation}
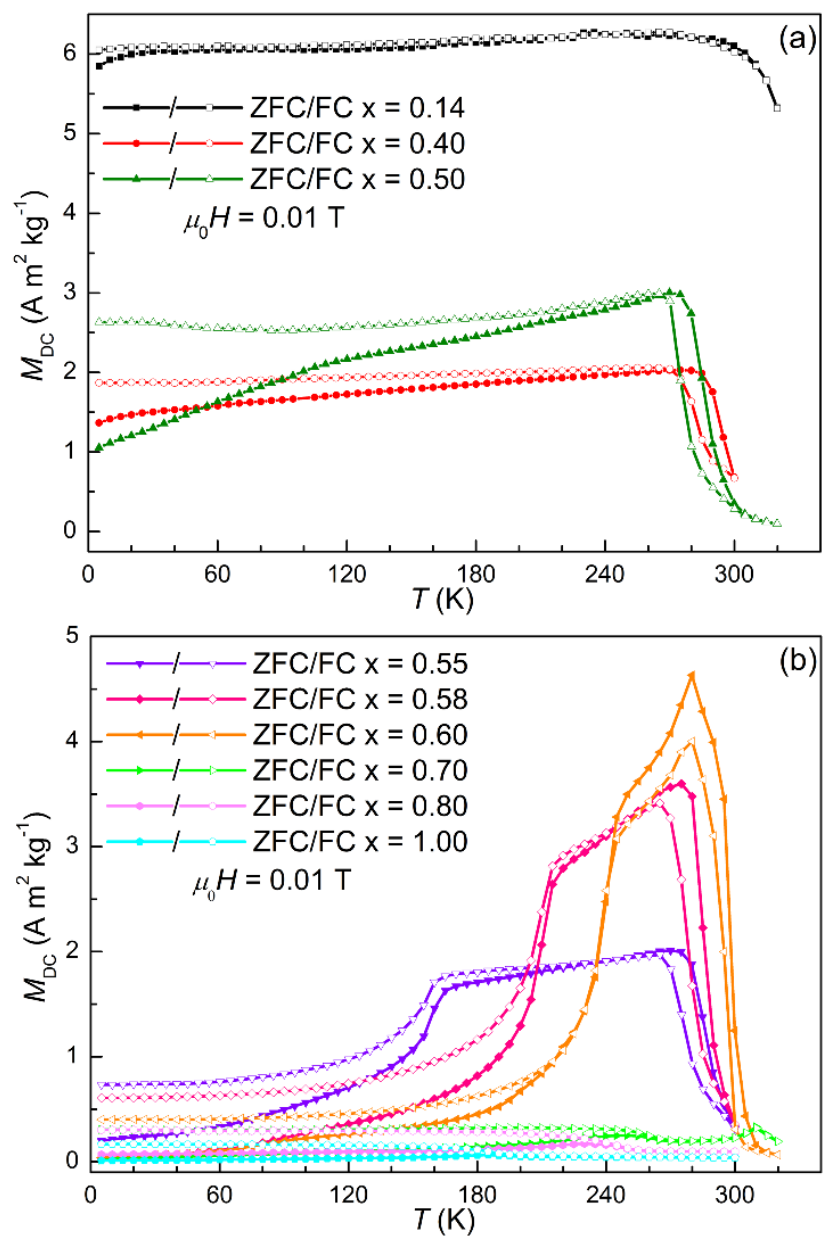

Figure S3 Magnetisation curves as a function of temperature for the $\mathrm{Mn}\left(\mathrm{Co}_{1-\mathrm{x}} \mathrm{Ni}_{\mathrm{x}}\right) \mathrm{Ge}$ samples, (1) $\mathrm{x}$ $=0.20,0.40,0.50$ and $(\mathrm{b}) \mathrm{x}=0.55,0.58,0.60,0.70,0.80$ and 1.00, in an applied field of $0.01 \mathrm{~T}$ on warming after zero-field cooling (ZFC, solid symbols) and field cooling (FC, open symbols). 


\section{Phase transition temperatures}

Table S1 Phase transition temperatures for annealed $\mathrm{Mn}\left(\mathrm{Co}_{1-\mathrm{x}} \mathrm{Ni}_{\mathrm{x}}\right) \mathrm{Ge}$ as determined from variable temperature x-ray diffraction and neutron diffraction experiments, and magnetisation measurements.

\begin{tabular}{ccccccc}
\hline $\mathrm{x}$ & $T_{\mathrm{M}}^{*}$ & $\mathrm{FWHM}$ & $T_{\mathrm{m}}^{\mathrm{W}}$ & $T_{\mathrm{m}}^{\mathrm{C} \ddagger}$ & $T_{\mathrm{C}}$ & $T_{\mathrm{N}}$ or $T_{\mathrm{N}}^{\mathrm{SP}-\mathrm{FM}}$ \\
& $(\mathrm{K})$ & $(\mathrm{K})$ & $(\mathrm{K})$ & $(\mathrm{K})$ & $(\mathrm{K})$ & $(\mathrm{K})$ \\
0.14 & $370(2)$ & $38(2)$ & - & - & $345(5)$ & - \\
0.30 & $324(5)$ & - & - & - & - & - \\
0.40 & $299(1)$ & $13(1)$ & $295(4)$ & $280(4)$ & - & - \\
0.50 & $290(1)$ & $17(1)$ & $285(4)$ & $275(4)$ & - & $155(4) / 170(5)^{\dagger}$ \\
0.55 & $291(1)$ & $14(1)$ & $285(4)$ & $275(4)$ & - & $210(4) / 215(5)$ \\
0.58 & $290(1)$ & $18(1)$ & $285(4)$ & $280(4)$ & - & $240(4) / 245(5)$ \\
0.60 & $312(1)$ & $15(1)$ & $300(4)$ & $295(4)$ & - & $306(5)$ \\
0.70 & - & - & - & - & - & $350(5)$ \\
0.90 & $442(5)$ & $20(5)$ & - & - & - & $360(5)$ \\
1.00 & - & - & - & - & - & - \\
\hline
\end{tabular}

* The structural transition temperature $T_{\mathrm{M}}$ for $\mathrm{x}=0.30,0.50$ and 0.55 are estimated from variable temperature x-ray diffraction experiments, with the other data derived from the neutron powder diffraction experiments.

* To distinguish the magnetic transitions around a magneto-structural transition and around a Curie temperature, the magnetisation change temperatures are marked using $T_{\mathrm{m}}^{\mathrm{W}}$ and $T_{\mathrm{m}}^{\mathrm{C}}$ around the magneto-structural transition.

$\dagger$ Magnetic transitions temperatures $T_{\mathrm{N}}^{\mathrm{SP}-\mathrm{FM}}$ derived from magnetisation and neutron diffraction experiments, respectively. 


\section{Analysis of neutron diffraction patterns}
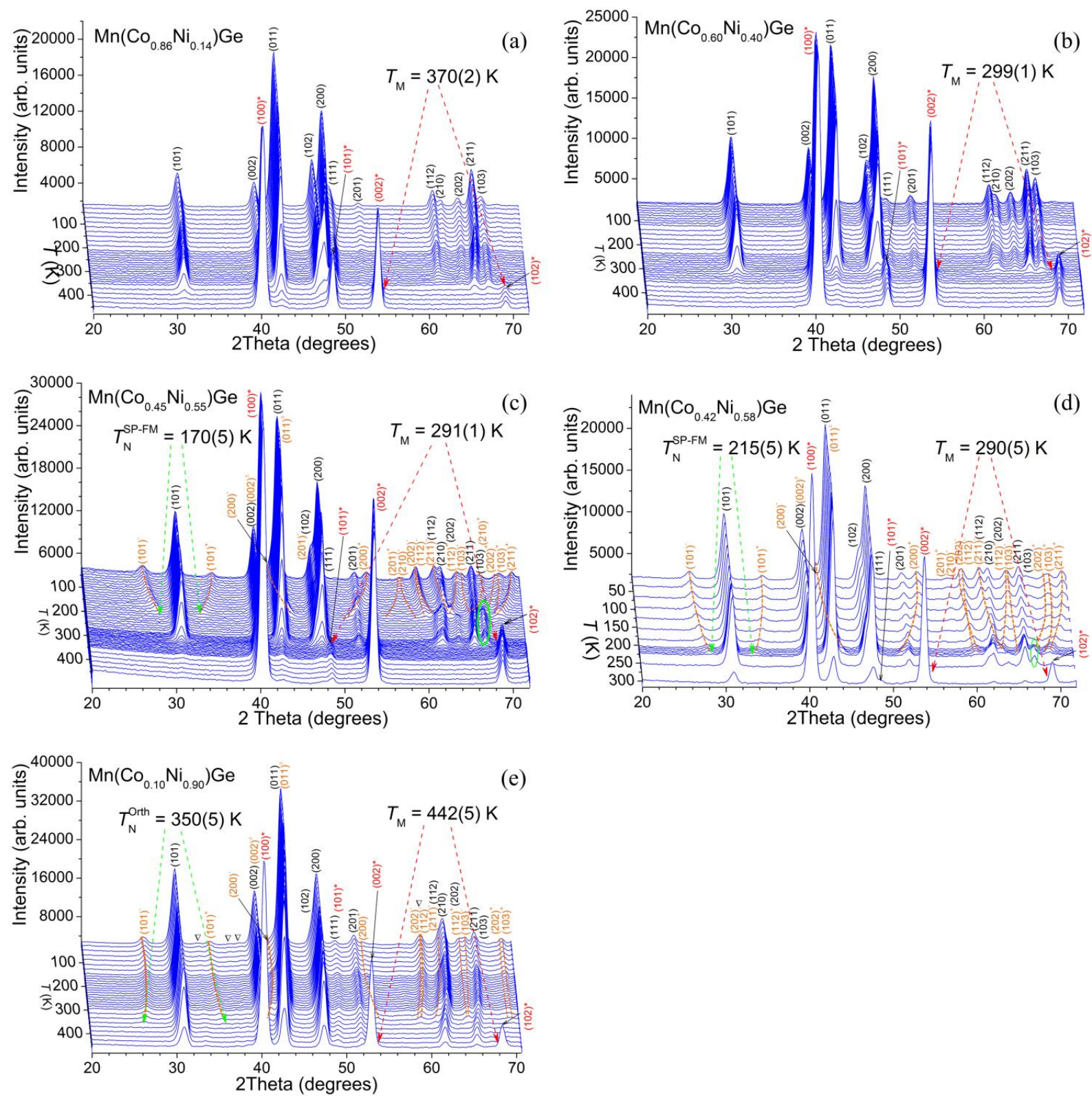

Figure S4 Powder neutron diffraction patterns $(\lambda=2.4143 \AA$ ) over the temperature range $10 \mathrm{~K}$ to 450 $\mathrm{K}$ for $\mathrm{Mn}\left(\mathrm{Co}_{1-\mathrm{x}} \mathrm{Ni}_{\mathrm{x}}\right) \mathrm{Ge}$ with (a) $\mathrm{x}=0.14$, (b) $\mathrm{x}=0.40$, (c) $\mathrm{x}=0.55$, (d) $\mathrm{x}=0.58$ and (e) $\mathrm{x}=0.90$. (The diffraction patterns for $x=0.60$ and $x=1.00$ are shown in Figs. 5(a) and 5(d).) All of the peaks are identified as the orthorhombic (Miller indices without asterisk) and hexagonal (Miller indices with asterisks) structures in the samples with $\mathrm{x}=0.14,0.40,0.55$ and 0.58 . In the sample with $\mathrm{x}=0.90$, the impurity phase $\mathrm{MnNi}_{1.25} \mathrm{Ge}_{0.75}\left(\mathrm{~Pb}_{3} / \mathrm{mmc}\right.$, indicated by triangles) is also observed. The curves in (c), (d) and (e) are guides for the evolution of the magnetic satellite peaks. Some satellite peaks which are too small to be discerned are not marked. $T_{\mathrm{M}}, T_{\mathrm{N}}^{\mathrm{SP}-\mathrm{FM}}$ and $T_{\mathrm{N}}^{\mathrm{Orth}}$ are the temperatures for the reverse martensitic transformation, spiral-AFM/FM transition in the orthorhombic structure and the AFM/FM transition in the orthorhombic structure. 


\subsection{Atomic occupancies}

Table S2 The nominal compositions and the actual compositions which are determined from the Rietveld refinements of the neutron diffraction patterns. No mixing atomic distribution was observed between $\mathrm{Mn}$ and $\mathrm{Ni}$.

\begin{tabular}{cc}
\hline Nominal Composition & Neutron Diffraction-Composition \\
$\mathrm{Mn}\left(\mathrm{Co}_{0.86} \mathrm{Ni}_{0.14}\right) \mathrm{Ge}$ & $\mathrm{Mn}\left(\mathrm{Co}_{0.864} \mathrm{Ni}_{0.136}\right) \mathrm{Ge}$ \\
$\mathrm{Mn}\left(\mathrm{Co}_{0.60} \mathrm{Ni}_{0.40}\right) \mathrm{Ge}$ & $\mathrm{Mn}\left(\mathrm{Co}_{0.612} \mathrm{Ni}_{0.388}\right) \mathrm{Ge}$ \\
$\mathrm{Mn}\left(\mathrm{Co}_{0.45} \mathrm{Ni}_{0.55}\right) \mathrm{Ge}$ & $\mathrm{Mn}\left(\mathrm{Co}_{0.428} \mathrm{Ni}_{0.572}\right) \mathrm{Ge}$ \\
$\mathrm{Mn}\left(\mathrm{Co}_{0.42} \mathrm{Ni}_{0.58}\right) \mathrm{Ge}$ & $\mathrm{Mn}\left(\mathrm{Co}_{0.416} \mathrm{Ni}_{0.584}\right) \mathrm{Ge}$ \\
$\mathrm{Mn}\left(\mathrm{Co}_{0.40} \mathrm{Ni}_{0.60}\right) \mathrm{Ge}$ & $\mathrm{Mn}\left(\mathrm{Co}_{0.382} \mathrm{Ni}_{0.618}\right) \mathrm{Ge}$ \\
$\mathrm{Mn}\left(\mathrm{Co}_{0.10} \mathrm{Ni}_{0.90}\right) \mathrm{Ge}$ & $\mathrm{Mn}\left(\mathrm{Co}_{0.102} \mathrm{Ni}_{0.898}\right) \mathrm{Ge}$ \\
$\mathrm{MnNiGe}$ & $\mathrm{MnNi}_{0.996} \mathrm{Ge}$ \\
\hline
\end{tabular}




\subsection{Irreducible representation analysis of ferromagnetic structures}

The magnetisation data for $\mathrm{Mn}\left(\mathrm{Co}_{0.86} \mathrm{Ni}_{0.14}\right) \mathrm{Ge}$ and $\mathrm{Mn}\left(\mathrm{Co}_{0.60} \mathrm{Ni}_{0.40}\right) \mathrm{Ge}$ (Figure 4(a)) shows features that suggest ferromagnetism. It is straightforward to analyse the ferromagnetic structure using irreducible representations. Therefore, irreducible representation analyses were carried out for both samples using BasIreps program in FullProf suite. For the 4c site (Mn atoms occupy 4c sites) in the orthorhombic structure (Pnma), the decomposition of the magnetic representation comprises eight representations:

$$
\Gamma_{\text {Mag }}^{4 c}=1 \Gamma_{1}+2 \Gamma_{2}+2 \Gamma_{3}+1 \Gamma_{4}+1 \Gamma_{5}+2 \Gamma_{6}+2 \Gamma_{7}+1 \Gamma_{8}
$$

The basis vectors of these irreducible representations are given in Table S2.

Table S3 Irreducible representation analysis for the 4c site in the orthorhombic structure (Pnma) with a propagation vector $\left[\begin{array}{lll}0 & 0 & 0\end{array}\right]$. The atomic position for the $4 \mathrm{c}$ site are $(\mathrm{x}, 1 / 4, \mathrm{y}),(1 / 2-\mathrm{x}, 3 / 4,1 / 2+\mathrm{z}),(-\mathrm{x}$, $3 / 4,-\mathrm{z})$, and $(1 / 2+\mathrm{x}, 1 / 4,-\mathrm{z})$.

\begin{tabular}{ccccc}
\hline Representation & Ordering mode & \multicolumn{3}{c}{ Magnetic moment directions } \\
$\Gamma_{1}$ & $\mathrm{G}_{\mathrm{y}}$ & $\mathrm{x}$ & $\mathrm{y}$ & $\mathrm{z}$ \\
$\Gamma_{2}$ & $\mathrm{~A}_{\mathrm{x}} \mathrm{C}_{\mathrm{z}}$ & +-++ & +-+ & \\
$\Gamma_{3}$ & $\mathrm{G}_{\mathrm{x}} \mathrm{F}_{\mathrm{z}}$ & +-+- & & ++- \\
$\Gamma_{4}$ & $\mathrm{~A}_{\mathrm{y}}$ & & +++ & \\
$\Gamma_{5}$ & $\mathrm{~F}_{\mathrm{y}}$ & & ++++ & \\
$\Gamma_{6}$ & $\mathrm{C}_{\mathrm{x}} \mathrm{A}_{\mathrm{z}}$ & ++--++ & & +-+- \\
$\Gamma_{7}$ & $\mathrm{~F}_{\mathrm{x}} \mathrm{G}_{\mathrm{z}}$ & ++++ & & + \\
$\Gamma_{8}$ & $\mathrm{C}_{\mathrm{y}}$ & & ++- & + \\
\hline
\end{tabular}

All of these representation models were simulated and a comparison of these simulations with the neutron diffraction patterns indicated that $F_{z}$ of $\Gamma_{3}$ and $F_{y}$ of $\Gamma_{5}$, corresponding to a ferromagnetic

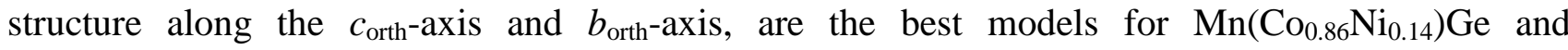
$\mathrm{Mn}\left(\mathrm{Co}_{0.60} \mathrm{Ni}_{0.40}\right) \mathrm{Ge}$, respectively. Figures S5(a) and S5(b) are the Rietveld refinements of the neutron diffraction patterns using the models $F_{z}$ of $\Gamma_{3}$ and $F_{y}$ of $\Gamma_{5}$ for $\mathrm{Mn}\left(\mathrm{Co}_{0.86} \mathrm{Ni}_{0.14}\right) \mathrm{Ge}$ and $\mathrm{Mn}\left(\mathrm{Co}_{0.60} \mathrm{Ni}_{0.40}\right) \mathrm{Ge}$, respectively, at $5 \mathrm{~K}$. Three phases were considered in the refinements corresponding to: the nuclear and magnetic scattering from the orthorhombic phase and the nuclear 
scattering of the hexagonal phase. (For comparison, the Rietveld refinement using $\mathrm{F}_{\mathrm{z}}$ of $\Gamma_{3}$ for $\mathrm{Mn}\left(\mathrm{Co}_{0.60} \mathrm{Ni}_{0.40}\right) \mathrm{Ge}$ gives bad fitting as shown in Figure $\left.\mathrm{S} 5(\mathrm{c})\right)$.
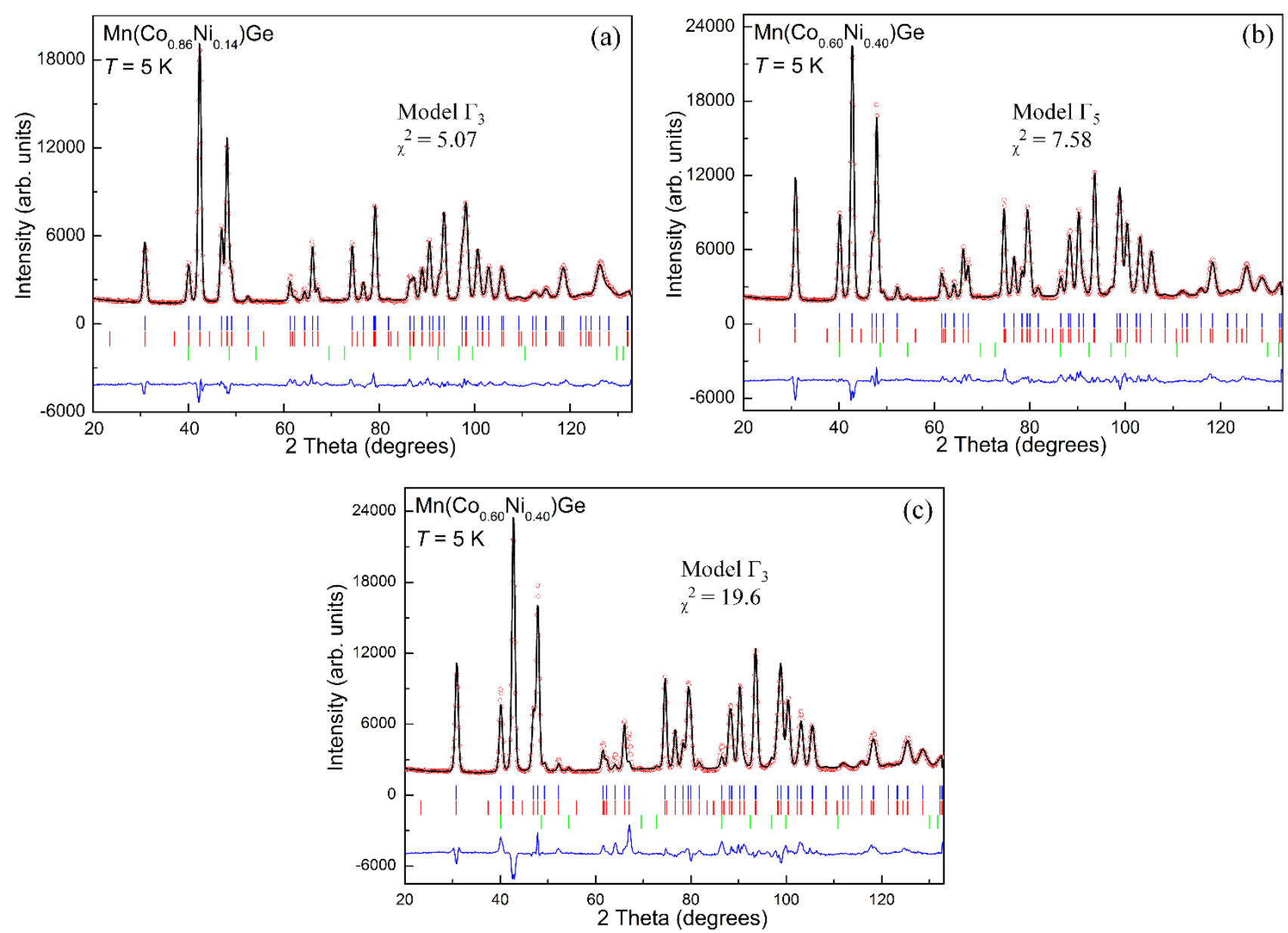

Figure S5 Rietveld refinements of the neutron diffraction patterns for (a) $\mathrm{Mn}\left(\mathrm{Co}_{0.86} \mathrm{Ni}_{0.14}\right) \mathrm{Ge}$ using model $\mathrm{F}_{\mathrm{z}}$ of $\Gamma_{3}$, (b) $\mathrm{Mn}\left(\mathrm{Co}_{0.60} \mathrm{Ni}_{0.40}\right) \mathrm{Ge}$ using model $\mathrm{F}_{\mathrm{y}}$ of $\Gamma_{5}$ and (c) $\mathrm{Mn}\left(\mathrm{Co}_{0.60} \mathrm{Ni}_{0.40}\right) \mathrm{Ge}$ using model $F_{z}$ of $\Gamma_{3}$ at $5 \mathrm{~K}$. The circles and solid lines on the circles are observed and calculated data, respectively. The horizontal rows of Bragg markers (from top to bottom) represent the nuclear and magnetic structures of orthorhombic, and the nuclear structure of the hexagonal phase, respectively. The trace lines represent the difference between observed and calculated data. $F_{z}$ of $\Gamma_{3}$ and $F_{y}$ of $\Gamma_{5}$ are the best models for $\mathrm{Mn}\left(\mathrm{Co}_{0.86} \mathrm{Ni}_{0.14}\right) \mathrm{Ge}$ and $\mathrm{Mn}\left(\mathrm{Co}_{0.60} \mathrm{Ni}_{0.40}\right) \mathrm{Ge}$, respectively. Compared with the refinement based on model $F_{y}$ of $\Gamma_{5}$ as shown in (b), $F_{z}$ of $\Gamma_{3}$ gives a poor quality fitting for $\operatorname{Mn}\left(\mathrm{Co}_{0.60} \mathrm{Ni}_{0.40}\right) \mathrm{Ge}($ see (c)). 


\subsection{AFM/FM transitions in the samples with $x=0.55$ to 0.60}

As shown in Figs. 7(a), S2(c) and S2(d), there is a AFM/FM transition at 175(5) K, 215(5) K and 245(5) $\mathrm{K}$ in $\mathrm{Mn}\left(\mathrm{Co}_{0.45} \mathrm{Ni}_{0.55}\right) \mathrm{Ge}, \mathrm{Mn}\left(\mathrm{Co}_{0.42} \mathrm{Ni}_{0.58}\right) \mathrm{Ge}$ and $\mathrm{Mn}\left(\mathrm{Co}_{0.40} \mathrm{Ni}_{0.60}\right) \mathrm{Ge}$, respectively. This magnetic transition is accompanied by the disappearance of the satellite peaks and the enhancements of some nuclear scattering peaks, such as the (101) orth and (103) orth peaks. The thermal evolution of the (101) orth peak intensity for $\mathrm{Mn}\left(\mathrm{Co}_{0.45} \mathrm{Ni}_{0.55}\right) \mathrm{Ge}$ and $\mathrm{Mn}\left(\mathrm{Co}_{0.40} \mathrm{Ni}_{0.60}\right) \mathrm{Ge}$ are shown in Figure S3. Abrupt enhancement is observed in both samples. Following analysis of neutron patterns indicate that the ferromagnetic (FM) structure is similar to that in $\mathrm{Mn}\left(\mathrm{Co}_{0.60} \mathrm{Ni}_{0.40}\right) \mathrm{Ge}$ with magnetic moments pointing to the $b_{\text {orth-axis. }}$

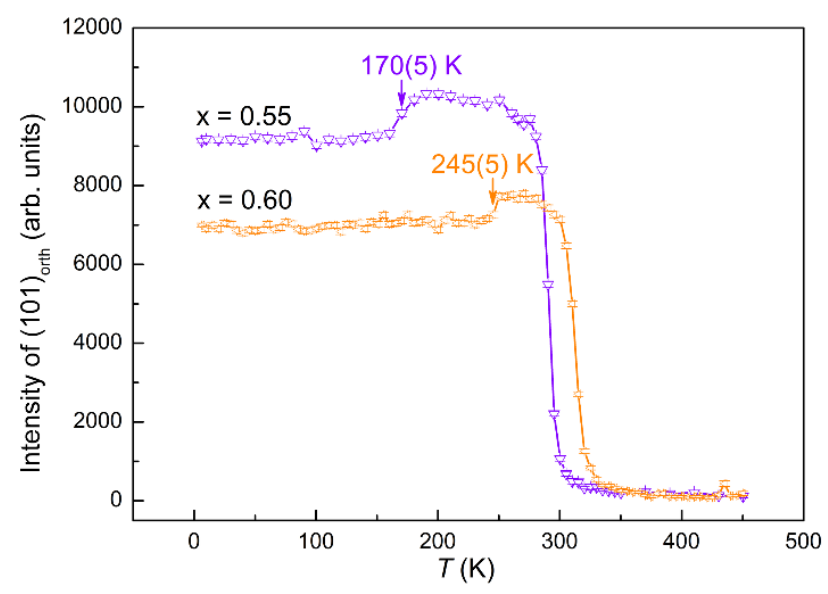

Figure S6 Thermal variation of the (101) orth peak intensity for $\mathrm{Mn}\left(\mathrm{Co}_{0.45} \mathrm{Ni}_{0.55}\right) \mathrm{Ge}$ and $\mathrm{Mn}\left(\mathrm{Co}_{0.40} \mathrm{Ni}\right.$ $\left.{ }_{0.60}\right) \mathrm{Ge}$. The $(101)_{\text {orth }}$ peak intensity is found to increase sharply in both the $\mathrm{Mn}\left(\mathrm{Co}_{0.45} \mathrm{Ni}_{0.55}\right) \mathrm{Ge}$ and $\mathrm{Mn}\left(\mathrm{Co}_{0.40} \mathrm{Ni}_{0.60}\right) \mathrm{Ge}$ samples at $175(5) \mathrm{K}$ and $245(5) \mathrm{K}$, respectively. 


\subsection{Analysis of incommensurate magnetic structures}

For the $\mathrm{Mn}\left(\mathrm{Co}_{1-\mathrm{x}} \mathrm{Ni}_{\mathrm{x}}\right) \mathrm{Ge}$ samples, there are spiral magnetic structures in the incommensurate region. The FullProf suite can be used to describe a spiral structure. In this work, the conical magnetic model $(j b t=5)$ were used. $(j b t$ : structure factor model and refinement method for the phase).

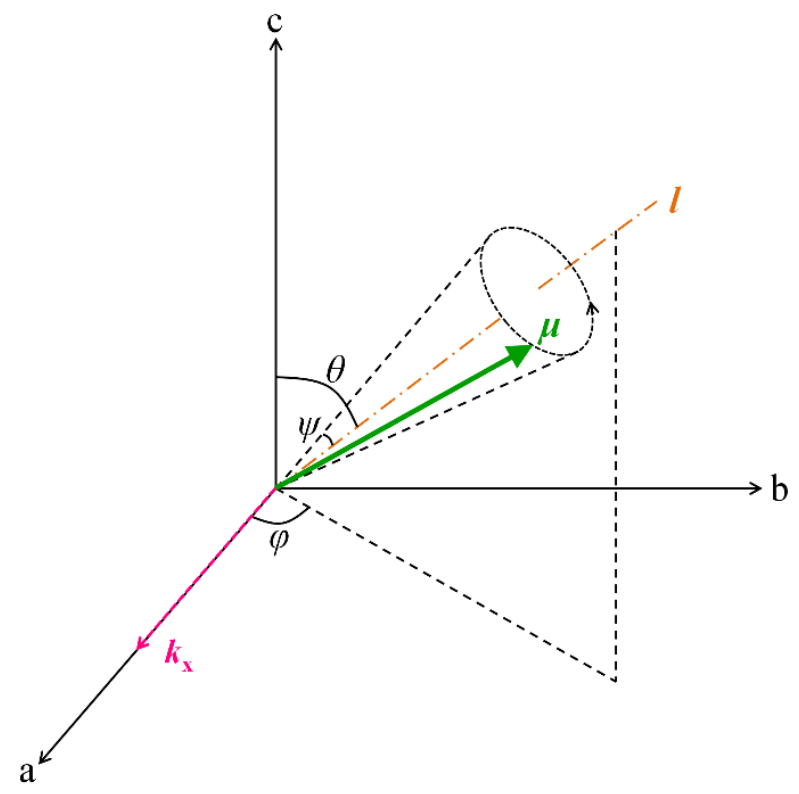

Figure S7 Coordinate system for a conical magnetic structure used in the Rietveld refinement based on FullProf suite. The spin vector $\boldsymbol{\mu}$ lies on the cone with a half-angle $\psi . \theta$ and $\varphi$ are the spherical angles of the cone axis (spiral axis) $l$ of the first atom with respect to the coordinate system. 


\subsubsection{Determination of spherical angles}

Variation of the parameters $\psi, \theta$ and $\varphi$ in the spiral structures produce only small differences in the magnetic diffraction patterns. This makes the refinement of these angles difficult. To search for the best refinement, different angles were tried (in $10^{\circ}$ steps per refinement). As an example, parameters from refinements using different values of angle $\theta$ are shown in Figure S7. The best refinement with the smallest reduced chi-square is $70^{\circ}$ (or $\left.110^{\circ}\right)$ for the $\mathrm{Mn}\left(\mathrm{Co}_{0.40} \mathrm{Ni}_{0.60}\right)$ Ge sample at $5 \mathrm{~K}$.

In the $\mathrm{Mn}\left(\mathrm{Co}_{1-\mathrm{x}} \mathrm{Ni}_{\mathrm{x}}\right) \mathrm{Ge}$ samples, the incommensurate magnetic structures have $\psi=90^{\circ}$ (flat spiral-structure) and $\varphi=0^{\circ} . \theta$ varies between $0^{\circ}$ and $90^{\circ}$ in the $a c$-plane with Ni content $\mathrm{x}$ and temperature (see Figure S8). For examples, $\theta=70^{\circ}, 0^{\circ}$ and $90^{\circ}$ - corresponding to: a cycloidal-spiral structure, a simple cycloidal structure in the $b c$-plane and a simple spiral structure in the $a b$-plane for $\mathrm{Mn}\left(\mathrm{Co}_{0.40} \mathrm{Ni}_{0.60}\right) \mathrm{Ge}\left(5 \mathrm{~K}\right.$, see Figure 6(c)), MnNiGe (5 K, see Figure 6(d)) and $\mathrm{Mn}\left(\mathrm{Co}_{0.10} \mathrm{Ni}_{0.90}\right) \mathrm{Ge}$ (at 180 K, see Figure S9), respectively.

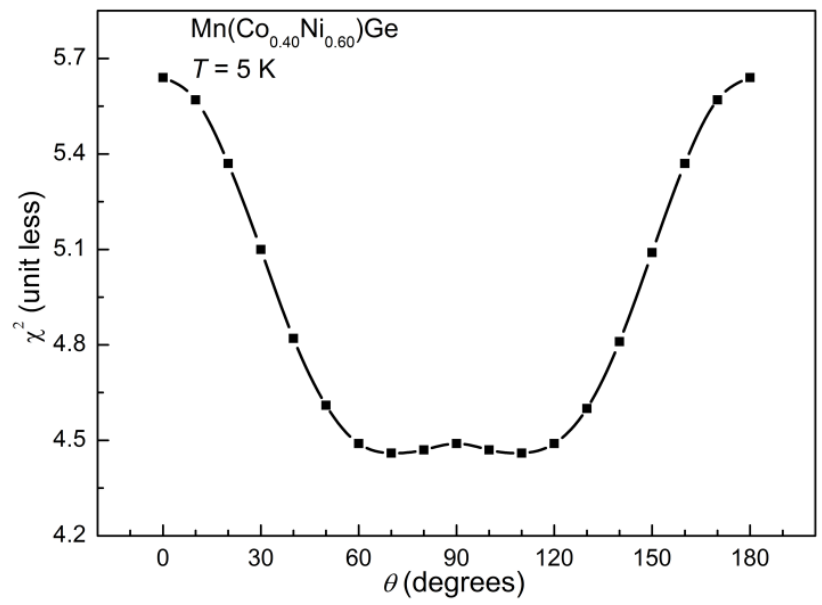

Figure S8 Reduced chi-square $\chi^{2}$ of the refinement results as a function of the cone axis angle $\theta$ for the neutron powder diffraction pattern of $\mathrm{Mn}\left(\mathrm{Co}_{0.40} \mathrm{Ni}_{0.60}\right) \mathrm{Ge}$ at $5 \mathrm{~K}$. 


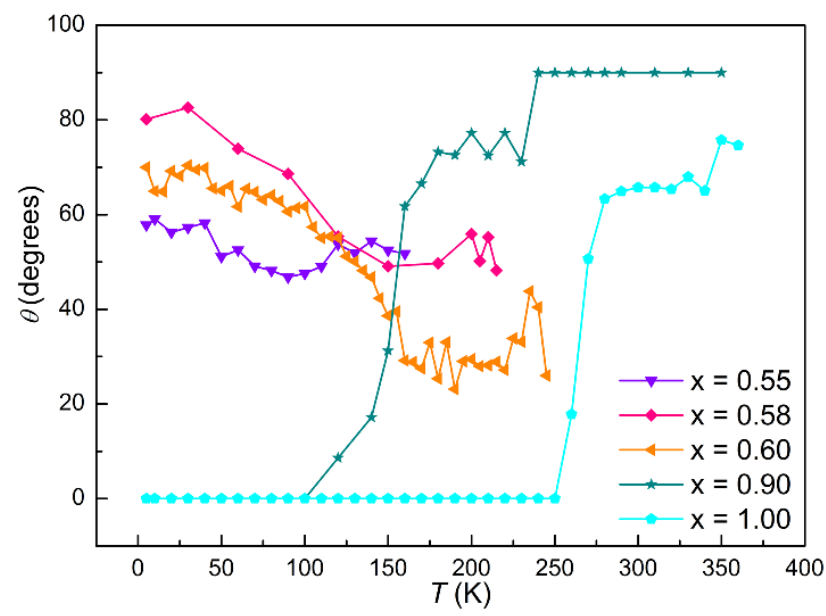

Figure S9 The angles $\theta$ of the spiral axis $l$ as functions of temperature for the spiral structure in the orthorhombic structure of the $\mathrm{Mn}\left(\mathrm{Co}_{1-\mathrm{x}} \mathrm{Ni}_{\mathrm{x}}\right) \mathrm{Ge}$ samples $(\mathrm{x}=0.55$ to 1.00$)$. Note: $l$ varies in the $a c$ plane. 


\subsubsection{Rietveld refinements of different spiral structures}
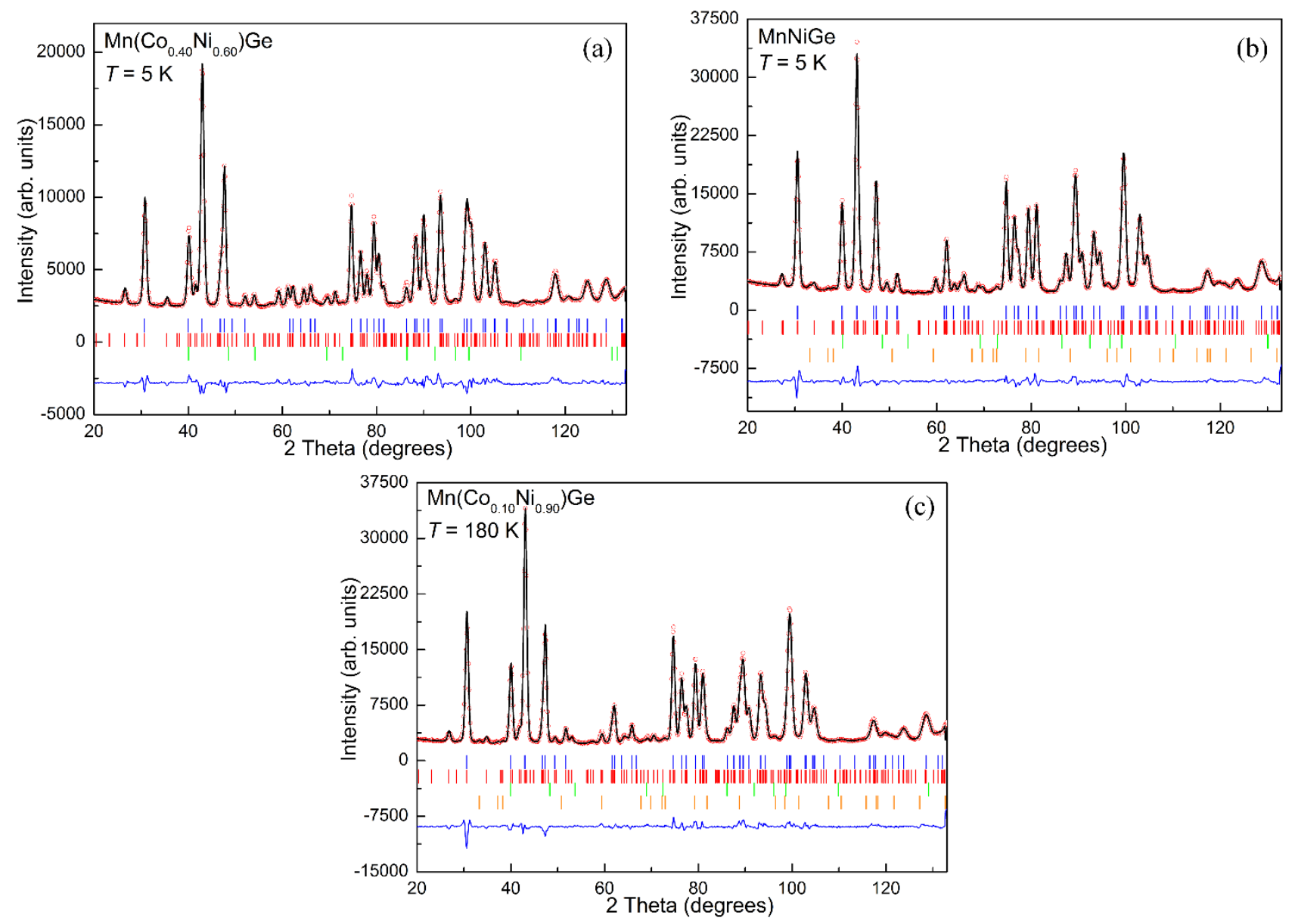

(d) $\mathrm{Mn}\left(\mathrm{Co}_{0.10} \mathrm{Ni}_{0.90}\right) \mathrm{Ge}-180 \mathrm{~K}$

(d) $\boldsymbol{k}_{\mathrm{x}}=0.222(1) \AA^{-1} ; \psi=90^{\circ} ; \varphi=0^{\circ} ; \theta=90^{\circ}$

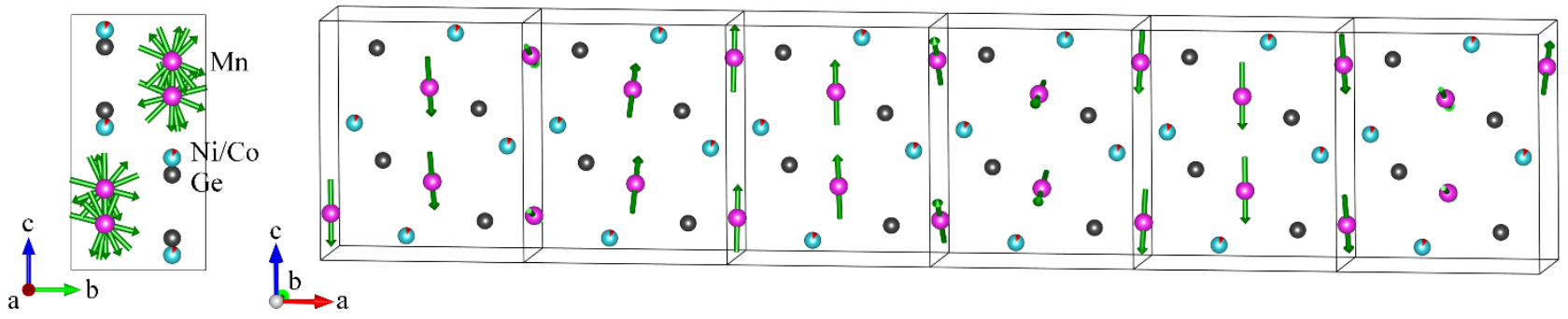

Figure S10 (a) Rietveld refinements of the neutron diffraction patterns for (a) $\mathrm{Mn}\left(\mathrm{Co}_{0.40} \mathrm{Ni}_{0.60}\right) \mathrm{Ge}$ at 5 $\mathrm{K}$, (b) $\mathrm{MnNiGe}$ at $5 \mathrm{~K}$ and (c) $\mathrm{Mn}\left(\mathrm{Co}_{0.10} \mathrm{Ni}_{0.90}\right) \mathrm{Ge}$ at $180 \mathrm{~K}$. The circles and solid lines on the circles are observed and calculated data, respectively. The horizontal rows of Bragg markers (from top to bottom) represent the nuclear and magnetic structures of the orthorhombic phase, the nuclear structures of the hexagonal phase and the $\mathrm{MnNi}_{1.25} \mathrm{Ge}_{0.75}$ impurity, respectively. The bottom lines are the difference between observed and calculated data. (d) is the magnetic structure of the orthorhombic phase for $\mathrm{Mn}\left(\mathrm{Co}_{0.10} \mathrm{Ni}_{0.90}\right) \mathrm{Ge}$ at $180 \mathrm{~K}$ projected on the $b c$-plane and $a c$-plane with six unit cells along $a_{\text {orth}}$, respectively. The propagation vector is $0.222(1) \AA^{-1}$ along $a_{\text {orth. The magnetic }}$ structures for $\mathrm{Mn}\left(\mathrm{Co}_{0.40} \mathrm{Ni}_{0.60}\right) \mathrm{Ge}$ and $\mathrm{MnNiGe}$ at $5 \mathrm{~K}$ are given in Figures 6(b) and 6(d), respectively. 


\subsection{Magnetic moments}

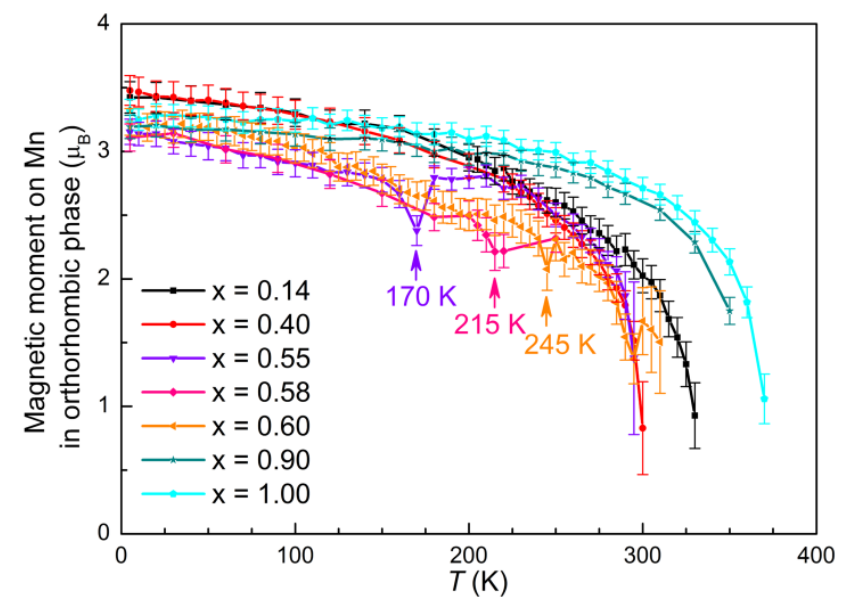

Figure S11 The variation of the magnetic moments with temperature for the Mn sublattice in the orthorhombic structure of $\mathrm{Mn}\left(\mathrm{Co}_{1-\mathrm{x}} \mathrm{Ni}_{\mathrm{x}}\right) \mathrm{Ge}$. The three dips noted around $\sim 170 \mathrm{~K}, \sim 215 \mathrm{~K}$ and $\sim 245 \mathrm{~K}$, for the $\mathrm{Mn}\left(\mathrm{Co}_{1-\mathrm{x}} \mathrm{Ni}_{\mathrm{x}}\right) \mathrm{Ge}$ samples with $\mathrm{x}=0.55,0.58$ and 0.60 may originate from difficulties with models used for the Rietveld refinement of the mixed spiral-AFM and $\mathrm{FM}_{b}$. 


\section{Magnetic interactions}

\subsection{Thermal evolution of lattice parameters}
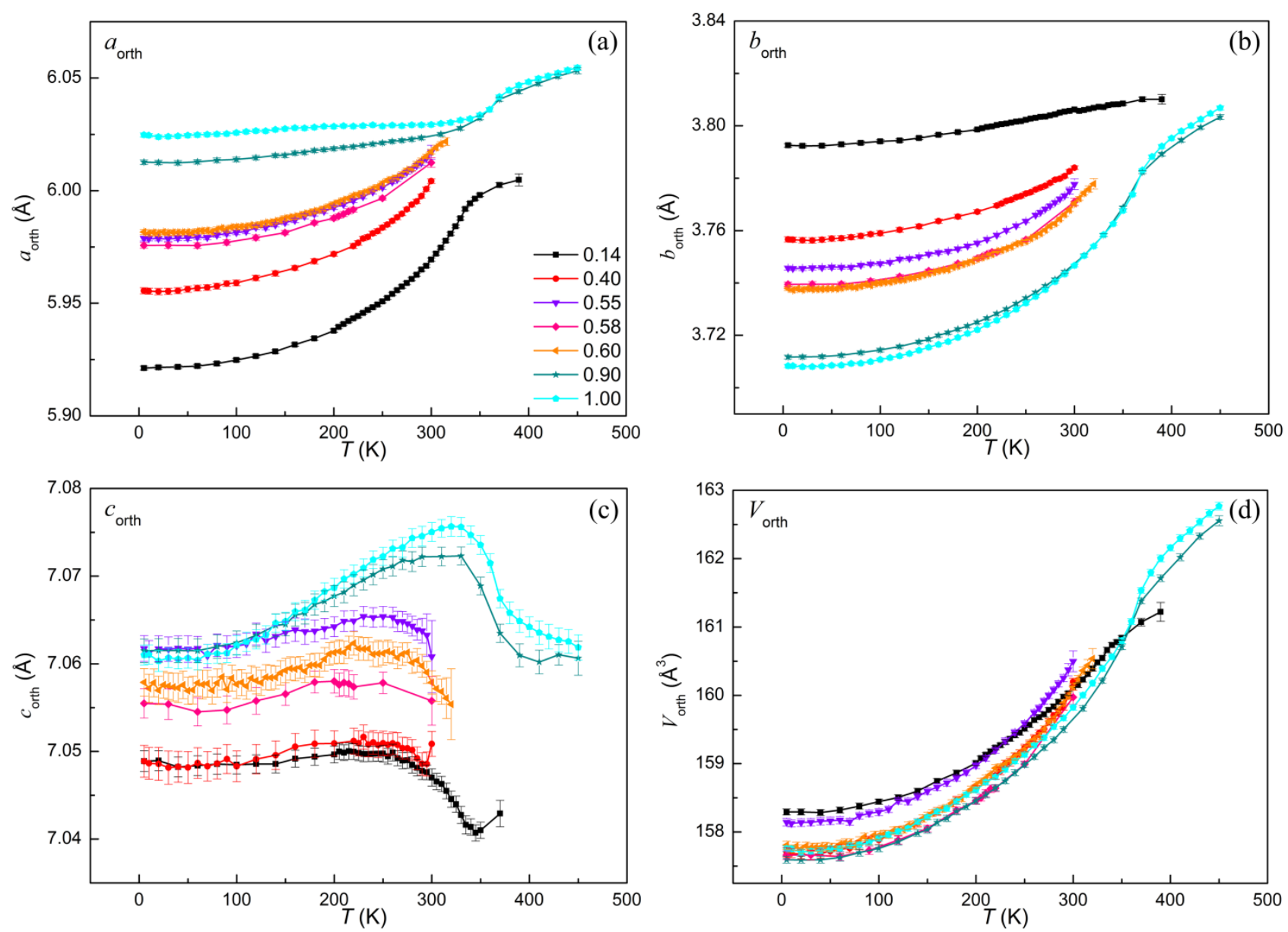

Figure S12 Thermal evolution of the lattice parameters in the orthorhombic structure of $\operatorname{Mn}\left(\mathrm{Co}_{1}\right.$ ${ }_{x} \mathrm{Ni}_{\mathrm{x}}$ )Ge with $\mathrm{x}=0.14,0.40,0.55,0.58,0.60,0.90$ and 1.00 . The data comes from the refinement results of the neutron diffraction patterns. 


\subsection{Thermal evolution of Mn-Mn distances}
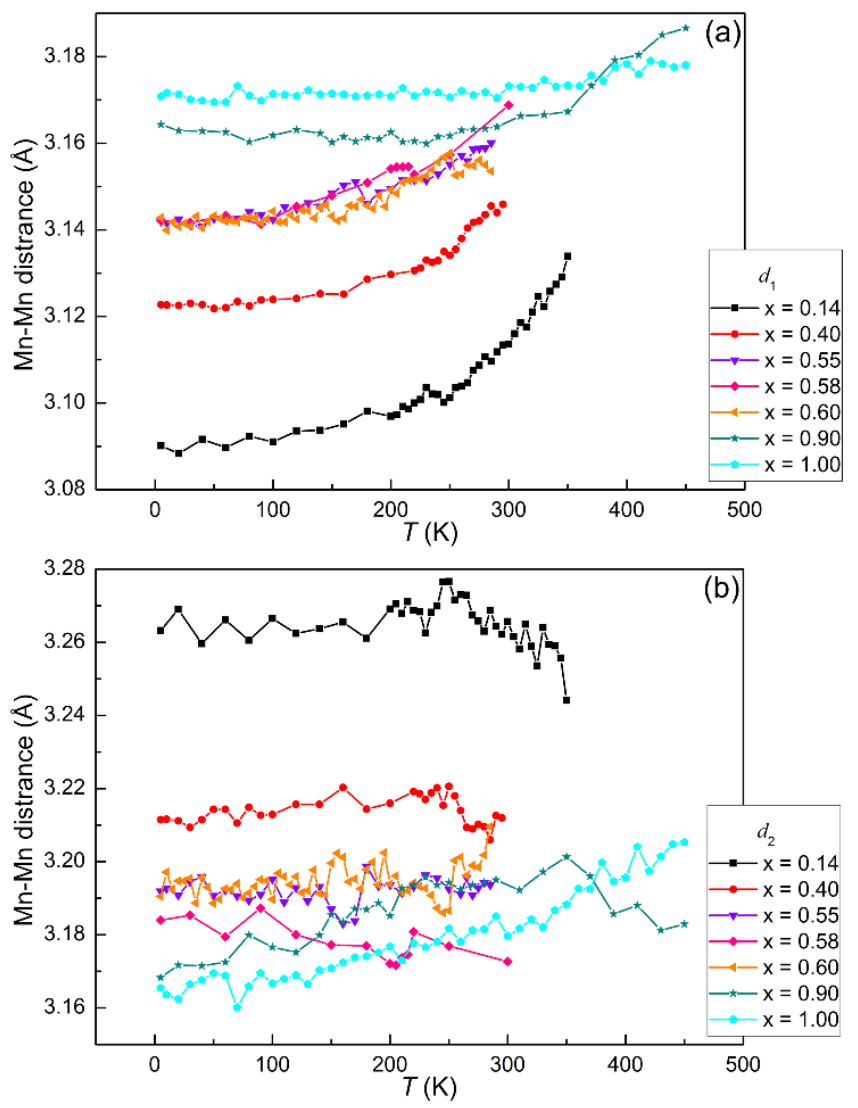

Figure S13 Thermal evolutions of the Mn-Mn distances, $d_{1}$ and $d_{2}$, in the orthorhombic structure of the $\mathrm{Mn}\left(\mathrm{Co}_{1-\mathrm{x}} \mathrm{Ni}_{\mathrm{x}}\right) \mathrm{Ge}$. 


\section{Magnetocaloric effect}

As indicated by the phase diagram (Figure 9), inverse MCE and direct MCE are expected in the samples with $x=0.55$ to 0.60 . The magnetic isotherms with increasing field for $\mathrm{Mn}\left(\mathrm{Co}_{0.40} \mathrm{Ni}_{0.60}\right) \mathrm{Ge}$ around $T_{\mathrm{N}}^{\mathrm{SP}-\mathrm{FM}}$ and $T_{\mathrm{M}}$ are shown in Figures. S13(a) and S13(b), respectively. In both figures, continuous metamagnetic behaviours are observed, confirming field-induced SP-AFM/FM and FMOrth/PM-Hex transitions. It is also observed in Figure S13(a) that application of a field $<1 \mathrm{~T}$ is enough to align the spiral magnetic moments above $200 \mathrm{~K}$, indicating the competition of the SP and FM structures.

Based on the isothermal magnetisation measurement, the magnetic entropy changes $-\Delta S_{\mathrm{M}}$ were calculated using Eq. 1 which derives by integrating the Maxwell function: ${ }^{1}$

$$
\Delta S_{\mathrm{M}}(T, \Delta H)=\mu_{0} \int_{H_{0}}^{H_{1}}\left(\frac{\partial M\left(T, H^{\prime}\right)}{\partial T}\right)_{H} \mathrm{~d} H^{\prime} .
$$

Figure S13(c) is the contour image of the magnetic entropy change based on the magnetic isotherms in Figure S13(a). Positive magnetic entropy changes (inverse MCE, note: the calculation is based on magnetisation measurement rather than demagnetisation) are obtained, e.g. $-\Delta S_{\mathrm{M}}^{\text {peak }}=-0.59(8) \mathrm{J} \mathrm{kg}^{-1}$ $\mathrm{K}^{-1}$ for $\mu_{0} \Delta H=1 \mathrm{~T}$ at $197(2) \mathrm{K}$. Such positive magnetic entropy change results from the SPAFM/FM transition, which occurs also in the samples with $\mathrm{x}=0.55$ and $0.58:-\Delta S_{\mathrm{M}}^{\text {peak }}\left(\mu_{0} \Delta H=1 \mathrm{~T}\right)$ $=-0.48(7) \mathrm{J} \mathrm{kg}^{-1} \mathrm{~K}^{-1}$ and $-0.52(8) \mathrm{J} \mathrm{kg}^{-1} \mathrm{~K}^{-1}$ at 142(4) $\mathrm{K}$ and 187(2) $\mathrm{K}$, respectively. These values are comparable with the value of $\sim-0.75 \mathrm{~J} \mathrm{~kg}^{-1} \mathrm{~K}^{-1}\left(\mu_{0} \Delta H=1 \mathrm{~T}\right)$ in $\mathrm{Mn}\left(\mathrm{Co}_{0.38} \mathrm{Ni}_{0.62}\right) \mathrm{Ge}$ reported by Zhang et al, ${ }^{2}$ but smaller than $-9.0 \mathrm{~J} \mathrm{~kg}^{-1} \mathrm{~K}^{-1}\left(\mu_{0} \Delta H=1 \mathrm{~T}\right)$ reported for $\mathrm{Mn}\left(\mathrm{Co}_{0.07} \mathrm{Ni}_{0.93}\right) \mathrm{Ge}_{1.05 .}{ }^{3} \mathrm{In}$ $\mathrm{Mn}\left(\mathrm{Co}_{0.07} \mathrm{Ni}_{0.93}\right) \mathrm{Ge}_{1.05}$, the SP-AFM/FM transition is accompanied by a Orth/Hex structural transition, one kind of FOMST. ${ }^{3}$ It is also noted that $-\Delta S_{\mathrm{M}}^{\text {peak }}$ shifts quickly to low temperature with magnetic field as indicated by the dashed line in Figure S13(c), indicating strong dependence of the $T_{\mathrm{N}}^{\mathrm{SP}-\mathrm{FM}}$ on magnetic field.

In contrast to the case around $T_{\mathrm{N}}^{\mathrm{SP}-\mathrm{FM}}$ in Figure S13(c), negative magnetic entropy changes (direct MCE) are obtained due to field induced FM-Orth/PM-Hex transition around $T_{\mathrm{M}}$ as shown in Figure $\mathrm{S} 13(\mathrm{~d})$. The magnetic entropy changes maxima $-\Delta S_{\mathrm{M}}^{\text {peak }}$ are $2.4(3) \mathrm{J} \mathrm{kg}^{-1} \mathrm{~K}^{-1}$ for $\mu_{0} \Delta H=1 \mathrm{~T}$ and $14(2) \mathrm{J} \mathrm{kg}^{-1} \mathrm{~K}^{-1}$ for $\mu_{0} \Delta H=5 \mathrm{~T}$ at $302(2) \mathrm{K}$. The former value is larger than counterpart $(\sim 1.6 \mathrm{~J}$ $\mathrm{kg}^{-1} \mathrm{~K}^{-1}$ for $\left.\mu_{0} \Delta H=1 \mathrm{~T}\right)$ in $\mathrm{Mn}\left(\mathrm{Co}_{0.38} \mathrm{Ni}_{0.62}\right) \mathrm{Ge}^{2}$ 
In addition, the refrigeration capacity $(R C)$ is also an important parameter for magnetocaloric materials, which is defined as: ${ }^{4}$

$$
R C=\int_{T_{r 1}}^{T_{r 2}}\left|\Delta S_{M}\right| d T
$$

$T_{r 1}$ and $T_{r 2}$ are the temperatures corresponding to the half-maximum of the isothermal magnetic entropy change peak $-\Delta S_{\mathrm{M}}^{\text {peak }}$ and $T_{r 1}<T_{r 2}$. $R C$ s in the present work are calculated using Eq. (S-2).
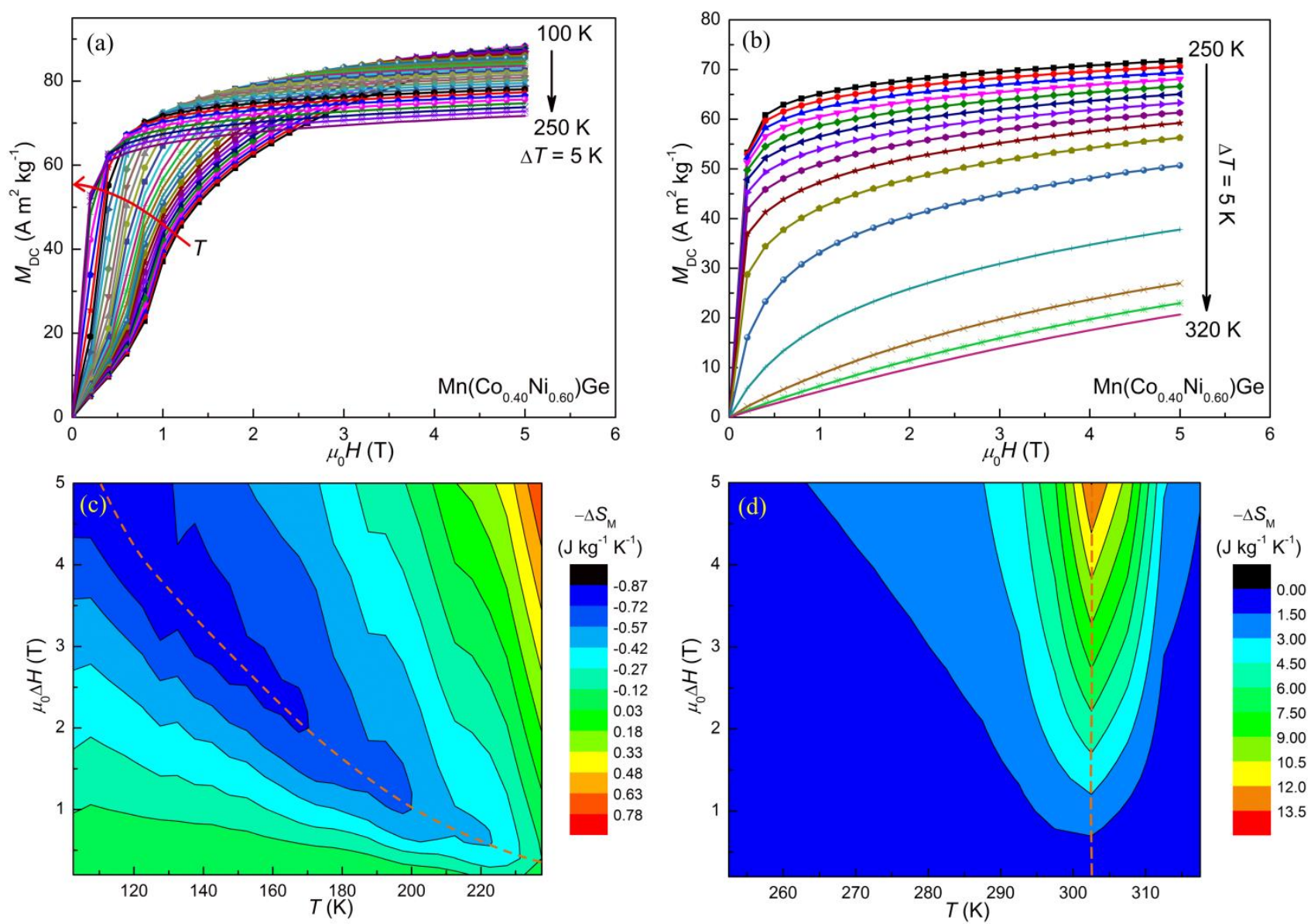

Figure S14 Isothermal magnetisation of $\mathrm{Mn}\left(\mathrm{Co}_{0.40} \mathrm{Ni}_{0.60}\right) \mathrm{Ge}$ around the transition temperatures (a) $T_{\mathrm{N}}^{\mathrm{SP}-\mathrm{FM}}=245(5) \mathrm{K}$ and (b) $T_{\mathrm{M}}=310(1) \mathrm{K}$. The measurement temperature increases (a) from $100 \mathrm{~K}$ to $250 \mathrm{~K}$ and (b) $250 \mathrm{~K}$ to $320 \mathrm{~K}$ with an interval of $5 \mathrm{~K}$. (c) and (d) are the contour images of the isothermal magnetic entropy changes $-\Delta S_{\mathrm{M}}$ with magnetic field changes from $\mu_{0} \Delta H=0.2 \mathrm{~T}$ to $\mu_{0} \Delta H$ $=5.0 \mathrm{~T}$ around $T_{\mathrm{N}}^{\mathrm{SP}-\mathrm{FM}}$ and $T_{\mathrm{M}}$, respectively. The dashed line in (c) indicates that $T_{\mathrm{N}}^{\mathrm{SP}-\mathrm{FM}}$ depends strongly on the magnetic field. 
Table S4 Magnetic entropy changes $\left(-\Delta S_{\mathrm{M}}\right)$ and refrigeration capacities $(R C)$ of the $\mathrm{Mn}\left(\mathrm{Co}_{1-\mathrm{x}} \mathrm{Ni}_{\mathrm{x}}\right) \mathrm{Ge}$ samples $(\mathrm{x}=0.40,0.50,0.55,0.58$ and 0.60$)$.

\begin{tabular}{c:ccccc:ccccc}
\hline $\mathrm{x}$ & $\mu_{0} \Delta H$ & $-\Delta S_{\mathrm{M}}^{\text {peak-1 } *}$ & $T_{\text {peak }}$ & $-\Delta S_{\mathrm{M}}^{\text {peak-2* }}$ & $T_{\text {peak }}$ & $\mu_{0} \Delta H$ & $-\Delta S_{\mathrm{M}}^{\text {peak-2* }}$ & $T_{\text {peak }}$ & FWHM & $R C$ \\
$(\mathrm{~T})$ & $\left(\mathrm{J} \mathrm{kg}^{-1} \mathrm{~K}^{-1}\right)$ & $(\mathrm{K})$ & $\left(\mathrm{J} \mathrm{kg}^{-1} \mathrm{~K}^{-1}\right)$ & $(\mathrm{K})$ & $(\mathrm{T})$ & $\left(\mathrm{J} \mathrm{kg}^{-1} \mathrm{~K}^{-1}\right)$ & $(\mathrm{K})$ & $(\mathrm{K})$ & $\left(\mathrm{J} \mathrm{kg}^{-1}\right)$ \\
0.40 & 1 & - & - & $3.1(4)$ & $292(2)$ & 5 & $14(2)$ & $292(2)$ & $11(1)$ & $140(20)$ \\
0.50 & 1 & - & - & $3.0(4)$ & $284(2)$ & 5 & $13(2)$ & $284(2)$ & $10(1)$ & $120(20)$ \\
0.55 & 1 & $-0.48(7)$ & $142(4)$ & $3.3(4)$ & $283(2)$ & 5 & $15(2)$ & $283(2)$ & $10(1)$ & $130(20)$ \\
0.58 & 1 & $-0.52(8)$ & $187(2)$ & $3.0(4)$ & $285(2)$ & 5 & $14(2)$ & $285(2)$ & $11(1)$ & $140(20)$ \\
0.60 & 1 & $-0.59(8)$ & $197(2)$ & $2.4(3)$ & $302(2)$ & 5 & $14(2)$ & $302(2)$ & $11(2)$ & $130(20)$ \\
\hline$*$
\end{tabular}

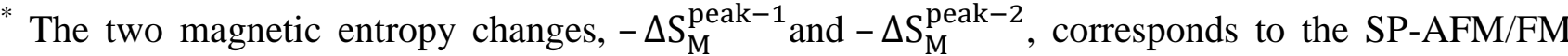
and FM-Orth /PM-Hex transitions around $\mathrm{T}_{\mathrm{N}}^{\mathrm{SP}-\mathrm{FM}}$ and $T_{\mathrm{M}}$, respectively. Inverse MCE and direct MCE are obtained around these two transitions.

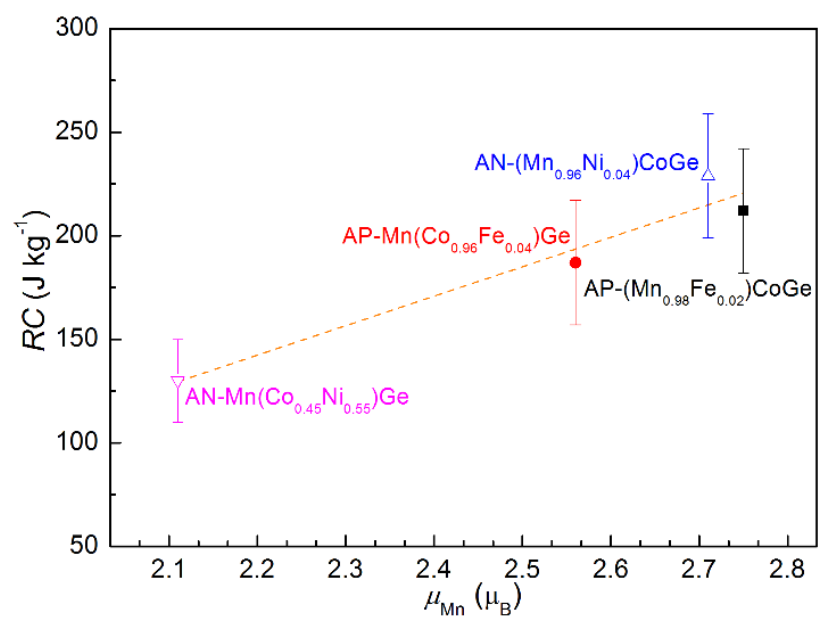

Figure S15 Relationship between $R C$ and the magnetic moment of Mn sublattice at the temperature where the orthorhombic phase fraction is $\sim 90 \mathrm{wt} \%$ for annealed $\mathrm{Mn}\left(\mathrm{Co}_{1-\mathrm{x}} \mathrm{Ni}_{\mathrm{x}}\right) \mathrm{Ge}$ (from this work), as-prepared $\left(\mathrm{Mn}_{1-\mathrm{x}} \mathrm{Fe}_{\mathrm{x}}\right) \mathrm{CoGe}(\mathrm{x}=0.02),{ }^{5}$ as-prepared $\mathrm{Mn}\left(\mathrm{Co}_{1-\mathrm{x}} \mathrm{Fe}_{\mathrm{x}}\right) \mathrm{Ge}(\mathrm{x}=0.04)^{6}$ and annealed $\left(\mathrm{Mn}_{1-\mathrm{x}} \mathrm{Ni}_{\mathrm{x}}\right) \mathrm{CoGe}(\mathrm{x}=0.04){ }^{7}$ The linear relationship between the $R C \mathrm{~s}$ and the magnetic moments on Mn sublattice indicates that the smaller $R C \mathrm{~s}$ in annealed $\mathrm{Mn}\left(\mathrm{Co}_{1-\mathrm{x}} \mathrm{Ni}_{\mathrm{x}}\right) \mathrm{Ge}$ is attributed to the relatively smaller magnetic moment in $\mathrm{Mn}\left(\mathrm{Co}_{1-\mathrm{x}} \mathrm{Ni}_{\mathrm{x}}\right) \mathrm{Ge}$. 


\section{References:}

(1) Brück, E., Developments in magnetocaloric refrigeration. J. Phys. D: Appl. Phys. 2005, 38, R381-R391.

(2) Zhang, C. L.; Chen, J.; Wang, T. Z.; Xie, G. X.; Zhu, C.; Wang, D. H., The magnetic phase transitions and magnetocaloric effect in $\mathrm{MnNi}_{1-\mathrm{x}} \mathrm{Co}_{\mathrm{x}} \mathrm{Ge}$ alloys. Solid State Commun. 2011, 151, 1359-1362.

(3) Zhang, C.; Wang, D.; Cao, Q.; Ma, S.; Xuan, H.; Du, Y., The magnetostructural transformation and magnetocaloric effect in Co-doped MnNiGe 1.05 alloys. J. Phys. D: Appl. Phys. 2010, 43, 205003.

(4) Gschneidner Jr, K. A.; Pecharsky, V. K.; Pecharsky, A. O.; Zimm, C. B., Recent Developments in Magnetic Refrigeration. Materials Science Forum 1999, 315-317, 69-76.

(5) Ren, Q. Y.; Hutchison, W. D.; Wang, J. L.; Studer, A. J.; Din, M. F. M.; Pérez, S. M.; Cadogan, J. M.; Campbell, S. J., The magneto-structural transition in $\mathrm{Mn}_{{ }_{1-} \mathrm{x}} \mathrm{Fe}_{\mathrm{x}} \mathrm{CoGe}$. J. Phys. D: Appl. Phys. 2016, 49, 175003.

(6) Ren, Q. Y.; Hutchison, W. D.; Wang, J. L.; Studer, A. J.; Campbell, S. J., First-order magnetostructural transition and magnetocaloric effect in $\mathrm{Mn}\left(\mathrm{Co}_{0.96} \mathrm{Fe}_{0.04}\right)$ Ge. J. Alloys Compd. 2017, 693, 32-39.

(7) Ren, Q. New materials for magnetic refrigeration: the magnetocaloric effect in MnCoGe-based intermetallics. Doctoral thesis, The University of New South Wales, Canberra, Australia, 2016. 